B IB IOTECA

INSTIUTIO DE QUINAICA

Unlygizjiada de São Paulo

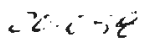

UNIVERSIDADE DE SÃO PAULO INSTITUTO DE QUIIMICA

\title{
ESTUDO TÉRMICO E VIBRACIONAL DO IONÖMERO NAFION
}

CARLOS NALVO MACHADO JÚNIOR DISSERTAÇÃO DE MESTRADO

ORIENTADOR: PROF.DR. YOSHIO KAWANO

Departamento de Química Fundamental Área Físico-Química

São Paulo

2002 


\section{DEDALUS - Acervo - CQ

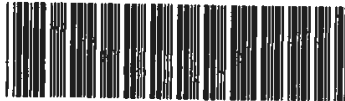 \\ 30100004688}

Ficha Catalográfica

Elaborada pela Divisão de Biblioteca e

Documentação do Conjunto das Químicas da USP.

Machado Júnior, Carlos Nalvo

Ml49e Estudo térmico e vibracional do ionômero nafion / Carlos Nalvo Machado Júnior. -- São Paulo, 2002. $75 \mathrm{p}$.

Dissertaçào (mestrado) - Instituto de Química da Universidade de São Paulo. Departamento de Química Fundamental.

Orientador: Kawano, Yoshio

1. Espectrocopia vibracional I. T. II. Kawano, Yoshio, orientador. 
BIBLIOTECA

INSTITUTO DE QUINICA

Gnlverșldado de São Pauto

\section{“Estudo Térmieo e Vỉbracional do lonômero Nafion"}

\section{CARLOS NALVO MACHADO JUUNIOR}

Dissertação de Mestrado submetida ao Instituto de Química da Universidade de São Paulo como parte dos requisitos necessários à obtenção do grau de Mestre em Química - Área: Físico-Química.

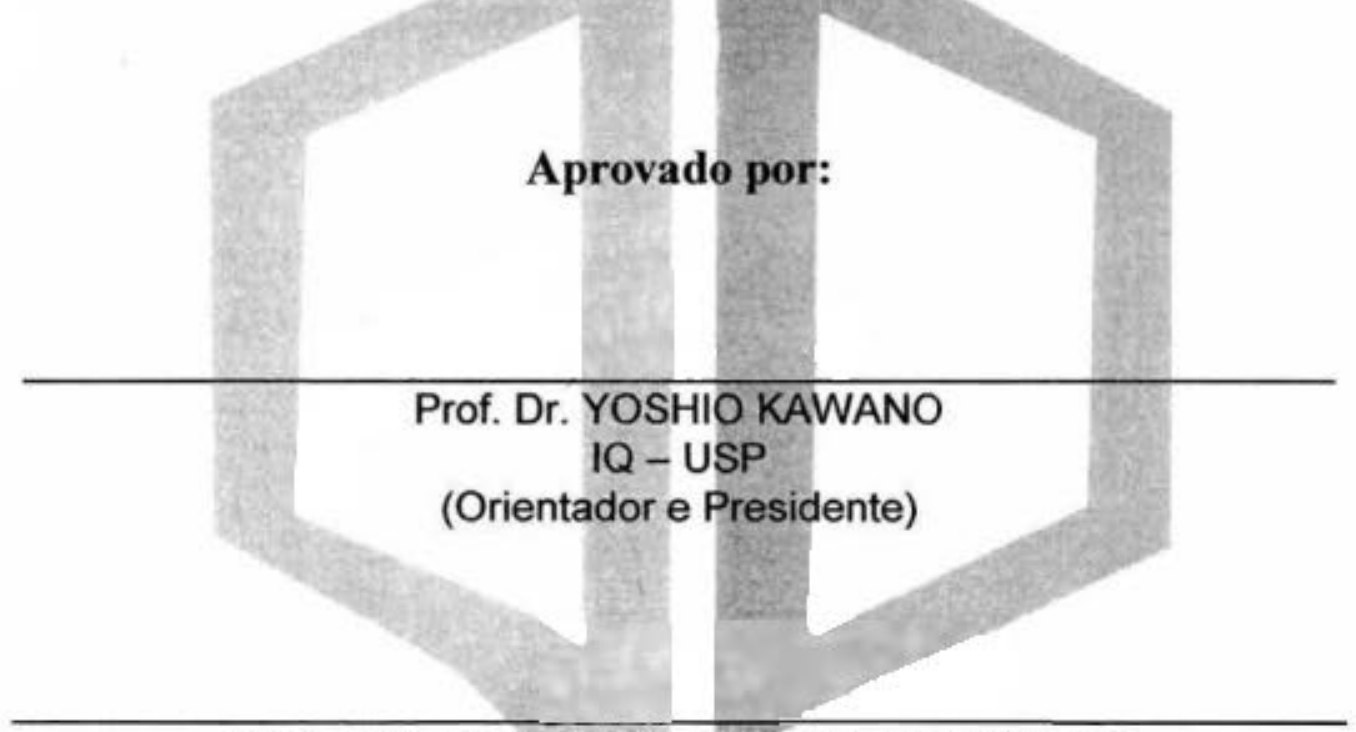

Profa. Dra. DENISE FREITAS SIQUEIRA PETRI

$$
\text { IQ - USP }
$$

Profa. Dra. NICOLE RAYMONDE DEMARQUETTE

$$
\text { EP - USP }
$$

SÃO PAULO

12 DE JUNHO 2002. 


\section{Agradecimentos}

Ao Prof. Dr. Yoshio Kawano, pela orientação paciente, dedicada e inteligente durante a realização deste trabalho.

Aos Profs.Drs. Oswaldo Sala e Márcia Laudelina Arruda Temperini, por me mostrarem o quanto há de belo em espectroscopia molecular.

À Profa. Dra. Dalva Lúcia Araújo de Faria pela maneira sempre atenciosa e carinhosa que me auxiliou na obtenção dos espectros Raman.

Ao Prof.Dr. Roberto M. Torresi pela doação das membranas Nafion.

Aos amigos dos laboratórios (B5 e B4), em especial ao Laércio pelas discussões interessantes que tivemos. 
Aos meus pais,

Carlos e Rosa,

por tudo.

Na estória da minha vida, vocês são os capítulos

que eu mais gosto de reler. 
Aos meus amigos, por tudo aquilo que vocês representam. Sem vocês, nem Dostoiévski faria sentido para mim. 


\section{Índice}

\section{Página}

$\begin{array}{ll}\text { Resumo } & 01\end{array}$

$\begin{array}{ll}\text { Abstract } & 02\end{array}$

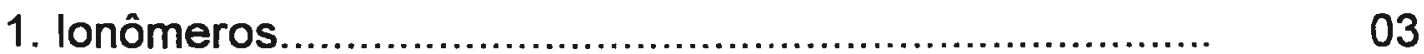

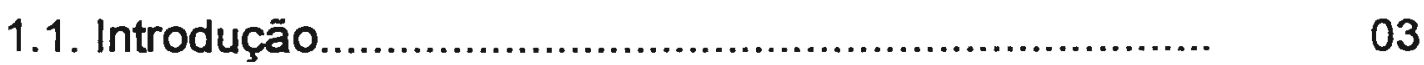

1.2. Resumo das descrições teóricas para os ionômeros.. 04

1.3. Histórico ........................................................... 06

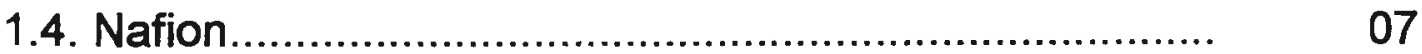

1.5. Morfologia do Nafion............................................... 09

1.6. Modelos para o Nafion............................................. 09

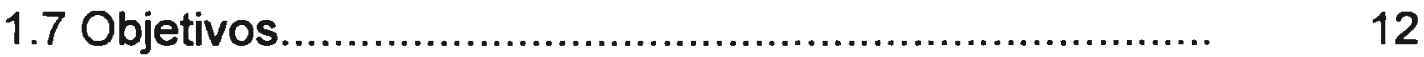

2. O modo vibracional...................................................

2.1. Espectro no infravermelho....................................... 15

2.2. Espectro Raman ................................................. 16

2.3. Fotoacústico por transformada de Fourier.................. 17

3. Análise Térmica........................................................ 20

3.1. Calorimetria Exploratória Diferencial........................ 20 
3.1.1. DSC por fluxo de calor....................................... 20

3.1.2. DSC por compensação de potência........................ 21

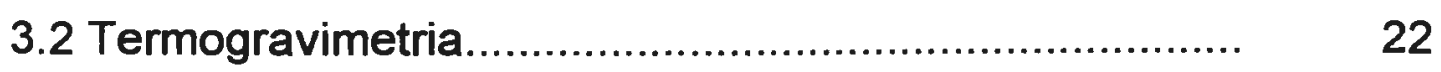

4 Materiais e Métodos.................................................. 24

4.1 Características das membranas............................... 24

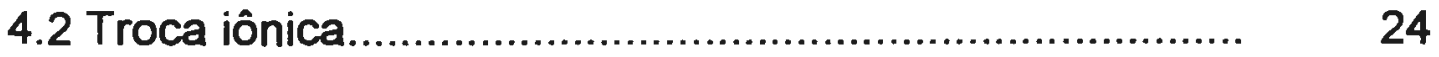

4.3 Equipamentos utilizados......................................... 24

4.3.1 Espectros no infravermelho................................... 24

4.3.2 Espectros Raman............................................. 24

4.3.3 Termogravimetria.............................................

4.3.4 Calorimetria Exploratória Diferencial (DSC).............. 25

5. Resultados e Discussão............................................... 26

5.1. Espectros fotoacústicos do Nafion........................... 26

5.2. Espectros Raman............................................... $\quad 30$

5.3. Considerações preliminares sobre a atribuição vibracional............................................................. $\quad 32$

5.4. Bandas do grupo éter.............................................

5.5. A água e o grupo sulfonato.....................................

5.6. A matriz fluorocarbônica........................................... 40

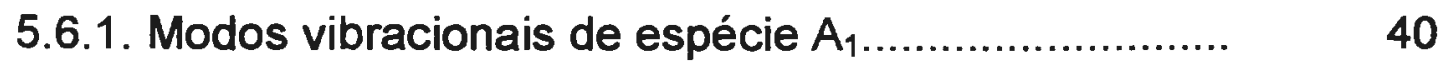




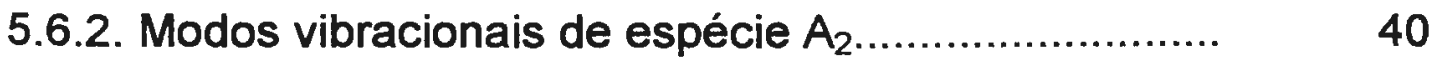

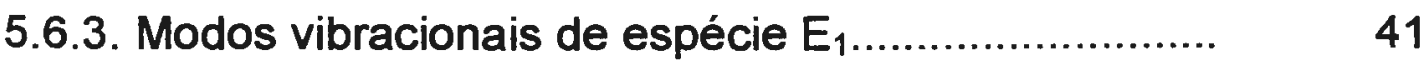

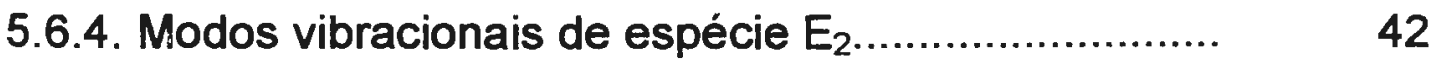

5.6.5. Comparação experimental $X$ teórica....................... 43

5.7. O estudo termogravimétrico...................................

5.7.1. Termogravimetria das membranas........................

5.7.2. Avaliação do conteúdo de água por TG................. 48

5.7.3. A degradação térmica da membrana...................... 54

5.8. DSC das membranas..........................................

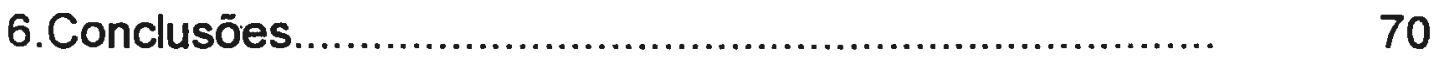

7. Referências bibliográficas.......................................... 73 


\section{Resumo}

O Nafion é um ionômero constituído por uma matriz de politetrafluoroetileno (PTFE) contendo ramificações laterais terminadas em grupos sulfônicos.

Neste trabalho, a membrana na forma ácida e nas formas salinas $\left(\mathrm{Li}^{+}, \mathrm{Na}^{+}\right.$, $\mathrm{K}^{+}, \mathrm{Rb}^{+}$e $\mathrm{Cs}^{+}$) foram analisadas, via espectroscopia vibracional e análise térmica.

Para proceder à análise vibracional, dividiu-se o ionômero em três grupos, cada qual pertencente a um grupo pontual distinto: o grupo sulfonato $\left(\mathrm{C}_{3 \mathrm{v}}\right)$; o grupo éter $\left(C_{2 v}\right)$ e a matriz fluorocarbônica $D(14 \pi / 15)$.

O grupo sulfonato apresenta modos vibracionais de estiramento simétrico $\left(1060 \mathrm{~cm}^{-1}\right.$ ) e de estiramento degenerado (na região de $1300 \mathrm{~cm}^{-1}$ ).

O Nafion apresenta dois grupos éter, os quais deram origem no espectro a duas bandas: uma em 984 e outra na região de $970 \mathrm{~cm}^{-1}$. Verificou-se que apenas a banda em $970 \mathrm{~cm}^{-1}$ sofre uma influência mais direta do ambiente iônico.

A atribuição das bandas da matriz polimérica foi feita considerando-se que a cadeia de PTFE apresenta estrutura helicoidal $\left(15_{7}\right)$. Nesta estrutura são previstas a existência de quatro espécies de simetria que apresentam atividade nos espectro Raman e infravermelho. No Raman são ativos os modos de espécie $A_{1}, E_{1}$ e $E_{2}$ e no infravermelho são ativos os modos de espécie $A_{2}$ e $E_{1}$.

$A$ análise térmica dividiu-se em: termogravimetria e calorimetria exploratória diferencial. A termogravimetria mostrou que a membrana na forma ácida apresenta um padrão de decomposição distinto das membranas nas formas salinas.

A calorimetria exploratória diferencial mostrou que a membrana na forma ácida apresenta três eventos endotérmicos: em $134^{\circ} \mathrm{C}$, em $250^{\circ} \mathrm{C}$ e o último em $325^{\circ} \mathrm{C}$. Na membrana nas formas salinas apenas o primeiro pico endotérmico é bastante evidente, o segundo pico é pouco pronunciado e o terceiro está completamente ausente. 


\section{Abstract}

Nafion is an ionomer that consists of a polytetrafluoroethylene (PTFE) backbone with side chains terminated with a sulfonate group.

In this work, Nafion in acid and saline forms $\left(\mathrm{Li}^{+}, \mathrm{Na}^{+}, \mathrm{K}^{+}, \mathrm{Rb}^{+} \mathrm{e} \mathrm{Cs}{ }^{+}\right)$forms were investigated by vibrational spectroscopy, thermogravimetry and differential scanning calorimetry. To proceed to the vibrational analysis the ionomero was splitted into three regions and which one has its own symmetry group. Sulfonate group $\left(C_{3 v}\right)$, ether group $\left(C_{2 v}\right)$ and the polymeric matrix $D(14 \pi / 15)$.

The sulfonate group presents two modes: the symmetric stretching (1060 $\mathrm{cm}^{-1}$ ) and the degenerated stretching (around $1300 \mathrm{~cm}^{-1}$ ).

Nafion has two ether groups which originated two bands: one in 984 and the other in $970 \mathrm{~cm}^{-1}$. We verify that only the band in $970 \mathrm{~cm}^{-1}$ is affected by the ionic ambient.

The assignment of the polymeric band was made considering that the PTFE has helicoidal structure $\left(15_{7}\right)$. In this structure four symmetry species are predicted. In Raman spectra the following species are active: $A_{1}, E_{1}$ and $E_{2}$ and the infrared are active the species: $A_{2}$ and $E_{1}$.

Thermal analysis consisted of thermogravimetry and differential scanning calorimetry. Thermogravimetry shows that water content is dependent of cation change. Thermogravimetry also shows that the membrane in the acid and saline forms have different mechanisms of decomposition.

Differential scanning calorimetry of Nafion-H shows three endothermic peaks: the first in $134^{\circ} \mathrm{C}$, the second in $250^{\circ} \mathrm{C}$ and the last in $325^{\circ} \mathrm{C}$. Nafion saline forms shows only the first peak. 


\section{1. lonômeros}

\subsection{Introdução}

Ionômeros são polímeros que apresentam ramificações contendo grupos iônicos ligados quimicamente às cadeias poliméricas numa proporçăo menor que $15 \%(\mathrm{em} \text { mols })^{[1]}$.

A introdução dessas ramificações, nas cadeias poliméricas, causa grandes modificações nas propriedades físicas e químicas do material, quando estas são comparadas com as propriedades do polímero precursor (não-

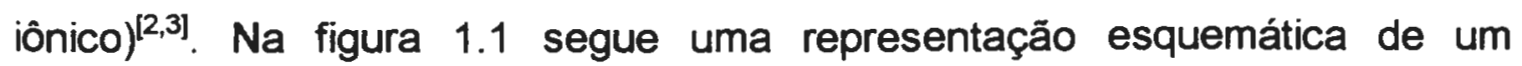
ionômero aniônico:

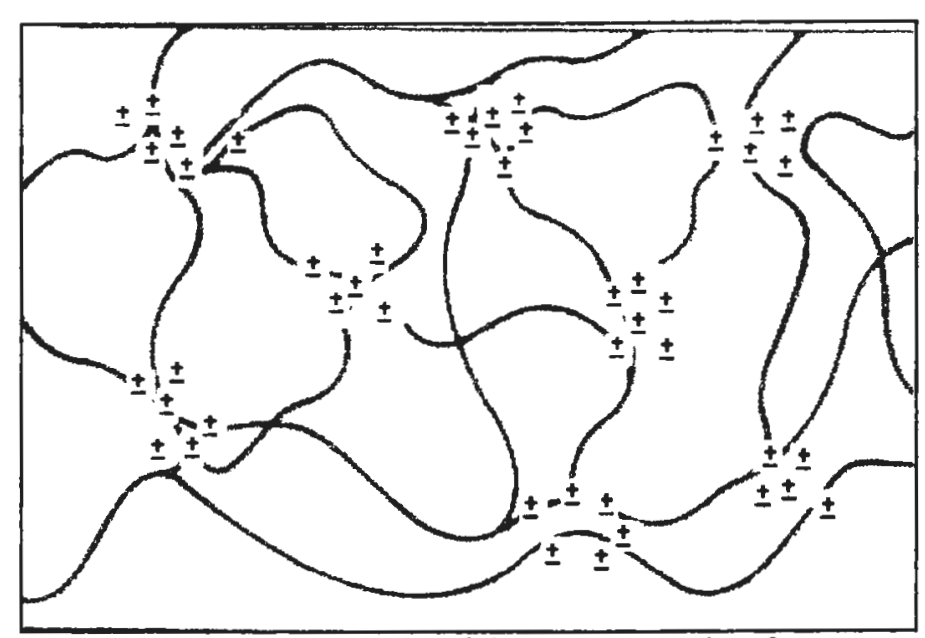

Figura 1.1 Representação esquemática de um ionômero aniônico. As linhas contínuas representam a cadeia carbônica, os (-) representam os grupos iônicos ligados covalentemente à cadeia carbônica e os $(+)$ representam os contra-íons.

A combinação de uma região iônica em uma matriz de baixa polaridade forma uma grande classe de ionômeros, os quais variam suas propriedades em função da matriz polimérica e da funcionalidade do grupamento iônico (carboxilato, sulfonato). As modificações das propriedades do polímero resultam da associação dos grupos iônicos formando agregados.

A primeira evidência experimental da existência de agregados iônicos em ionômeros advém da existência de um máximo de reflexão em 
experimentos de espalhamento de raios- $X$ a baixos ângulos (SAXS ${ }^{[4-9]}$. Este máximo de reflexão - denominado pico iônico - é decorrente da diferença de densidade eletrônica entre as regiões ricas e pobres em íons no polímero. Portanto, como o pico iônico está ausente no precursor não-iônico (no caso do Nafion, o politetrafluoroetileno (PTFE)), ele foi atribuído à presença de agregados iônicos em ionômeros.

\subsection{Resumo das descrições teóricas para os ionômeros}

Do ponto de vista teórico, a primeira descrição para os ionômeros foi desenvolvida por Eisenberg ${ }^{[10]}$. Neste trabalho, ele assumiu a existência de dois tipos de agregados iônicos: os multipletos e os clusters. Os multipletos constituídos de poucos pares iônicos, entre 6 e 8 pares iônicos. Acima desses valores de concentração de grupos iônicos ligados à cadeia polimérica, há a formação de agregados maiores designados "clusters", os quais apresentam estrutura micelar (micelas reversas).

Diversas variações do modelo de Eisenberg foram propostas por Forsman ${ }^{[11]}$, Dreyfus ${ }^{[12]}$ e Dayte e Taylor ${ }^{[13]}$, as quais exploraram o balanço das forças envolvidas na agregação dos dipolos. Entretanto, as conclusões gerais sobre as características dos multipletos foram similares às obtidas no trabalho de Eisenberg.

Em 1973, Marx et al. ${ }^{[14]}$ propuseram um modelo no qual o pico iônico foi atribuído à diferença de densidade eletrônica entre os cátions metálicos e as cadeias poliméricas. Este modelo admite a existência de multipletos, com raio de aproximadamente $5 \AA$, arranjados numa rede paracristalina. A conclusão dos autores foi que o pico iônico resultava de uma interferência entre os agregados iônicos, correspondendo a uma distância regular entre os agregados.

Em 1974, Macknight et al. ${ }^{[15]}$ sugeriram que o pico iônico era devido a uma interferência intra-agregado. Neste modelo designado "core-shell", os autores assumiram que os agregados (core), com raio de 8-10 $\AA$ e contendo 
aproximadamente 50 pares iônicos, encontram-se circundados por um material de baixa densidade eletrônica: as cadeias poliméricas (shell).

Em 1980, Roche et al. ${ }^{\text {n] }}$ propuseram o modelo lamelar, que é conceitualmente semelhante ao modelo "core-shell", entretanto, ele apresenta diferenças na geometria do agregado. Neste modelo, os autores propuseram que a região dos agregados iônicos (core) apresenta a estrutura de uma lamela envolvida por lamelas de cadeias carbônicas (shell). A origem do pico iônico é atribuída à diferença de densidade eletrônica entre a lamela central e as lamelas das extremidades.

Em 1982, Yarusso e Coope ${ }^{[16]}$ propuseram o modelo da esfera rígida modificada, no qual os agregados são considerados como esferas rígidas com aproximadamente $10 \AA$ de raio e contendo aproximadamente 20 pares iônicos. Os autores atribuíram o pico iônico ao efeito de espalhamento entre os agregados.

Os modelos de esfera rígida e core-shell explicam quantitativamente bem o pico iônico observado em experimentos de SAXS. Todavia, eles não conseguem explicar satisfatoriamente bem as propriedades mecânicas, as quais indicam uma morfologia em duas fases.

Em 1990, surgiu um modelo capaz de conciliar os dados de SAXS com os resultados das análises das propriedades mecânicas. Este modelo, EHM ${ }^{[17]}$ (Eisenberg-Hird-Moore), postula que as cadeias existentes, nas vizinhanças dos agregados, apresentam mobilidade reduzida se comparadas às cadeias de regiões mais afastadas dos agregados. A mobilidade das cadeias no polímero é função de sua massa molecular e, portanto, ancorando uma cadeia a um agregado, ocorre um aumento em sua massa molecular efetiva, o que reduz sua mobilidade.

Aumentando o número de íons, é esperado que o tamanho e/ou a quantidade de multipletos aumentem. Neste caso, Eisenberg et al. ${ }^{[17]}$, propuseram que aquelas regiōes de mobilidade reduzida que circundam cada multipleto podem se sobrepor, formando grandes regiöes contíguas de mobilidade reduzida, assim chamadas clusters. No modelo EHM, os clusters não possuem tamanho ou geometria definidos e são formados por íons, moléculas de água e segmentos da cadeia polimérica. A existência de clusters, conforme concebida neste modelo, permite explicar a presença de duas 
transições vítreas $\left(T_{g}\right)$ observadas em estudos de relaxação mecânica de alguns ionômeros.

Segundo os autores, somente ionômeros que contêm clusters podem apresentar duas transições vítreas. Eles consideraram que, para baixas concentrações de íons, apenas multipletos devem existir e estes multipletos isolados são muito pequenos para apresentarem a sua própria $T_{g}$. Nesta situação apenas uma $T_{g}$ é observada, freqüentemente em uma temperatura superior àquela apresentada pelo polímero não-iônico, e esta diferença devese às forças interiônicas que dificultam a mobilidade das cadeias.

Com o aumento de grupos iônicos ligados quimicamente às cadeias poliméricas, os clusters são formados. Estes últimos são caracterizados por grandes regiões de material polimérico com mobilidade reduzida, de tal forma que o material pode apresentar um comportamento de duas fases e exibir outra $T_{g}$. Nestes casos, os ionômeros podem apresentar duas transições vítreas: uma associada ao movimento das cadeias próximas dos clusters e que apresentam mobilidade reduzida e outra das cadeias afastadas dos c/usters.

Embora existam várias evidências da existência de clusters e multipletos, ainda existem dúvidas sobre o tamanho e as modificações que os clusters sofrem devido às variações do conteúdo de água na membrana ${ }^{[18]}$. Assim, modificações dos modelos existentes foram propostas para tentar compreender as interaçōes que conduzem à formação dos agregados ${ }^{[19]}$.

\subsection{Histórico ${ }^{[3]}$}

O desenvolvimento dos ionômeros tem início em 1930, quando foi registrada uma patente para a carboxilação de elastômeros.

Em 1949, B. F. Goodrich introduziu um dos primeiros elastômeros baseados em interações iônicas, o poli(butadieno-co-acrilonitrila-co-ácido acrílico). Este material quando neutralizado com $\mathrm{Zn}^{2+}$ apresentou melhoria nas propriedades elásticas e de adesão, quando comparado com copolímeros convencionais. 
No início da década de 1950, uma segunda família de elastômeros com um grau substancial de interações iônicas foi introduzida pela E. I. Du Pont de Nemours \& Co. Inc. Estes ionômeros foram sintetizados através da sulfonação de polietileno clorado e o material assim obtido, quando curado com óxidos de metais, deu origem a uma combinação de ligações cruzadas de natureza iônica e covalente. Estes materiais foram comercializados pelo nome de Hypalon ${ }^{\circledast}$.

Em meados de 1960, a Du Pont passou a comercializar o poli(etileno-coácido metacrílico) parcialmente neutralizado com $\mathrm{Zn}^{2+}$ ou $\mathrm{Na}^{+}$, com o nome de Surlyn ${ }^{\otimes}$. Este ionômero possui propriedades elásticas superiores aos polietilenos convencionais e, por isso, encontra, atualmente, grande aplicação no setor de embalagens.

Ainda na década de 1960 foi desenvolvida, pela Du Pont, a membrana Nafion $^{\otimes}$, o primeiro ionômero perfluorossulfonado disponivel comercialmente. Atualmente esta membrana é utilizada como trocadora de cátions em uma grande variedade de processos eletroquímicos.

\subsection{Nafion ${ }^{\circledast}$}

Os ionômeros perfluorosulfonados foram desenvolvidos pela E. I. Du Pont de Nemours \& Co., Inc., em meados da década de 1960 e passaram a ser comercializados no início da década de 1970.

As membranas Nafion são sintetizadas a partir da copolimerização de unidades de tetrafluoretileno TFE $\left(\mathrm{CF}_{2}=\mathrm{CF}_{2}\right)$ e do éter fluorado $\left(\mathrm{CF}_{2} \mathrm{CFOC}\left(\mathrm{CH}_{3}\right) \mathrm{FOCF}_{2} \mathrm{CF}_{2} \mathrm{SO}_{2} \mathrm{~F}\right)$. O produto precursor da copolimerização (precursor não-iônico), que contém o grupo final $\mathrm{SO}_{2} \mathrm{~F}$, pode ser convertido a sulfonato, através da reação de hidrólise do material precursor. As equações químicas das reações de síntese do Nafion são mostradas a seguir: 


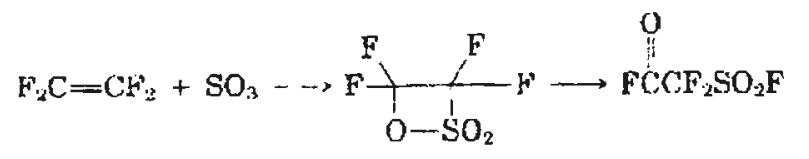

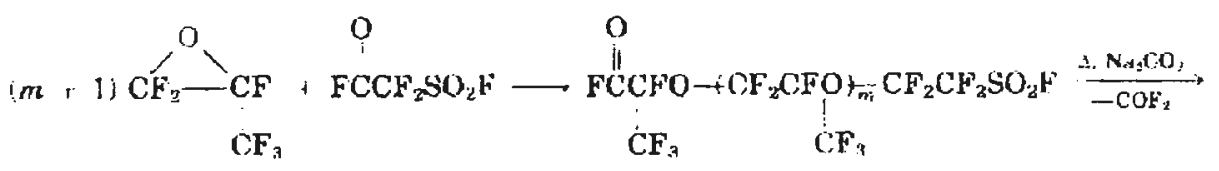

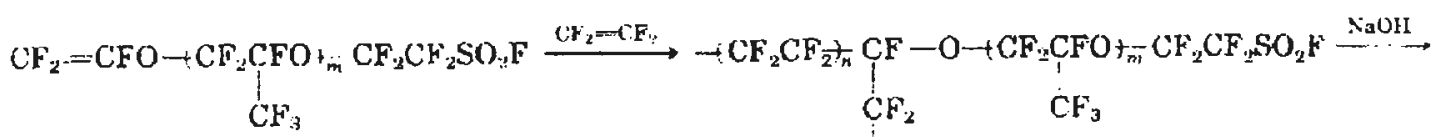

$$
\begin{aligned}
& \text { XR Resin } \\
& \begin{array}{c}
-\mathrm{CF}_{2} \mathrm{CF}_{2}+\mathrm{CF} \\
\mathrm{CF}_{2}-\mathrm{O}+\mathrm{CF}_{3} \mathrm{CFO}+\mathrm{CF}_{2} \mathrm{CF}_{2} \mathrm{SO}_{3} \mathrm{Na} \\
\mathrm{CF}_{3}
\end{array} \\
& \text { Nation }
\end{aligned}
$$

As membranas Nafion são, portanto, copolímeros constituídos de uma cadeia principal de politetrafluoroetileno (PTFE) e de cadeias laterais de éter fluorado terminadas por grupos sulfônicos $\left(\mathrm{SO}_{3}{ }^{-}\right)$. A fórmula estrutural do Nafion segue abaixo:

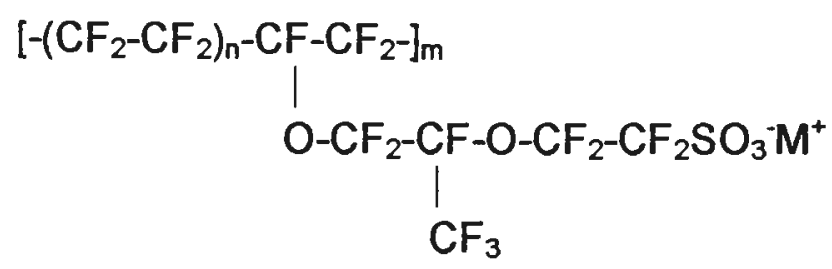

$\mathrm{Na}$ fórmula estrutural representada acima, $\mathrm{M}^{+}$é um contra-íon $\left(\mathrm{H}^{+}, \mathrm{Li}^{+}\right.$, $\mathrm{Na}^{+}$, etc.). A massa equivalente da membrana Nafion disponível comercialmente e utilizada neste trabalho é de $1100 \mathrm{~g}$ do polímero por mol de grupos $\mathrm{SO}_{3}^{-}(\mathrm{n} \cong 6.5)$. 


\subsection{Morfologia do Nafion}

A morfologia do Nafion foi estudada por microscopia de força atômica $(A F M)^{[20]}$ e por difração de raios-X a baixos ângulos $(S A X S)^{[5,21]}$, sendo observada uma reflexão que foi atribuída ao agregado iônico

Espalhamentos de raios- $X$ a ângulos largos (WAXS) revelaram que existe cristalinidade no Nafion não hidrolisado ${ }^{[5]}$. Já, o estudo de polímeros de diferentes massas equivalentes demonstrou que o decréscimo da massa equivalente também acarreta um decréscimo na cristalinidade da amostra, ou seja, quanto maior a quantidade de grupos sulfonato, menor a cristalinidade da matriz polimérica.

Por outro lado, o efeito da hidratação da membrana altera de maneira pouco significativa a cristalinidade da matriz polimérica, quando comparada com a mudança da massa equivalente. Resultados similares foram obtidos para membranas substituidas por diferentes cátions. Portanto, a formação de agregados iônicos não destrói completamente a cristalinidade da matriz polimérica.

\subsection{Modelos para o Nafion}

Para descrever a microestrutura das membranas Nafion foram propostos alguns modelos baseados principalmente na interpretação de dados espectroscópicos ${ }^{[2]}$, de SAXS ${ }^{[5,21]}$ e de transporte iônico ${ }^{[2-27]}$.

Em 1977, Gierke. ${ }^{[28]}$ propôs, a partir de resultados de SAXS, um dos primeiros modelos para descrever a microestrutura da membrana Nafion. Este modelo propõe a formação de agregados iônicos esféricos, apresentando as cadeias laterais terminadas com o grupo sulfonato no interior da esfera e formando estruturas de micelas inversas. Neste modelo os agregados possuem raio ao redor $20 \AA$ e estão espaçados de $50 \AA$. A conexão entre os agregados é feita por canais de cerca de $10 \AA$ de diâmetro, conforme representado na figura 1.2: 


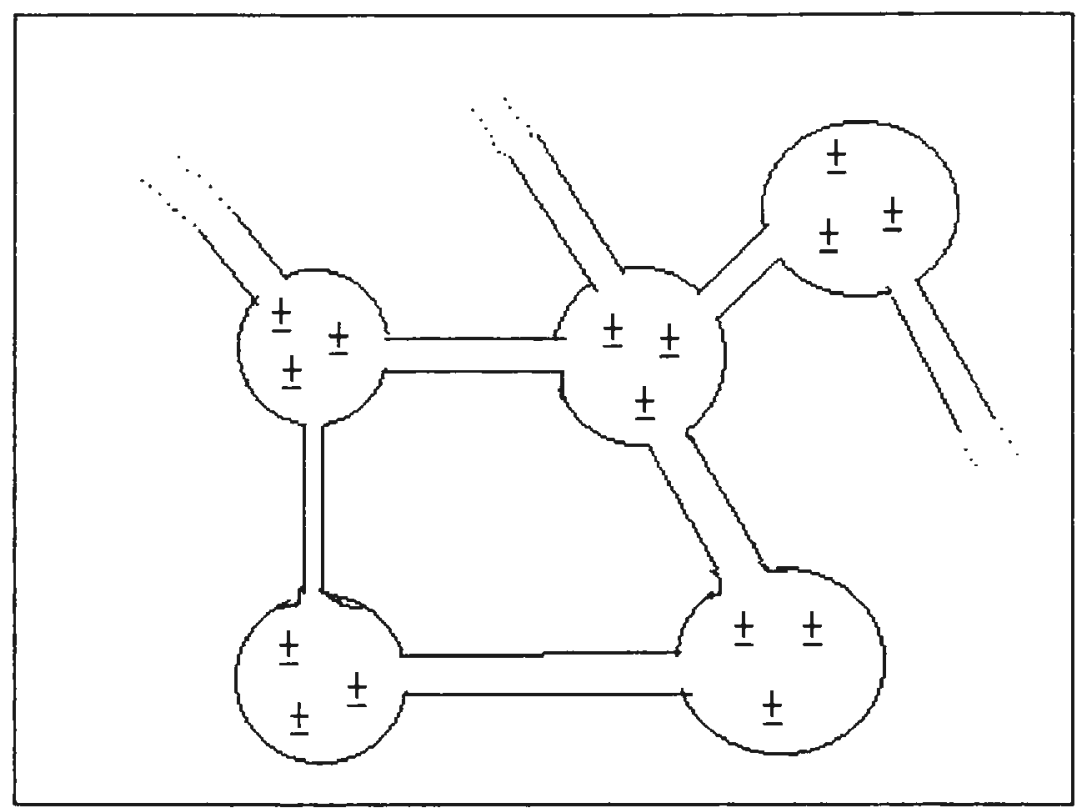

Figura 1.2 Representação esquemática do modelo de Gierke para o ionômero Nafion.

A presença de canais interligando os agregados explica de maneira satisfatória a condução iônica apresentada pelas membranas Nafion.

No modelo de Gierke, os grupos sulfonados encontram-se próximos à interface do agregado, e em contato com a água absorvida que se encontra no interior do agregado. Esta estrutura satisfaz a tendência dos grupos sulfonatos de serem hidratados e minimiza as interaçōes desfavoráveis entre a água e a matriz fluorocarbônica.

Foram encontradas evidências experimentais de transporte iônico ${ }^{[23]}$ e de $\mathrm{RMN}$ de ${ }^{23} \mathrm{Na}^{[24]}$, que são satisfatoriamente descritas por este modelo. No entanto, ele encontra dificuldade em explicar alguns resultados de SAXS e de expansão em água.

Yeager e Steck ${ }^{[25]}$, com base em estudos de transporte iônico, propuseram um modelo em 3 fases para descrever a microestrutura das membranas Nafion. Uma representação esquemática da estrutura da membrana neste modelo é mostrada na figura 1.3: 


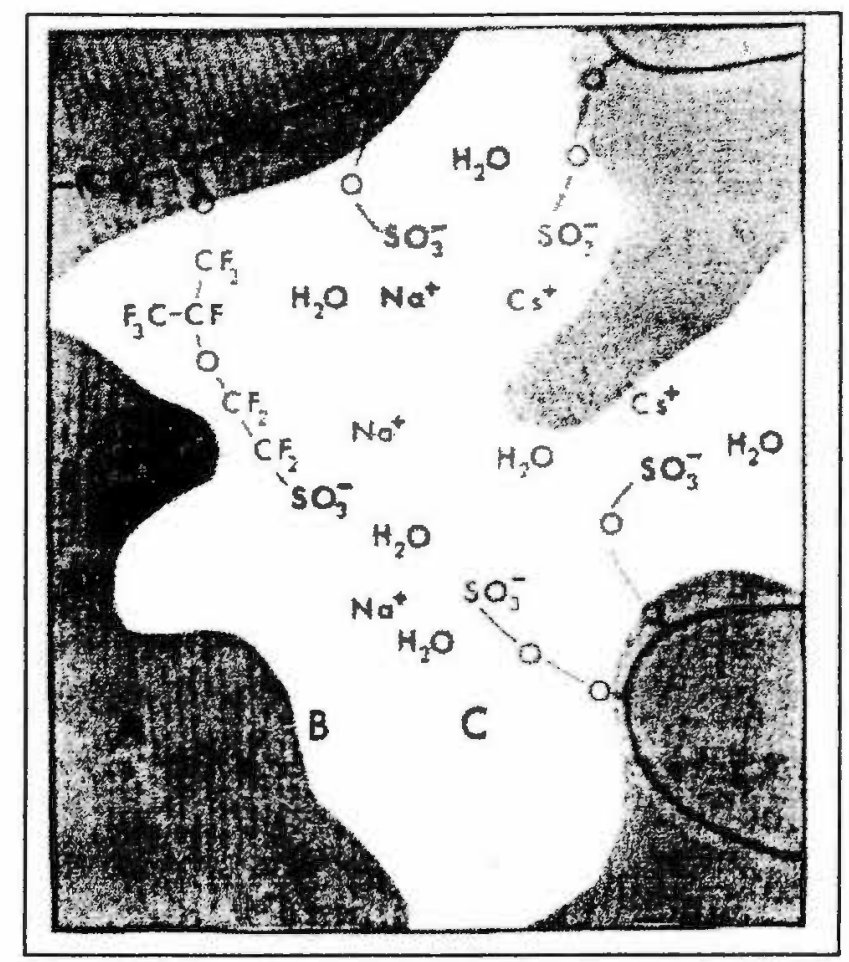

Figura 1.3: Representação esquemática do modelo de Yeager e Steck para o ionômero Nafion.

Neste modelo são consideradas três regiōes: uma consiste de uma fase hidrofóbica composta pelas cadeias fluorocarbônicas (A); outra constituída de agregados iônicos contendo água e os grupos iônicos (B); e a última é uma região interfacial que contem grande número de cadeias laterais e uma pequena quantidade de água e pares iônicos isolados. Este modelo explica a presença do desdobramento das bandas vibracionais da água, apontado por Falk ${ }^{[29]}$, apresentando as moléculas de água submetidas a dois ambientes distintos.

Foram publicados outros trabalhos que tentaram elucidar a microestrutura complexa do Nafion ${ }^{[19,30]}$ e descrever os mecanismos de transporte de cargas nestas membranas, mas não existe ainda um modelo que contemple o conjunto dos dados adquiridos.

O Nafion vem sendo utilizado como membrana trocadora de íns na produção eletrolítica de cloro e soda cáustica ${ }^{[11]}$, apresentando vantagens em relação a outras tecnologias como, por exemplo, a do amálgama de mercúrio. A membrana Nafion também é utilizada como catalisador em reações orgânicas, protetor de corrosão, e existem possibilidades de aplicações futuras 
em sensores de espécies químicas em meio biológico como, por exemplo, sensores de óxido nítrico em meio fisiológico.

Logo, a elucidação da microestrutura e a compreensão dos mecanismos de transporte nas membranas Nafion são essenciais para melhorar a performance destas membranas em suas aplicações atuais e para o desenvolvimento de aplicações futuras.

\subsection{Objetivos}

O objetivo desta dissertação foi estudar via espectroscopia vibracional Raman e infravermelho - e análise térmica - termogravimetria e calorimetria exploratória diferencial, membranas Nafion de massa equivalente 1100 (massa de membrana ( $\mathrm{g} / \mathrm{mol}$ de grupos sulfonato). Em particular, o enfoque deu-se sobre as interações entre as espécies químicas no interior dos agregados iônicos, e a maneira pela qual estas interações são alteradas pela substituição de íons nos agregados.

Os capítulos 2 e 3 visam apresentar de maneira reduzida os princípios das técnicas espectroscópicas e de análise térmica que foram utilizadas neste trabalho. 


\section{0 modo vibracional ${ }^{[31,32]}$}

O modo das vibraçōes moleculares pode ser satisfatoriamente descrito como um tema da mecânica de pequenas oscilações, dado que o sistema está sujeito a uma função potencial que representa um equilibrio estável e que depende unicamente das distâncias internucleares. Segue um breve desenvolvimento sobre 0 tratamento mecânico de tais sistemas.

Dada uma molécula com $N$ átomos, existem $3 N\left(x_{1}, x_{2}, \ldots, x_{3 N}\right)$ coordenadas cartesianas de posição. Admitindo-se um tratamento clássico, a descrição do movimento, desprezando a ação de forças externas, poderia ser obtida a partir da resolução de um sistema de equações diferenciais do tipo:

$$
m_{i} \frac{\partial^{2} x_{i}}{\partial t^{2}}=\sum_{j=1}^{3 N} F_{j i}
$$

$\mathrm{Na}$ qual $\mathrm{F}_{\mathrm{ji}}$ corresponde à força sofrida no iésimo átomo devida ao jésimo átomo.

Entretanto, as ligações entre os átomos impõem restriçōes ao movimento molecular, que faz com que as coordenadas $\left\{x_{1}, x_{2}, \ldots x_{3 N}\right\}$ não sejam todas independentes e conseqüentemente as equações do tipo (2.1) também não serão todas independentes.

Todavia, as restriçōes impostas pelas ligaçōes entre os átomos satisfazem equações da seguinte forma:

$$
f\left(x_{1}, x_{2}, \ldots, x_{3 N}, t\right)=0
$$

As restrições, que satisfazem relaçōes conforme a equação acima, são ditas restrições holonômicas. Portanto, em um sistema, se existirem k restrições holonômicas, estas podem ser utilizadas para eliminar $k$ das $3 N$ coordenadas e então sobrarão $3 \mathrm{~N}-\mathrm{k}$ coordenadas independentes. Outra formulação possivel e mais usual em espectroscopia molecular consiste em considerar $3 \mathrm{~N}-\mathrm{k}$ novas coordenadas 
independentes $\left(q_{1}, q_{2}, \ldots, q_{3 N-k}\right)$ que guardam com as coordenadas cartesianas relações da forma:

$$
x_{1}=x_{1}\left(q_{1}, q_{2}, \ldots, q_{3 N-k}, t\right)
$$

As novas coordenadas são chamadas de coordenadas generalizadas. Entretanto, no estudo das vibrações moleculares, elas também são chamadas de coordenadas internas, pois representam as distâncias e os ângulos formados entre as ligações. As coordenadas internas $\left(q_{i}\right)$ apresentam, sobretudo, a vantagem de representar o campo de forças na molécula, independentemente da orientação desta no espaço.

O número de coordenadas internas é $3 \mathrm{~N}-6$ para moléculas não-lineares, ou $3 N-5$ para moléculas lineares. Este número de coordenadas também pode ser obtido, introduzindo-se, nas equações de movimento, as condições de conservação de momento linear e de conservação de momento angular.

Por sua vez, estas $3 \mathrm{~N}-6$ (3N-5) coordenadas darão origem ao mesmo número de equações diferenciais do tipo (2.1) que levarão, na resolução do problema, admitindo-se a aproximação do oscilador harmônico, às $3 \mathrm{~N}-6$ ou $3 \mathrm{~N}-5$ freqüências próprias de oscilação do sistema.

Uma solução particular para as equações (2.1) escritas em coordenadas internas seria dada por:

$$
q_{i \alpha}=L_{i \alpha} \cos \left(2 \pi v_{\alpha}+\phi_{\alpha}\right) \quad(i=1,2, \ldots, 3 N-6)
$$

A solução geral pode ser obtida através da combinação linear das soluções particulares e então vem que:

$$
q_{i}=\sum_{\alpha} Q_{0 \alpha} q_{i \alpha}=\sum_{\alpha} Q_{0 \alpha} L_{i \alpha} \cos \left(2 \pi v_{\alpha} t+\phi_{\alpha}\right)=\sum_{\alpha} L_{i \alpha} Q_{\alpha}
$$

Na qual $Q_{\alpha}=Q_{0 \alpha} \cos \left(2 \pi v_{\alpha} t+\phi_{\alpha}\right)$ correspondem às coordenadas normais.

O tratamento do modo vibracional, em coordenadas normais, permite desacoplar os osciladores. Nestas coordenadas todos os átomos executam 
deslocamentos com a mesma freqüência, embora a amplitude da vibração possa variar.

O objetivo último da análise vibracional consiste em atribuir uma freqüência observada no espectro a uma determinada coordenada normal. Até agora, foi focado apenas o tratamento mecânico das oscilações. No próximo item será abordada a maneira pela qual estas vibrações interagem com a radiação incidente.

\subsection{Espectro no Infravermelho}

Para que ocorra a absorção da radiação incidente por uma dada molécula, é necessário que o campo elétrico oscilante associado à vibração molecular, entre em ressonância com o campo elétrico da radiação eletromagnética. Para isso, a freqüência absorvida deverá ser uma das freqüências próprias da molécula.

A regra de seleção para que haja atividade no infravermelho pode ser expressa pelo momento de transição que é dado por:

$$
[\mu]_{m n}=\int \Psi_{m}\left(Q_{\alpha}\right) \mu \Psi_{n}\left(Q_{\alpha}\right) d Q_{\alpha}
$$

Na equação (2.6), $\mu$ representa o momento de dipolo do estado vibracional fundamental e $\psi_{m}$ e $\psi_{n}$ são, respectivamente, as autofunções dos estados fundamental e excitado.

A atividade no infravermelho associada à coordenada normal $Q_{\alpha}$ pode, pois, ser determinada resolvendo-se o momento de transição para cada uma das componentes cartesianas $(x, y, z)$ :

$$
\begin{aligned}
& {\left[\mu_{x}\right]_{m n}=\int \Psi_{m}\left(Q_{\alpha}\right) \mu_{x} \Psi_{n}\left(Q_{\alpha}\right) d Q_{\alpha}} \\
& {\left[\mu_{y}\right]_{m n}=\int \Psi_{m}\left(Q_{\alpha}\right) \mu_{y} \Psi_{n}\left(Q_{\alpha}\right) d Q_{\alpha}} \\
& {\left[\mu_{z}\right]_{m n}=\int \Psi_{m}\left(Q_{\alpha}\right) \mu_{z} \Psi_{n}\left(Q_{\alpha}\right) d Q_{\alpha}}
\end{aligned}
$$


$E$, portanto, a vibração associada à coordenada normal $Q_{\alpha}$ será ativa no infravermelho desde que uma das integrais do tipo (2.7) seja diferente de zero.

\subsection{Espectro Raman}

O fenômeno de espalhamento Raman pode ser descrito como uma colisão inelástica entre um fóton e uma molécula, com modificação na energia do fóton espalhado.

Se o fóton perde parte de sua energia para a molécula, que passa para um estado excitado, obtém-se uma banda Raman Stokes, caso ocorra o contrário e o fóton ganhe energia no processo (colidindo com uma molécula que já se encontre em algum estado excitado) tem-se uma banda Raman anti-Stokes.

O efeito Raman contrapõe-se ao espalhamento Rayleigh, no qual o fóton espalhado possui a mesma energia do fóton incidente.

Os três fenômenos podem ser esquematizados conforme a figura 2.1:

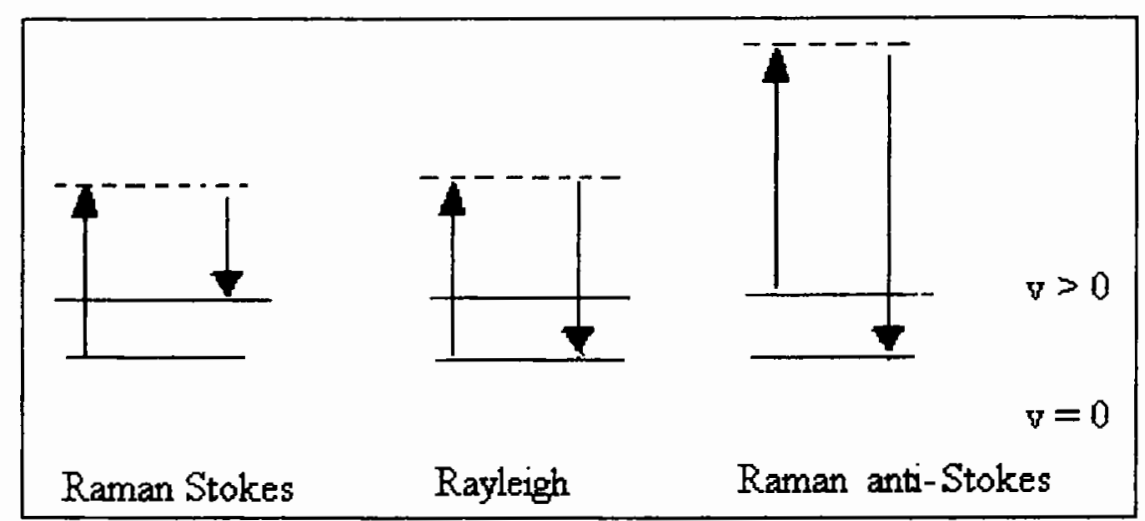

Figura 2.1. Representação esquemática dos espalhamentos Rayleigh, Raman Stokes e Raman anti-Stokes.

$\mathrm{Na}$ figura 2.1 as linhas contínuas representam auto-estados da molécula e as linhas tracejadas representam estados virtuais ou intermediários (combinação linear de auto-estados).

As bandas Stokes são mais intensas que as bandas anti-Stokes, pois suas intensidades dependem das populações dos diferentes estados, que obedecem, numa situação de equilíbrio térmico, à distribuição de Boltzmann. 
O efeito Raman é fisicamente diverso da absorção no infravermelho e, conseqüentemente, apresenta regras de seleção distintas. A atividade no efeito Raman está ligada à variação do tensor de polarizabilidade com a vibração considerada. Tem-se, portanto, a regra de seleção expressa por:

$$
[\alpha]_{m n}=\int \Psi_{m}\left(Q_{a}\right) \alpha \Psi_{n}\left(Q_{a}\right) d Q_{a}
$$

O tensor de polarizabilidade é um tensor simétrico $\left(\alpha_{i j}=\alpha_{j i}\right)$ contendo seis componentes, $\alpha_{x x}, \alpha_{y y}, \alpha_{z z}, \alpha_{x y}, \alpha_{x z}$ e $\alpha_{y z}$ e, portanto, a equação (2.8) deve ser resolvida para as seis componentes:

$$
\begin{aligned}
& {\left[\alpha_{x x}\right]_{m n}=\int \Psi_{m}\left(Q_{a}\right) \alpha_{x x} \Psi_{n}\left(Q_{a}\right) d Q_{a}} \\
& {\left[\alpha_{y y}\right]_{m n}=\int \Psi_{m}\left(Q_{a}\right) \alpha_{y y} \Psi_{n}\left(Q_{a}\right) d Q_{a}} \\
& \ldots \ldots \ldots \ldots \ldots \ldots \ldots \ldots
\end{aligned}
$$

Analogamente ao infravermelho, se uma destas integrais for diferente de zero a vibração associada à coordenada normal $Q_{a}$ apresentará atividade no espectro Raman.

\subsection{Fotoacústico por transformada de Fourier ${ }^{[33]}$}

Os espectros obtidos por transformada de Fourier apresentam vantagem em relação àqueles obtidos pelas técnicas de dispersão. Essa vantagem se traduz no espectro pelo aumento da relação sinalruído, a qual é obtida minimizando a quantidade de elementos dispersivos.

A técnica de obtenção do espectro infravermelho por transformada de Fourier faz uso do interferômetro de Michelson. A figura 2.2 apresenta a representação esquemática de um espectrômetro FTIR, contendo um interferômetro de Michelson. 


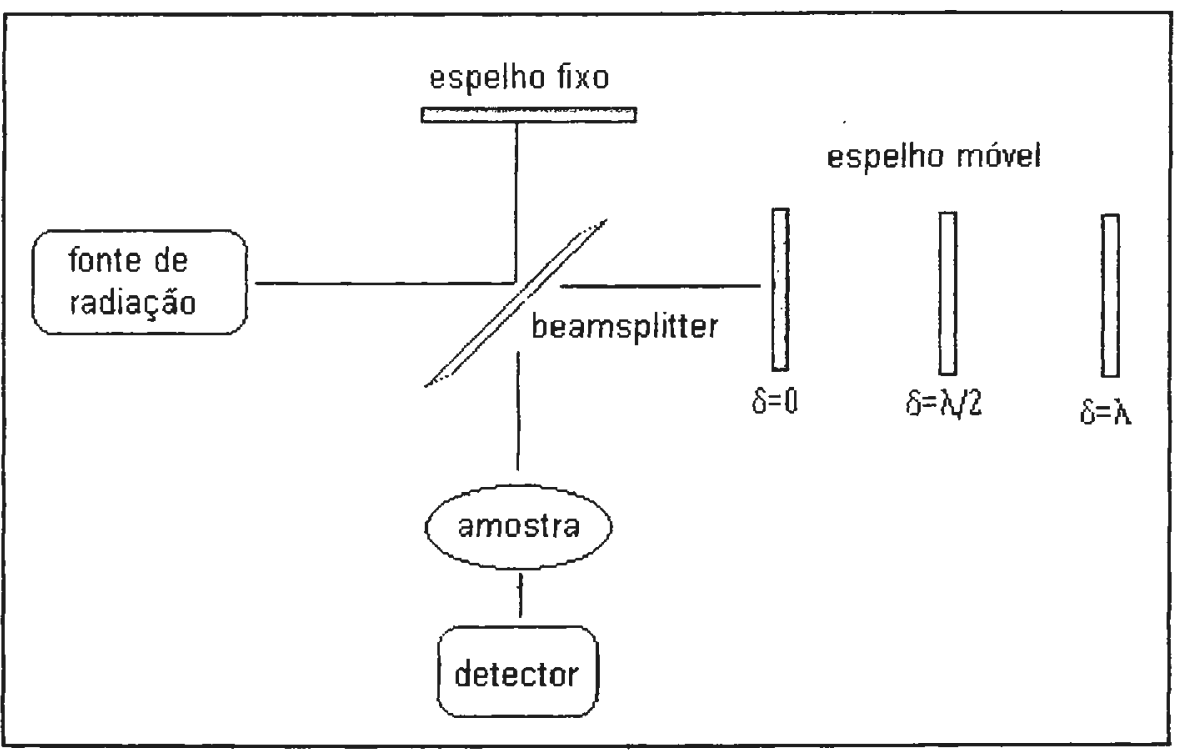

Figura 2.2. Esquema de um espectrômetro FTIR.

À medida que o espelho móvel muda de posição, o caminho óptico da radiação que atravessa o separador de feixes (beamsplitter) é alterado e a interferência desta onda com a radiação que é refletida pelo espelho fixo fazem com que a radiação que incide na amostra apresente intensidade modulada.

Obtém-se, desta maneira, o interferograma que é uma função de intensidade $(I(\delta))$ por caminho óptico $(\delta)$.

Pode-se obter o espectro $(B(v))$ aplicando-se, no interferograma, o operador de Transformada de Fourier. A expressão analítica deste operador em $\mathrm{l}(\delta)$ é mostrada na equação (2.9):

$$
B(v)=\int^{+\infty} I(\delta) \cos (2 \pi v \delta) d \delta
$$

Entretanto, na expressão (2.9) os limites de integração não são realizáveis fisicamente, uma vez que ( $\delta$ ) é dado pelo deslocamento do espelho móvel. Esta limitação no intervalo de integração leva ao aparecimento, no espectro, de "pés" na banda.

Na figura 2.3 é mostrada uma representação esquemática destes "pés" na banda: 


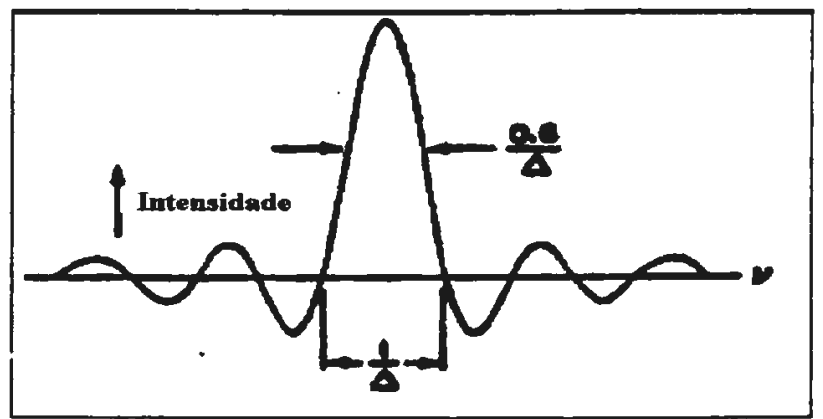

Figura 2.3. Espectro típico com os "pés" na banda.

Para minimizar este problema, o interferograma é multiplicado por uma função de apodização ("ápodos" = sem pés). Existem diversas funções de apodização, todas elas minimizam os "pés" no espectro, mas também diminuem a intensidade e aumentam a largura da banda. Após a apodização o espectro assume o seguinte apresentado na figura 2.4 :

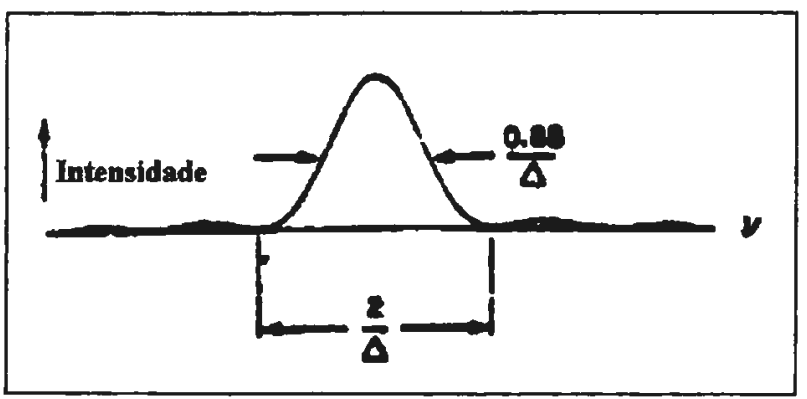

Figura 2.4. Espectro típico obtido após a apodização. 


\section{Análise Térmica ${ }^{[34,35]}$}

As diferentes técnicas de análise térmica são caracterizadas pelo monitoramento de uma ou mais propriedades físicas de um sistema, quando este é submetido a uma variação controlada de temperatura. Neste trabalho foram utilizadas duas dessas técnicas: a calorimetria exploratória diferencial (DSC) e a termogravimetria (TG).

Os princípios de cada uma dessas técnicas são, a seguir, apresentados de maneira sintética.

\subsection{Calorimetria Exploratória Diferencial}

Na técnica de DSC uma amostra e uma referência são submetidas a uma variação controlada de temperatura e em decorrência de um evento térmico na amostra, surge uma diferença de temperatura entre a referência e a amostra. Essa diferença de temperatura é monitorada e convertida para fluxo de calor dando origem à curva de DSC.

Os equipamentos de DSC dividem-se em dois grupos: os de fluxo de calor e os de compensação de potência.

\subsubsection{DSC por fluxo de calor}

Na calorimetria exploratória diferencial por fluxo de calor, a diferença de temperatura entre uma referência e a amostra é monitorada em função do tempo ou da temperatura, sob condições controladas de temperatura e esta diferença de temperatura entre a amostra e a referência é proporcional ao fluxo de calor.

O esquema de um sistema de DSC por fluxo de calor é mostrado na figura 3.1: 


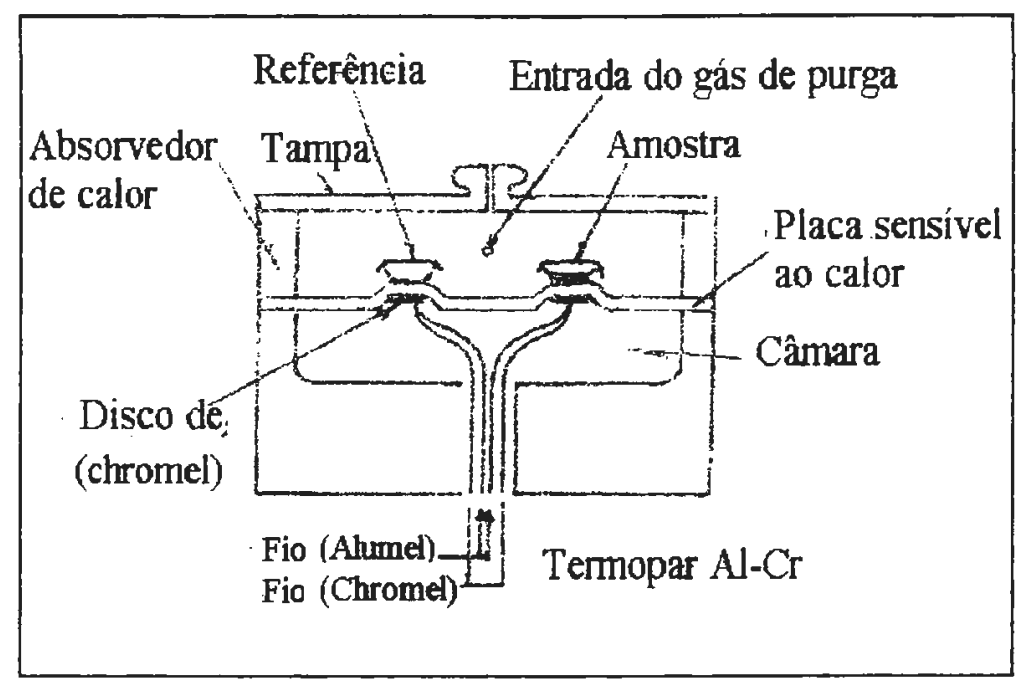

Figura 3.1: Esquema do aparelho de DSC por fluxo de calor da TA Instruments.

A constituição do compartimento de amostra é diferente do DTA clássico. O termopar é colocado na base dos suportes da referência e da amostra e uma segunda série de termopares mede a temperatura do forno e da placa termosensivel.

Durante uma transição de fase, o calor liberado ou absorvido pela amostra altera o fluxo de calor através da placa termossensível. Esta variação no fluxo de calor causa um incremento na diferença de temperatura que é medida entre a placa termossensivel e o forno, dando origem à curva de DSC.

Neste trabalho foi utilizado um aparelho de DSC por fluxo de calor, da TA Instruments, conforme descrito acima.

\subsubsection{DSC por compensação de potência}

Um calorímetro DSC por compensação de potência emprega um principio de operação diferente do sistema de DSC descrito anteriormente. A estrutura de um calorimetro por compensação de potência é mostrada na figura 3.2: 


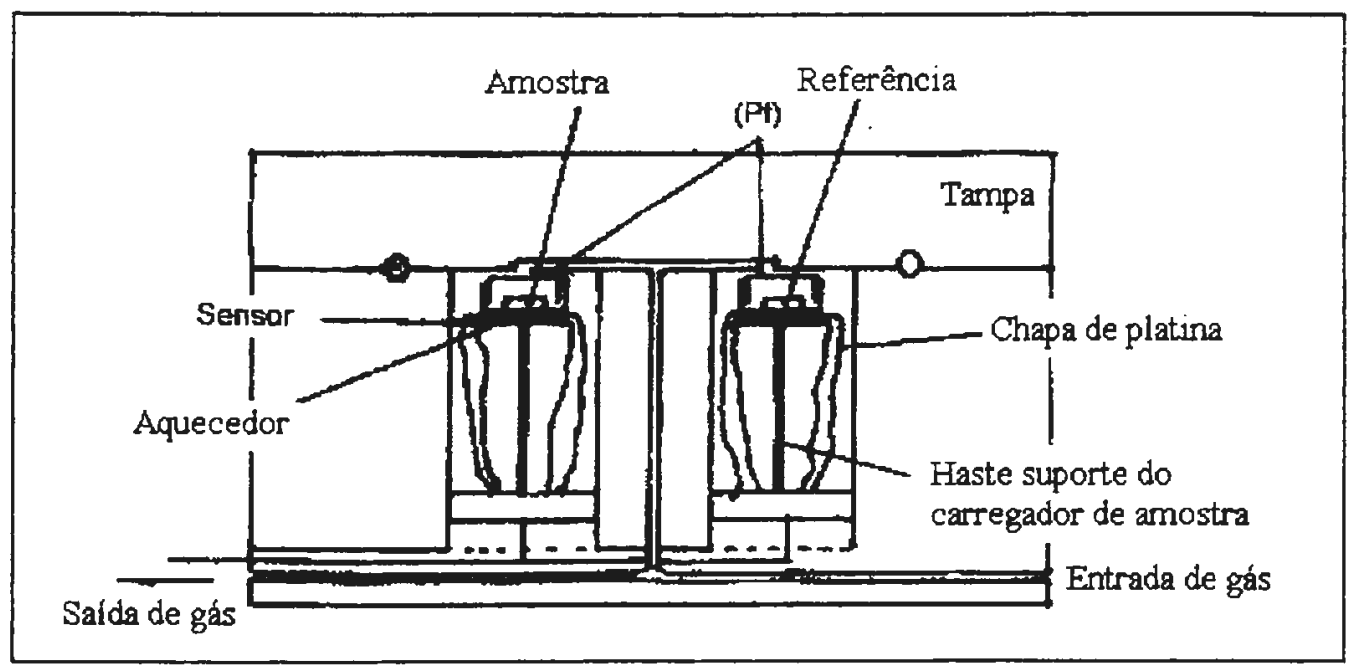

Figura 3.2. Esquema do aparelho de DSC por compensação de potência da Perkin Elmer Corp.

A base do carregador de amostra é colocada num recipiente de resfriamento e os carregadores da referência e da amostra são individualmente equipados com um sensor, o qual mede a diferença de temperatura entre a base do carregador e uma resistência aquecida.

Se uma diferença de temperatura é detectada entre a amostra e a referência, devido a uma transição térmica na amostra, uma certa quantidade de energia é fornecida até que a diferença de temperatura seja menor que um valor pré-estabelecido, usualmente $0,01 \mathrm{~K}$. A energia empregada por unidade de tempo é monitorada em função da temperatura ou do tempo, dando origem à curva de DSC por compensação de potência.

\subsection{Termogravimetria}

A termogravimetria (TG) é uma técnica de análise térmica que monitora a variação de massa de uma amostra em função da temperatura (no modo de varredura) ou em função do tempo (no modo isotérmico). A TG é normalmente utilizada para caracterizar a decomposição e a estabilidade térmica de materiais sob diversas condições.

Uma das dificuldades em se utilizar a termogravimetria é que a curva de TG é fortemente influenciada pelas condições experimentais empregadas. Fatores como a massa da amostra, a natureza e a pressão do gás no 
carregador de amostra e a taxa de aquecimento têm forte influência na curva de TG resultante. Assim sendo, os parâmetros ótimos para a obtenção das curvas têm de ser ajustados e mantidos durante o curso dos experimentos.

As curvas de TG são expressas pela porcentagem em massa $(\% \mathrm{~m})$, ou variação da porcentagem em massa $(\% \Delta \mathrm{m})$ da amostra em função da temperatura $(T)$ ou do tempo ( $t)$.

$\mathrm{Na}$ figura 3.3 segue um diagrama da aparelhagem envolvida na termogravimetria:

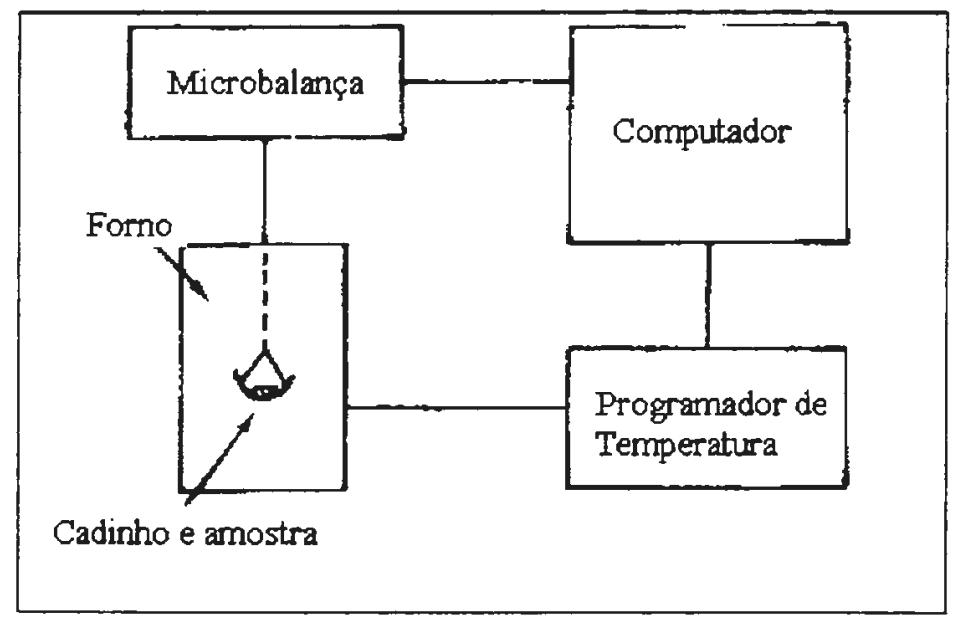

Figura 3.3. Diagrama da aparelhagem usada na termogravimetria. 


\section{Materiais e Métodos}

\subsection{Caracteristicas das membranas}

As membranas Nafion estudadas apresentavam as seguintes

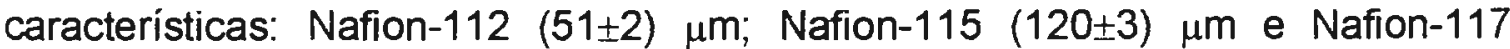
(178 \pm 3$) \mu \mathrm{m}$. Todas as membranas possuíam massa equivalente $1100(1100 \mathrm{~g} \mathrm{de}$ polímero/mol de grupos sulfonato), provenientes da Aldrich.

\subsection{Troca iônica}

As substituições iônicas nas membranas foram feitas mergulhando-as em solução $1 \mathrm{~mol} / \mathrm{L}$ dos respectivos cátions de metais alcalinos, por um período de 24 horas, à temperatura ambiente, conforme procedimento descrito na literatura ${ }^{[25]}$

\subsection{Equipamentos utilizados}

\subsubsection{Espectros no infravermelho}

Os espectros no infravermelho das membranas na forma ácida e nas formas salinas foram adquiridos por técnica fotoacústica, pois a mesma possibilita a obtenção dos espectros sem tratamento prévio da amostra. Para a aquisição dos espectros foi utilizado o equipamento da Bomem, modelo DA3, equipado com acessório fotoacústico da MTEC modelo 200. Para aumento da relação sinal/ruído, cada espectro consistiu na acumulação de 64 varreduras. 


\subsubsection{Espectros Raman}

Os espectros Raman das membranas foram obtidos, usando-se equipamento Renishaw Raman Imaging Microscope, System 3000, com linha de excitação em $632.8 \mathrm{~nm}$. Cada espectro consistiu na acumulação de 200 varreduras, visando otimizar a razão sinal/ruído.

\subsubsection{Termogravimetria}

As curvas termogravimétricas das membranas foram obtidas, usando-se equipamento Hi-Res TGA 2950, da TA Instruments. Os parâmetros utilizados foram os seguintes:

Intervalo de temperatura: 25 a $700^{\circ} \mathrm{C}$;

Atmosfera: $\mathrm{N}_{2}$;

Vazão do gás de purga: $100 \mathrm{~mL} / \mathrm{min}$

Rampa de aquecimento: $20^{\circ} \mathrm{C} / \mathrm{min}$

Resolução: 3

\subsubsection{Calorimetria Exploratória Diferencial (DSC)}

As curvas DSC foram obtidas usando-se equipamento DSC-10, da TA Instruments. Os parâmetros para a aquisição das curvas são os seguintes:

Intervalo de temperatura: 25 a $350^{\circ} \mathrm{C}$;

Atmosfera: $\mathrm{N}_{2}$;

Vazão do gás de purga: $40 \mathrm{~mL} / \mathrm{min}$

Rampa de aquecimento: $10^{\circ} \mathrm{C} / \mathrm{min}$ 


\section{Resultados e Discussão}

\subsection{Espectros Fotoacústicos do Nafion}

Dentre as técnicas de obtenção de espectro no infravermelho, optou-se pela técnica fotoacústica por não requerer nenhuma preparação prévia da amostra. $O$ equipamento utilizado foi o espectrômetro com transformada de Fourier da Bomem, modelo DA3, equipado com acessório fotoacústico da MTEC modelo 200.

Foram obtidos os espectros fotoacústicos na região do infravermelho (450 a $4000 \mathrm{~cm}^{-1}$ ) da membrana Nafion na sua forma original (ácida) e substituída por diferentes contra-íons $\left(\mathrm{Li}^{+}, \mathrm{Na}^{+}, \mathrm{K}^{+}, \mathrm{Rb}^{+} \mathrm{e} \mathrm{Cs}^{+}\right)$. A substituiçăo nas membranas foi feita mergulhando-as em soluções salinas de concentração $1 \mathrm{~mol} / \mathrm{L}$ durante um período de 24 horas, conforme procedimento descrito na literatura ${ }^{[25]}$. A seguir são apresentados os espectros fotoacústicos dessas membranas.

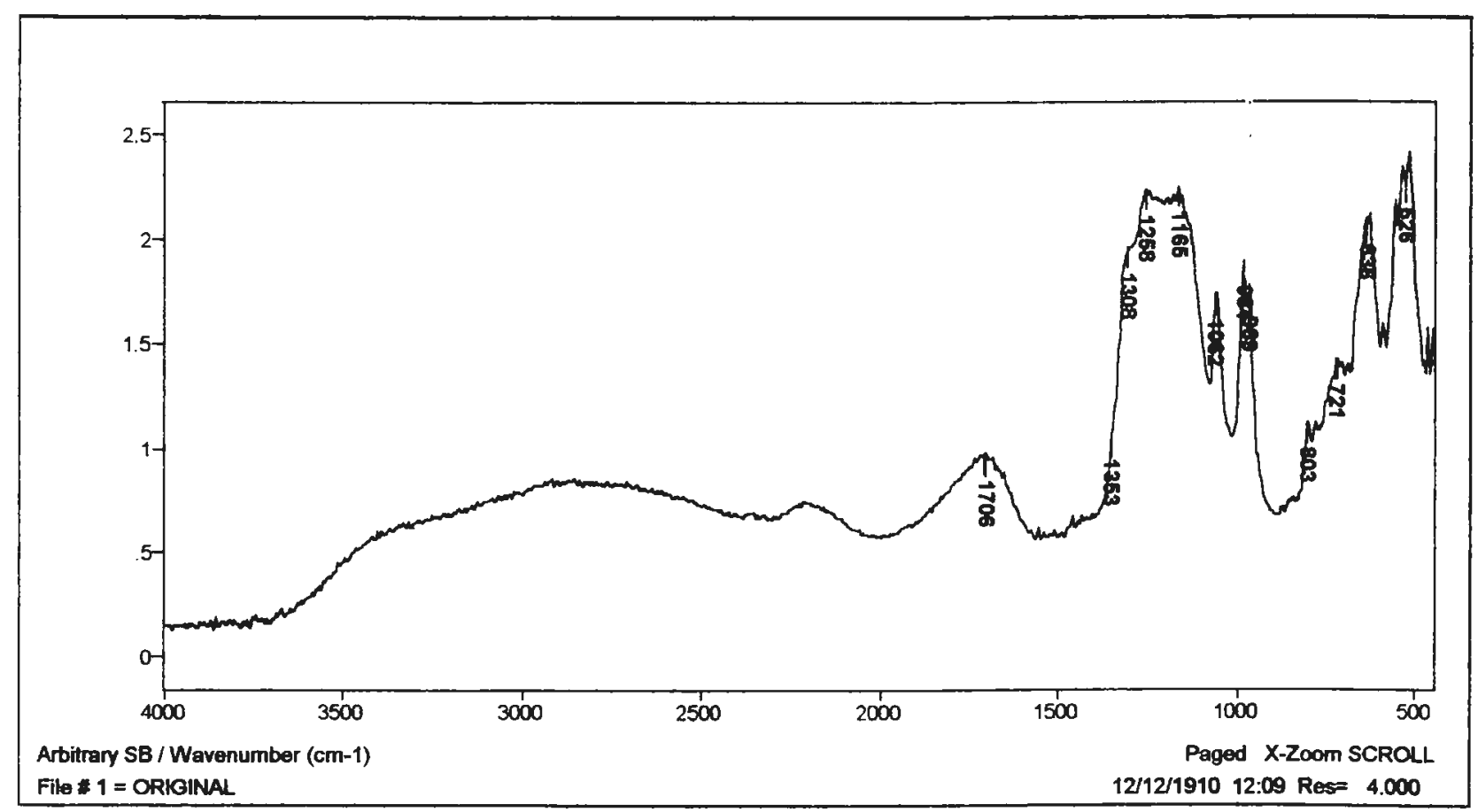

Figura 5.1. Espectro fotoacústico na região do infravermelho para a membrana na forma ácida. 


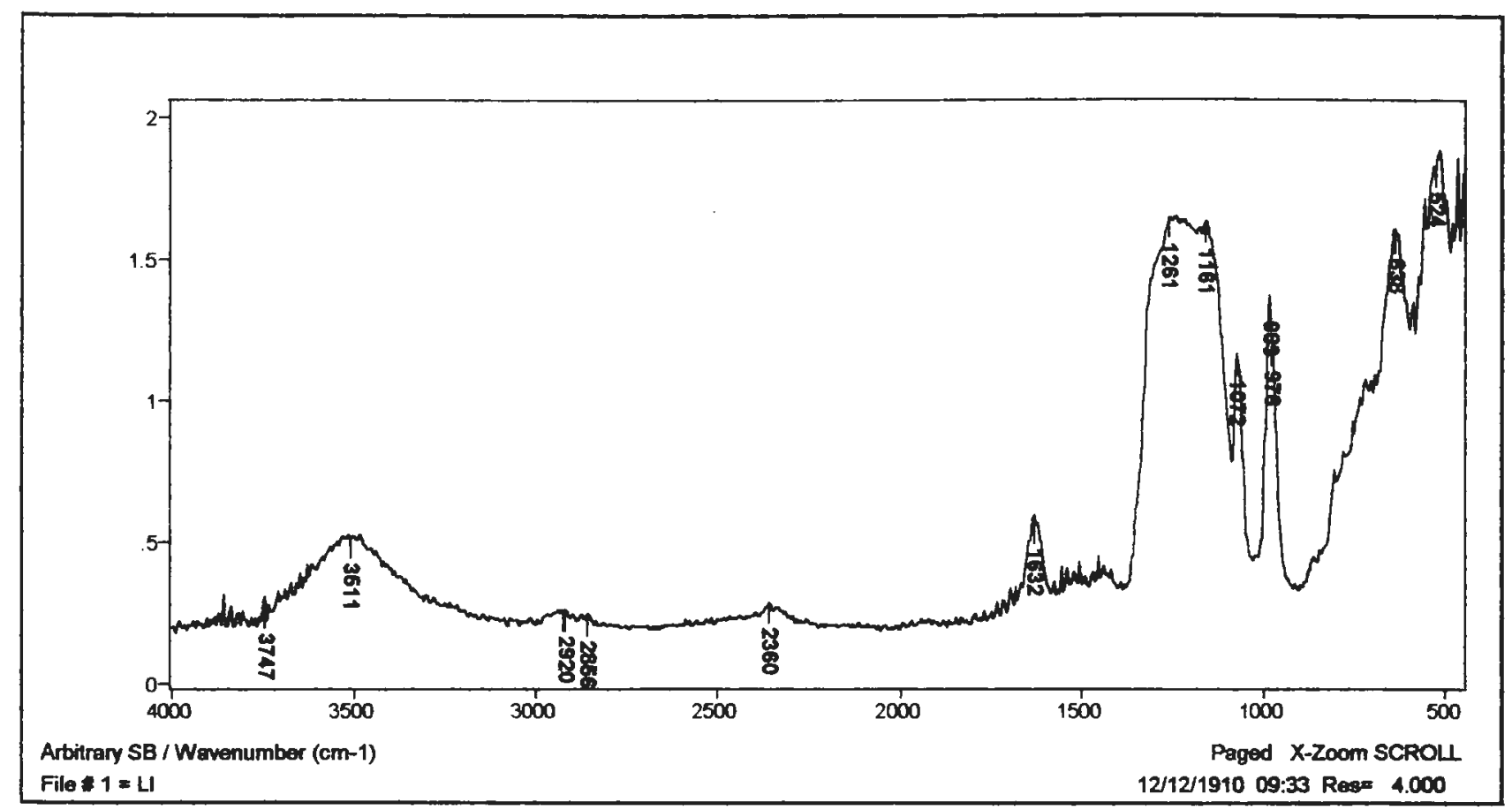

Figura 5.2. Espectro fotoacústico na região do infravermelho para a membrana na forma $\mathrm{Li}^{+}$.

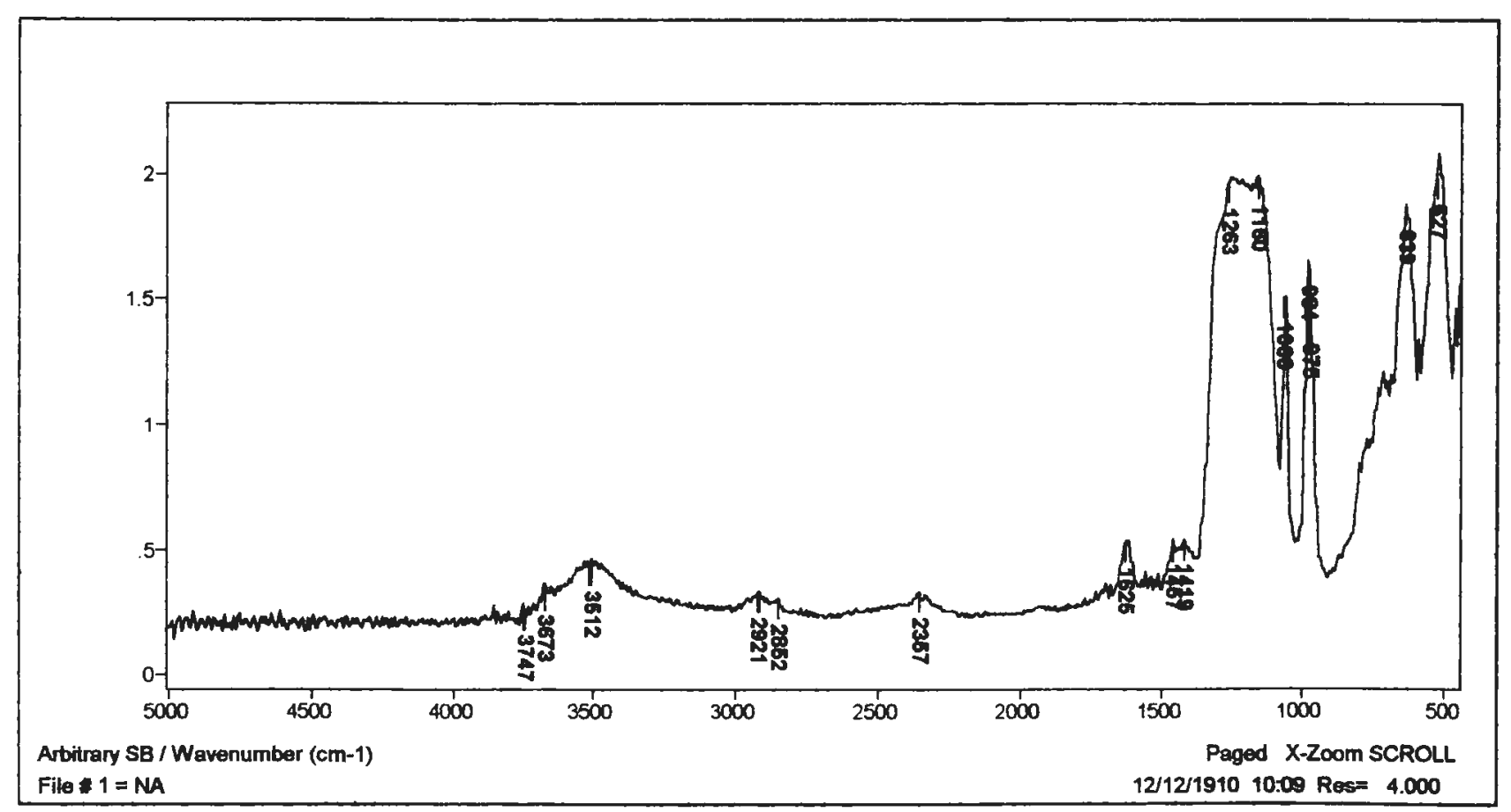

Figura 5.3. Espectro fotoacústico na região do infravermelho para a membrana na forma $\mathrm{Na}^{+}$. 


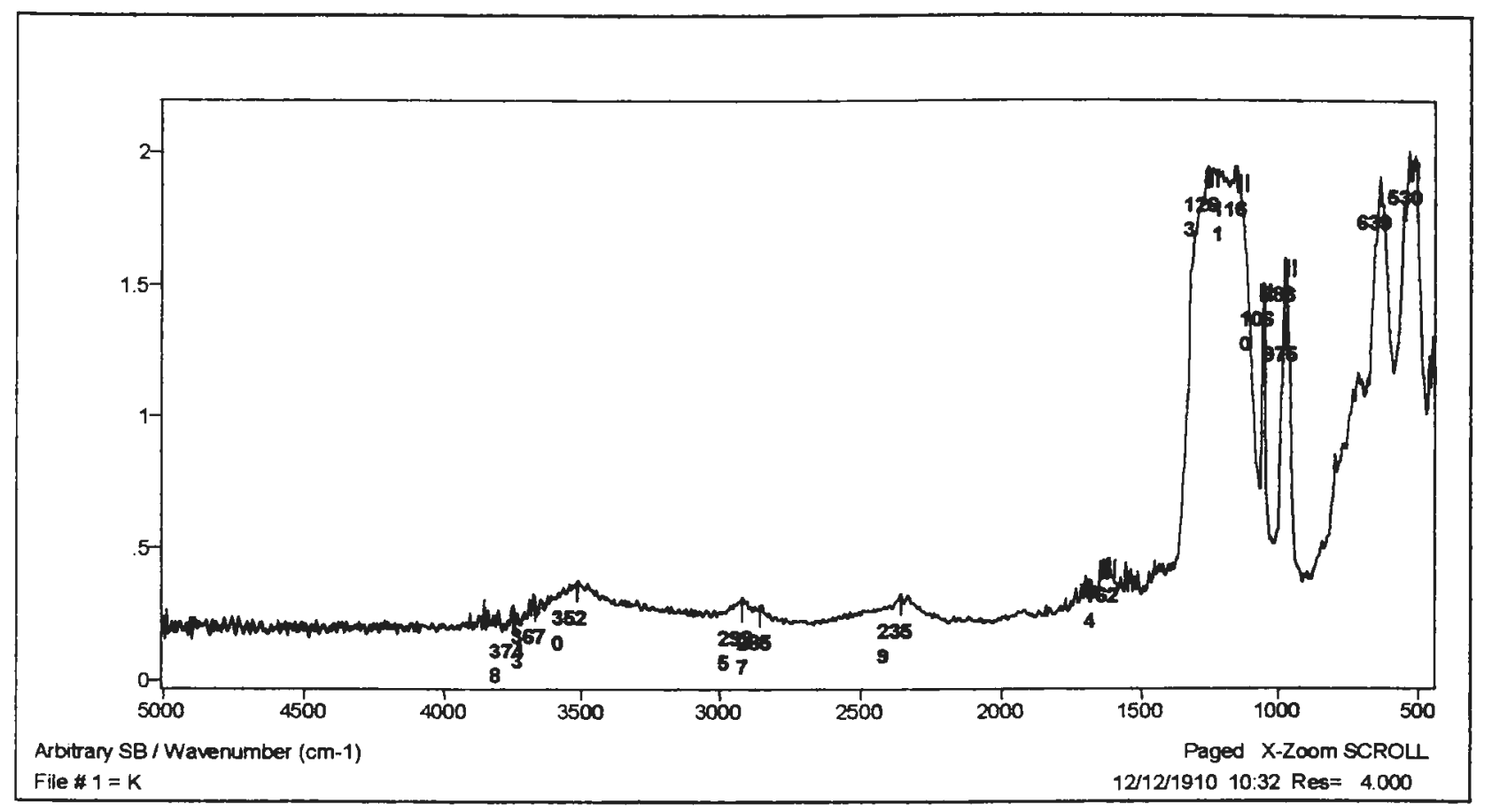

Figura 5.4. Espectro fotoacústico na região do infravermelho para a membrana na forma $\mathrm{K}^{+}$.

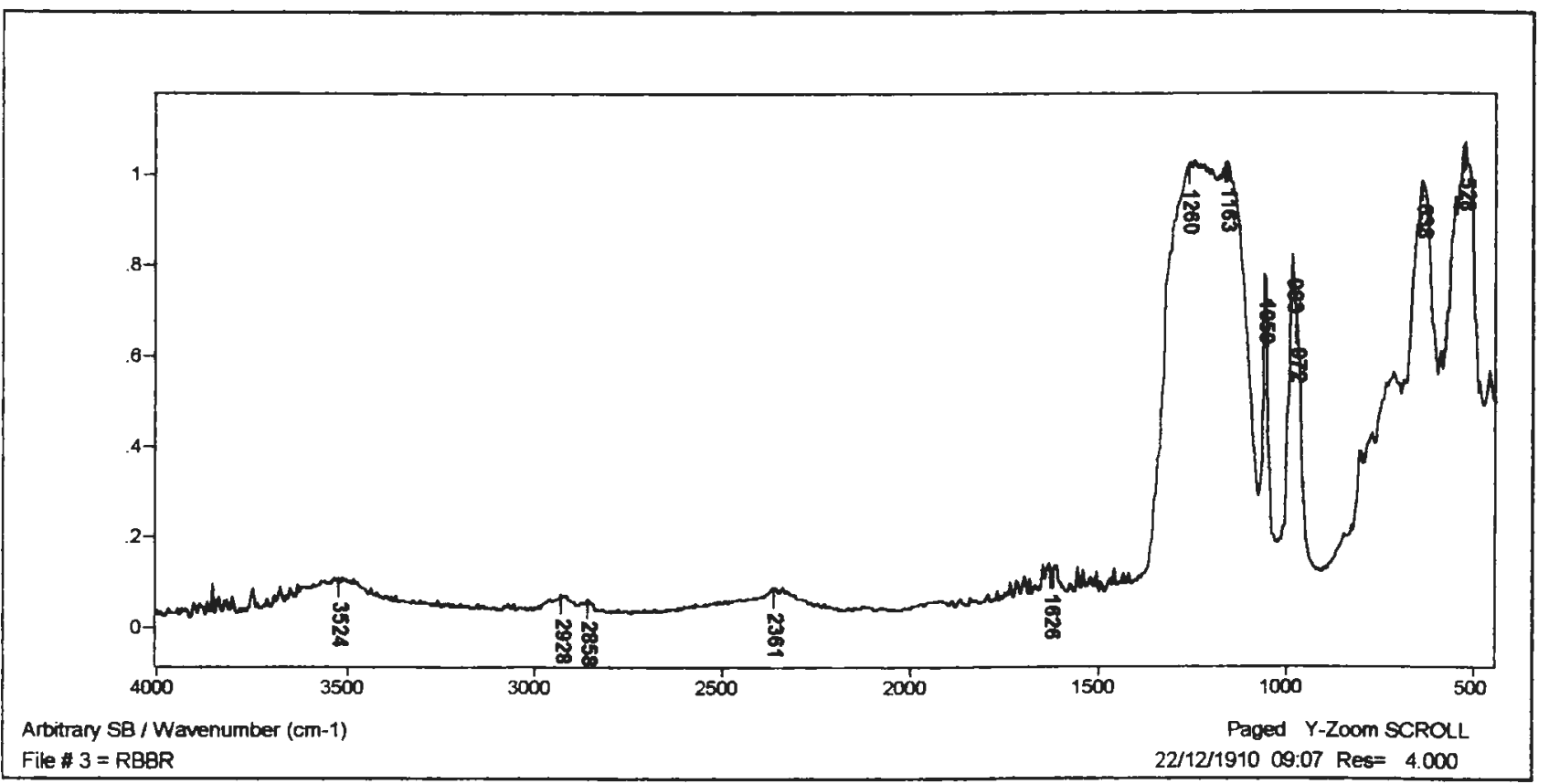

Figura 5.5. Espectro fotoacústico na região do infravermelho para a membrana na forma $\mathrm{Rb}^{+}$. 


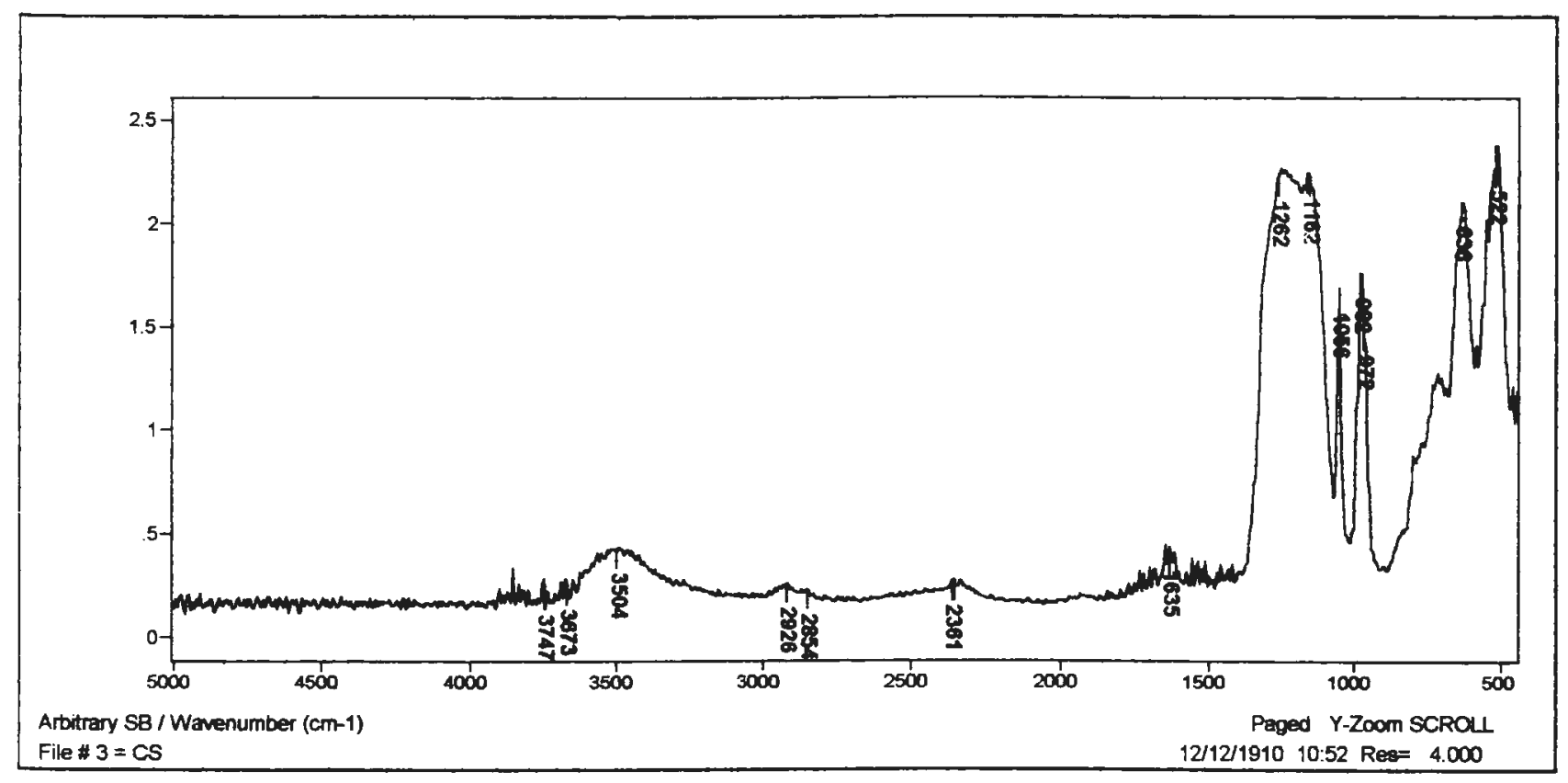

Figura 5.6. Espectro fotoacústico na região do infravermelho para a membrana na forma $\mathrm{Cs}^{+}$.

Nos espectros fotoacústicos apresentados, as bandas relacionadas às espécies que se encontram no interior do agregado sofrem deslocamento de banda, sendo este fato razoável uma vez que os cátions devem estar inseridos na região intema do cluster, interagindo com a água e os grupos sulfonatos presentes nessa região.

O grupo sulfonato apresenta, em seu espectro infravermelho, modos de estiramento simétrico (espécie $A_{1}$ ) e de estiramento degenerado (espécie $E$ ), entretanto, a banda do modo de estiramento degenerado não é bem resolvida no espectro fotoacústico da membrana devido à superposição desta banda com as bandas de estiramento dos grupos - $\mathrm{CF}_{2^{-}}$e -C-C-. Assim, usamos a banda de estiramento simétrico (na região de $1060 \mathrm{~cm}^{-1}$ ) para caracterizar mudanças no ambiente químico no interior dos agregados. 


\subsection{Espectros Raman}

Foram obtidos os espectros de microscopia Raman das membranas Nafion em sua forma original (ácida) e nas formas salinas $\left(\mathrm{Li}^{+}, \mathrm{Na}^{+}, \mathrm{K}^{+}\right.$e $\left.\mathrm{Rb}^{+}\right)$usando-se equipamento Renishaw Raman Imaging Microscope, System $\mathbf{3 0 0 0}$ (excitação em $632.8 \mathrm{~nm}$ ). Também foram adquiridos espectros Raman de membranas substituídas com $\mathrm{Rb}^{+}$, mas variando-se o ânion $\left(\mathrm{NO}_{3}^{-}, \mathrm{F}^{-}, \mathrm{Cl}\right.$ ). Nenhum desses espectros apresentou qualquer mudança significativa.

A membrana tanto em sua forma original (ácida), como nas formas salinas apresentava forte fluorescência o que impedia a obtenção dos espectros Raman. A obtenção dos espectros só foi possivel através da redução da área de aquisição de imagem na câmera CCD. A redução da área de aquisição, aumentou a confocalidade do espectro, e como o espalhamento Raman ocorre preferencialmente na superfície da amostra, houve um aumento da relação das intensidades de espalhamento Raman/fluorescência.

Os espectros Raman das membranas săo mostrados a seguir.

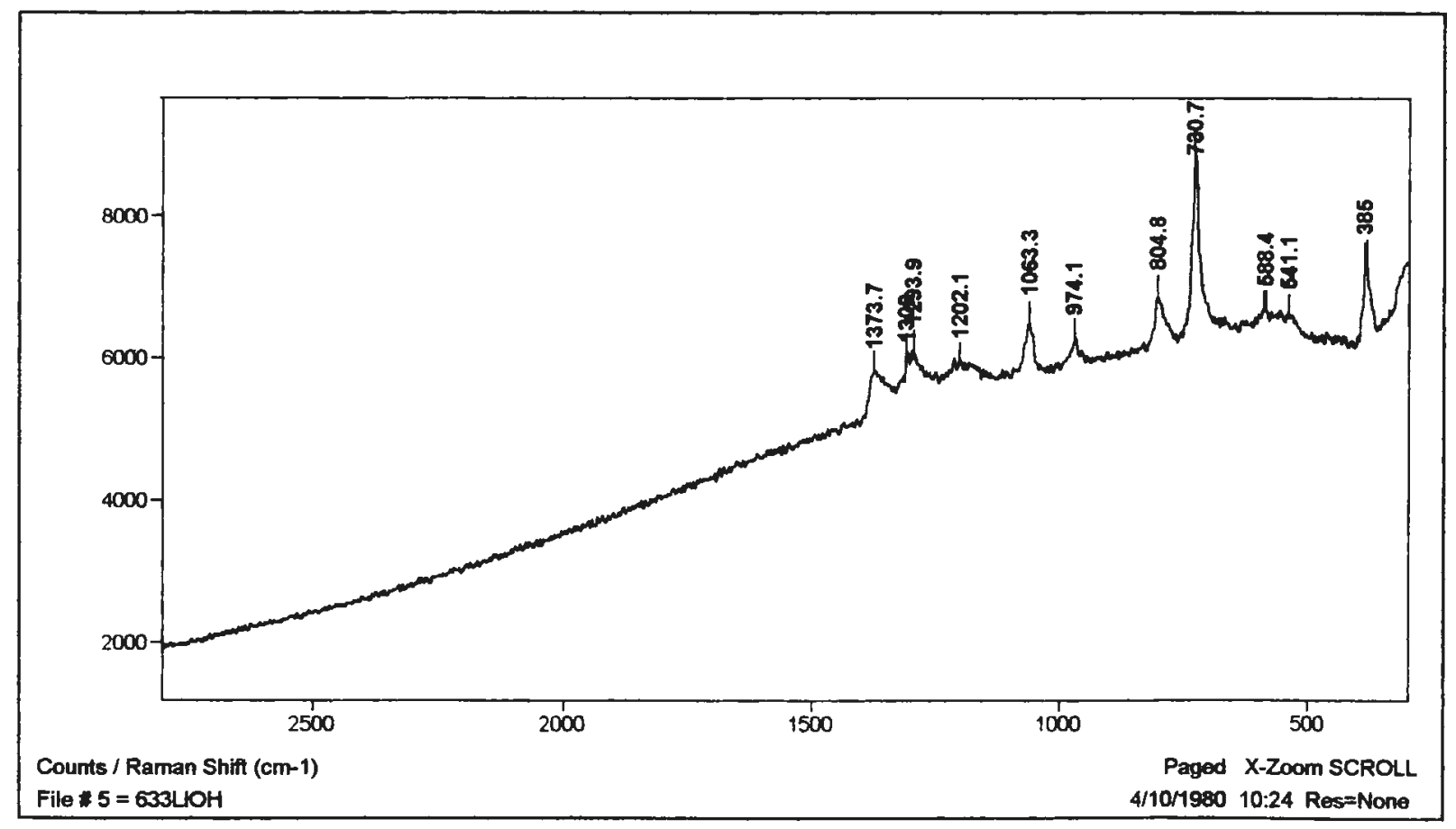

Figura 5.7:. Espectro Raman da membrana na forma $\mathrm{Li}^{+}$. 


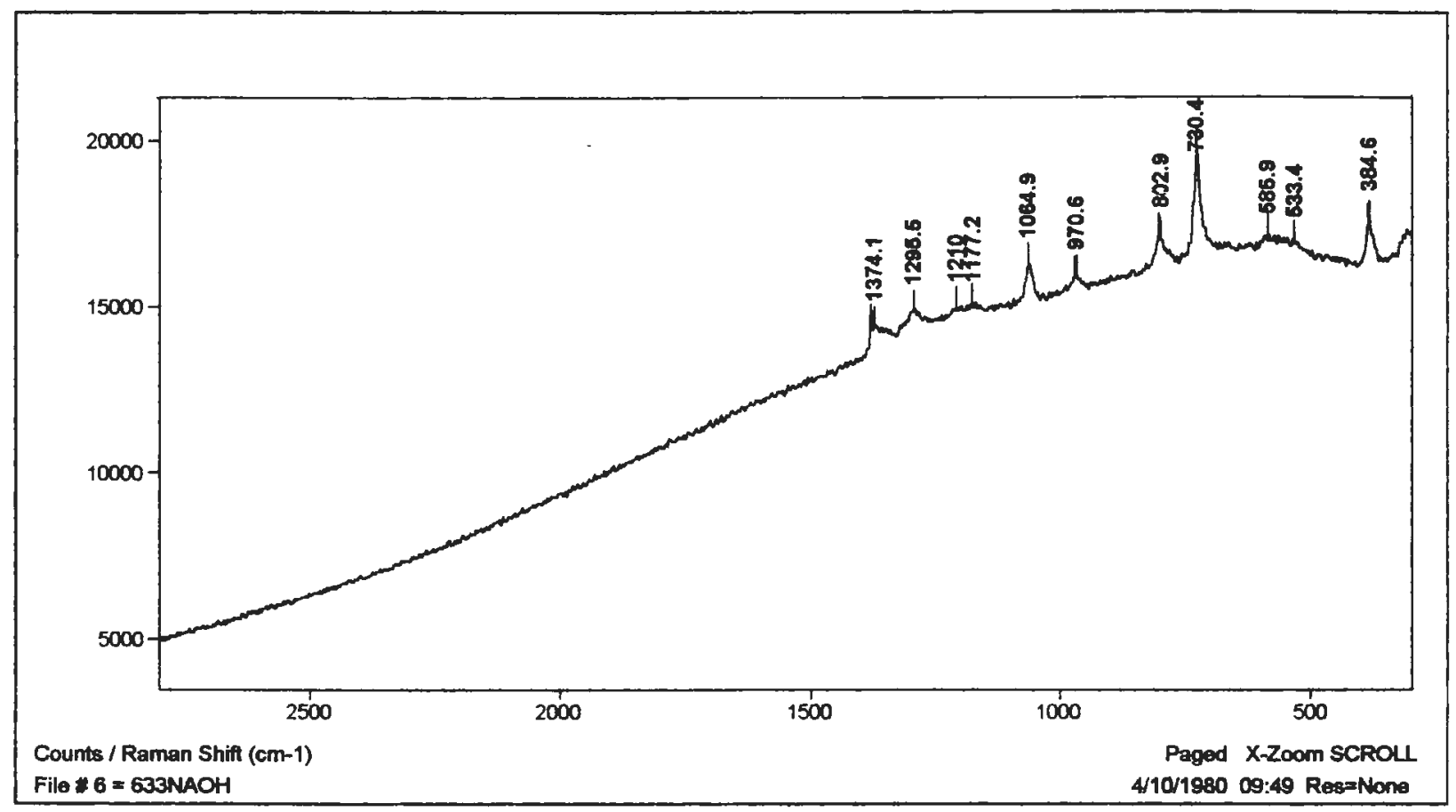

Figura 5.8: Espectro Raman da membrana na forma $\mathrm{Na}^{+}$.

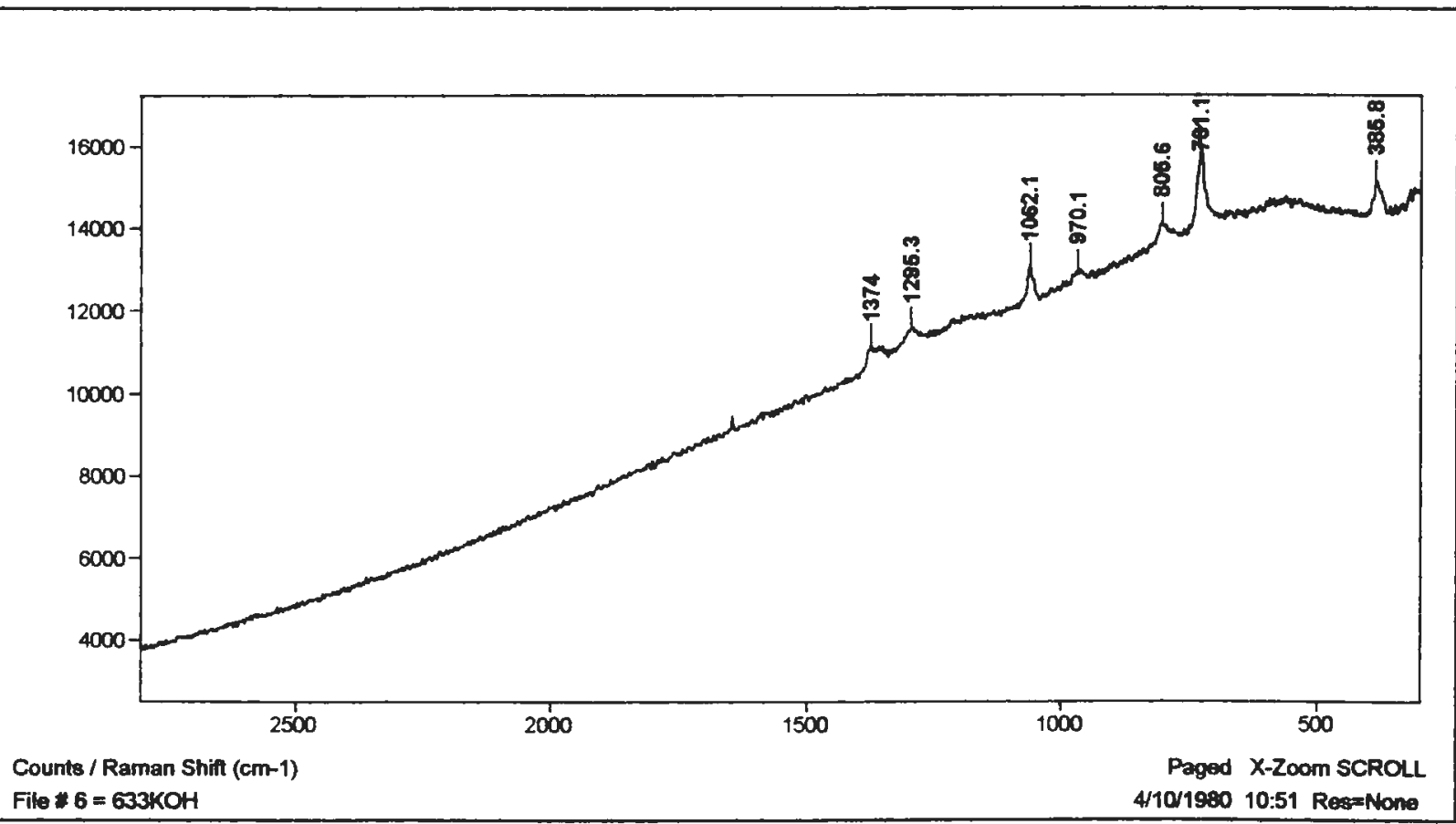

Figura 5.9:. Espectro Raman da membrana na forma $\mathrm{K}^{+}$. 


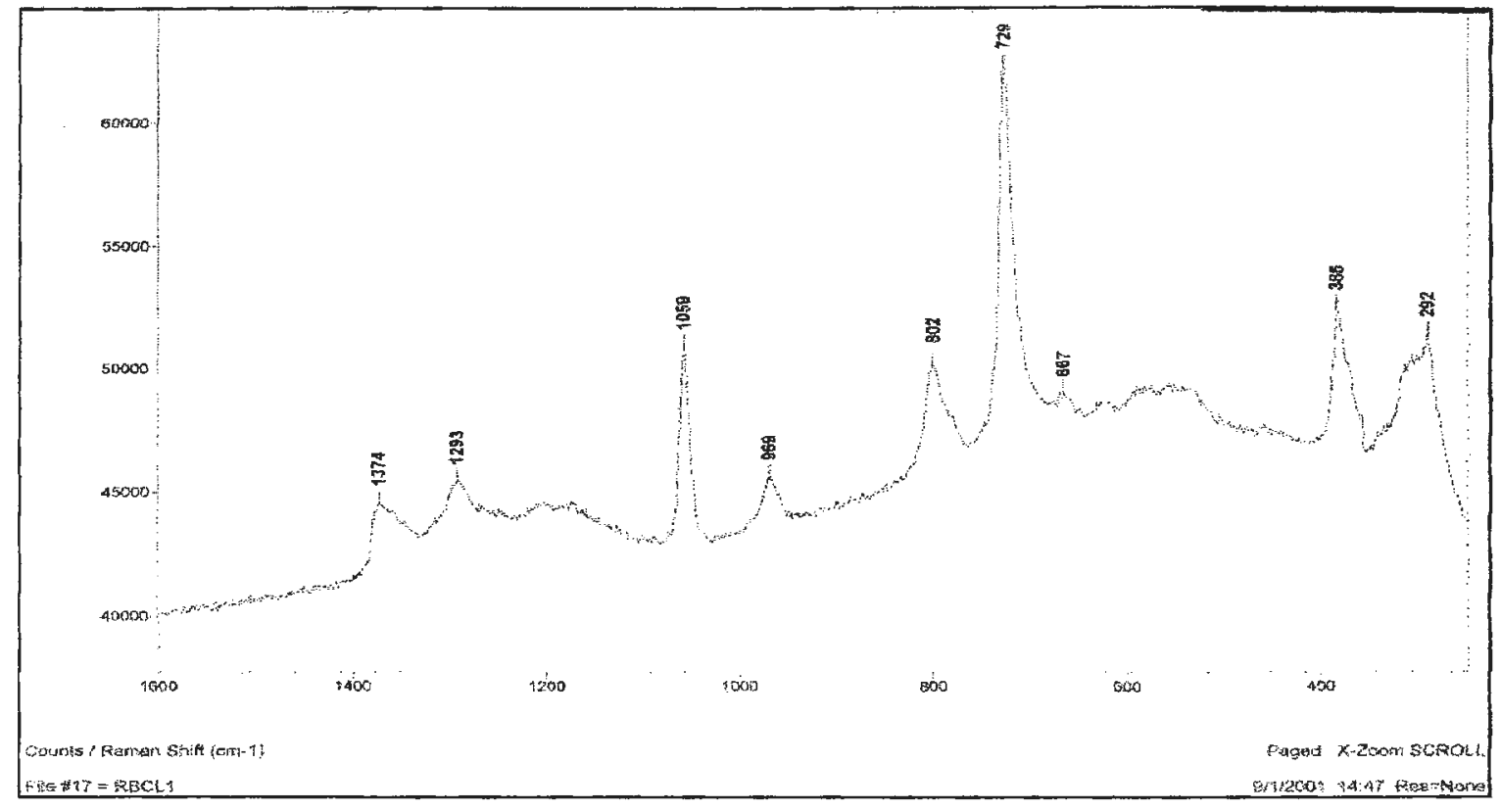

Figura 5.10: Espectro Raman da membrana substituída, usando-se $\mathrm{RbCl}$.

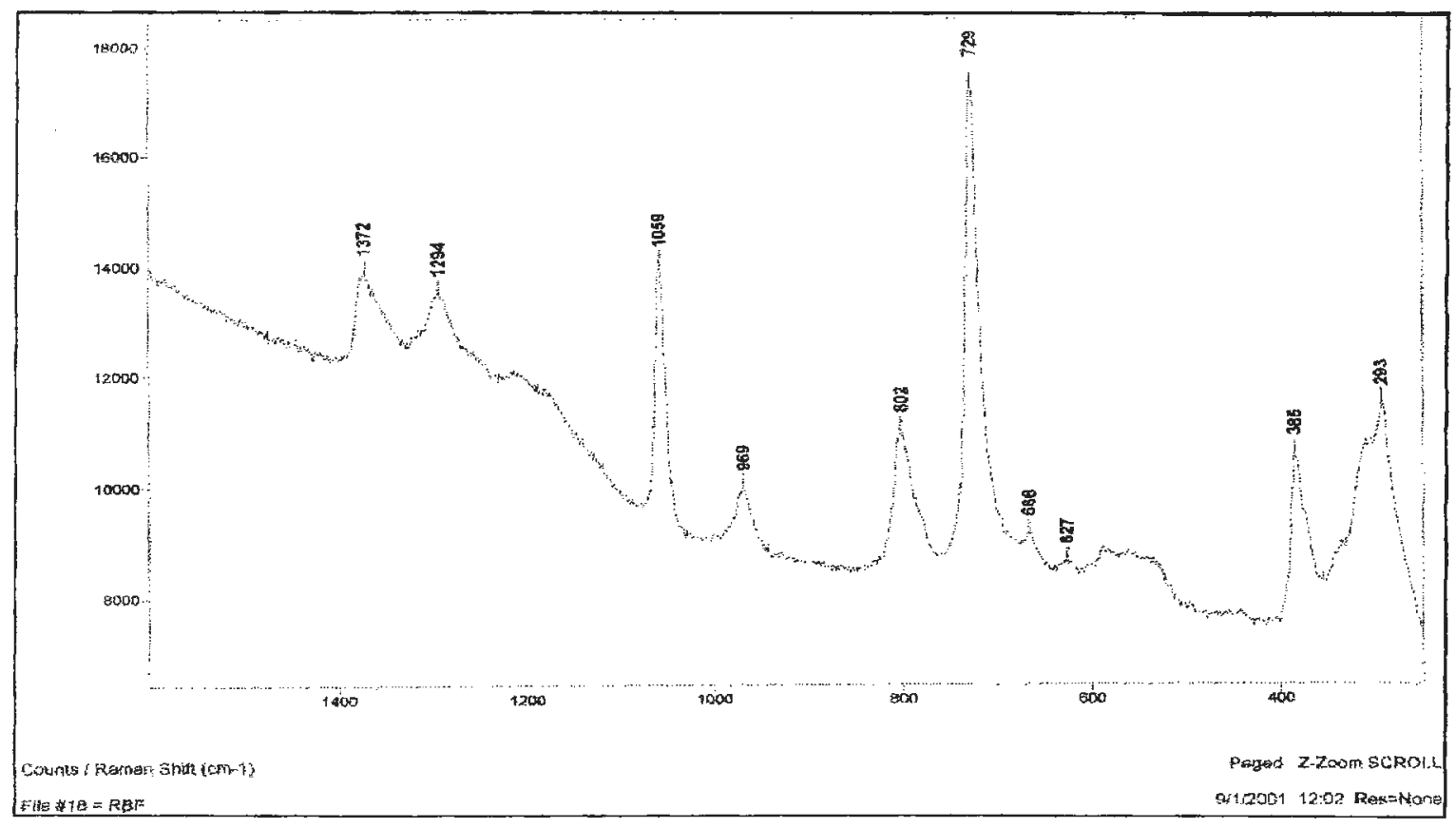

Figura 5.11: Espectro Raman da membrana substituída, usando-se RbF 


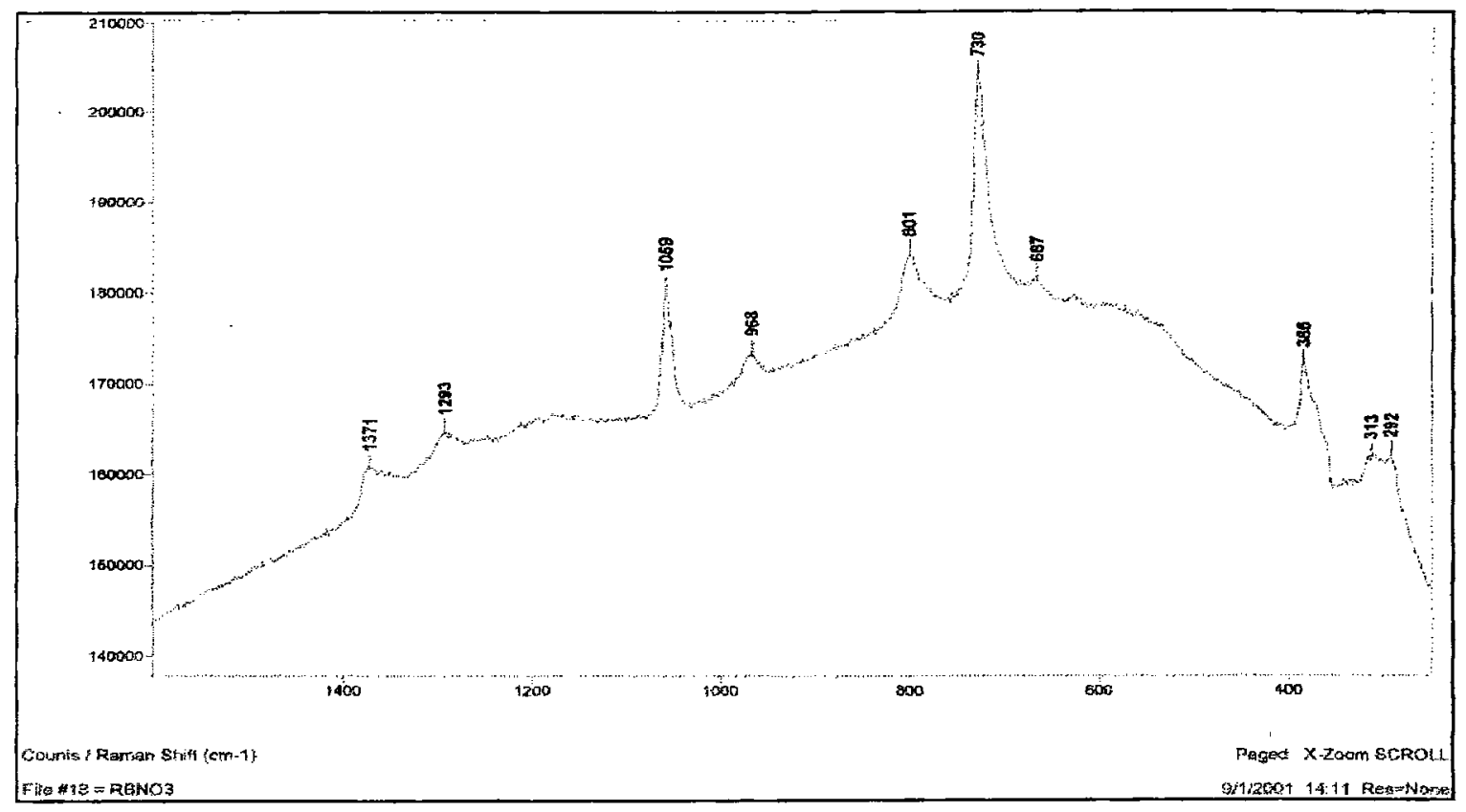

Figura 5.12: Espectro Raman da membrana substituída, usando-se $\mathrm{RbNO}_{3}$

\subsection{Considerações Preliminares sobre a atribuição vibracional $^{[36]}$}

A espectroscopia molecular faz uso, para a atribuição das bandas num espectro, de uma teoria matemática denominada teoria dos grupos. A teoria dos grupos trabalha com elementos abstratos de um conjunto qualquer, desde que sejam satisfeitas algumas condições acerca da relação entre esses elementos. No caso da atribuição vibracional esses elementos são as operações de simetria que são definidas com base na geometria molecular, supondo que a molécula seja um corpo rígido. Assim sendo, para que se possa proceder à atribuição vibracional, via teoria dos grupos, é necessária a identificação de simetrias na molécula.

Porém, o ionômero Nafion apresenta uma estrutura complexa, sendo que sua geometria não permite a identificação de nenhum elemento de simetria, exceto o eixo $\mathrm{C}_{1}$.

Devido à inexistência de outros elementos de simetria na molécula, sobre os quais se baseia a análise vibracional, a metodologia adotada neste trabalho consistiu em dividir a molécula em regiōes que, tomadas isoladamente, 
apresentam elementos de simetria, e é sobre estas regiões que se baseia a atribuição vibracional do ionômero.

No caso do Nafion, a análise foi feita dividindo-se o ionômero em três regiōes: a matriz fluorocarbônica do PTFE, os grupos éter e o grupo sulfonato. Os grupos éter e o grupo sulfonato pertencem aos grupcs de ponto, $C_{2 v}$ e $C_{3 v}$, respectivamente, já a classificação do grupo de ponto da matriz fluorocarbônica é mais complexa.

Através de estudos sobre a cristalinidade do PTFE ${ }^{[38,39]}$ descobriu-se que este polimero apresenta uma estrutura semicristalina e as cadeias poliméricas encontram-se em uma conformação helicoidal, com as unidades $\mathrm{CF}_{2}$ se repetindo ao longo da hélice. Entretanto, esta conformação é dependente da temperatura: abaixo de $19^{\circ} \mathrm{C}$ o PTFE apresenta 13 unidades $\mathrm{CF}_{2}$ a cada 6 voltas na hélice (136), entre $19^{\circ} \mathrm{C}$ e $30^{\circ} \mathrm{C}$ existem 15 unidades $\mathrm{CF}_{2}$ a cada 7 voltas na hélice (157) e acima de $30^{\circ} \mathrm{C}$ não há consenso sobre a conformação da cadeia do PTFE.

Assim, o PTFE pertence aos grupos de ponto $D(12 \pi / 13)$ se a conformação for a hélice $\left(13_{6}\right)$ ou $D(14 \pi / 15)$ se a conformação for a hélice $\left(15_{7}\right)$.

Os modos normais da hélice $\left(13_{6}\right)$ do PTFE estão classificados em 8 espécies de simetria:

$$
\Gamma\left(13_{6}\right)=4 A_{1}+3 A_{2}+8 E_{1}+9 E_{2}+\ldots+9 E_{6}
$$

e os modos normais da hélice (157) estão classificados em 9 espécies de simetria:

$$
\Gamma\left(15_{7}\right)=4 A_{1}+3 A_{2}+8 E_{1}+9 E_{2}+\ldots+9 E_{7}
$$

Em ambos os casos, os modos que são opticamente ativos pertencem às espécies de simetria $A_{1}, A_{2}, E_{1}$ e $E_{2}$. Os modos de simetria $A_{1}$ e $E_{2}$ apresentam atividade apenas no Raman, os modos de simetria $A_{2}$ apresentam atividade apenas no infravermelho e os modos de simetria $E_{1}$ apresentam atividade tanto no espectro Raman quanto no infravermelho.

No PTFE existem 24 modos normais que são opticamente ativos, os quais podem ser descritos aproximadamente pelos seguintes movimentos: 


$$
\begin{aligned}
& A_{1}: v(C-C), v_{s}\left(C F_{2}\right), \delta\left(C F_{2}\right), \gamma_{t}\left(C F_{2}\right) ; \\
& A_{2}: v_{a}\left(C F_{2}\right), \gamma_{w}\left(C F_{2}\right), \gamma_{r}\left(C F_{2}\right) ; \\
& E_{1}: v(C-C), v_{s}\left(C F_{2}\right), \delta\left(C F_{2}\right), \gamma_{t}\left(C F_{2}\right), v_{a}\left(C F_{2}\right), \gamma_{w}\left(C F_{2}\right), \gamma_{r}\left(C F_{2}\right), \delta(C-C-C) ; \\
& E_{2}: v(C-C), v_{s}\left(C F_{2}\right), \delta\left(C F_{2}\right), \gamma_{t}\left(C F_{2}\right), v_{a}\left(C F_{2}\right), \gamma_{w}\left(C F_{2}\right), \gamma_{r}\left(C F_{2}\right), \delta(C-C-C) e \\
& \tau(C-C) .
\end{aligned}
$$

Entretanto, a análise do PTFE no estado sólido deveria ser ainda mais complexa, pois em sólidos deve-se considerar o grupo de espaço, do qual o grupo de ponto da molécula é um subgrupo (do ponto de vista da teoria dos grupos). Ou seja, seria necessário levar em consideração operações de simetria pertencentes à matriz polimérica, mas que não estivessem contidas em uma única cadeia. Um exemplo de tais operações de simetria são as operações de translação.

Todavia, Koenig e Boerio ${ }^{[36]}$ argumentaram que não é necessária a utilização de grupos de espaço, pois a interação entre moléculas vizinhas no PTFE deveria gerar um desdobramento de várias bandas nos espectros Raman e iníravermelho, e como tal desdobramento não é observado nos espectros do PTFE, não é necessária a utilização do grupo de espaço para a atribuição das bandas nos espectros e pode-se, portanto, fazer uso apenas do grupo de ponto da molécula para a atribuição das bandas da matriz fluorocarbônica.

\subsection{Bandas do grupo éter}

No espectro infravermelho da membrana Nafion (forma ácida), encontramse, na região de 960 a $990 \mathrm{~cm}^{-1}$, duas bandas: uma em $984 \mathrm{~cm}^{-1}$ e outra como um ombro em $969 \mathrm{~cm}^{-1}$. Estas bandas estão completamente ausentes no espectro infravermelho do politetrafluoroetileno e têm sido atribuidas ao estiramento C-O-C do grupo éter ${ }^{[23]}$.

O ionômero Nafion apresenta dois grupos éter em sua cadeia lateral, conforme pode ser observado em sua fórmula estrutural (pág.08), sendo o primeiro deles mais próximo da cadeia fluorocarbônica e o segundo mais próximo do grupo sulfonato. 
Nos espectros fotoacústicos, pode-se observar que há um deslocamento da banda em $969 \mathrm{~cm}^{-1}$ (banda I) com a substituição dos cátions, enquanto que a banda em $984 \mathrm{~cm}^{-1}$ (banda II) quase não é influenciada pela troca dos cátions.

A tabela 5.1 sintetiza essas informaçōes:

Tabela 5.1. Efeito dos cátions nas bandas dos grupos éter

\begin{tabular}{|c|c|c|}
\hline Forma da membrana & Banda I /(cm $\left.{ }^{-1}\right)$ & Banda III $\left(\mathrm{cm}^{-1}\right)$ \\
\hline ácida, original & 969 & 984 \\
\hline $\mathrm{Li}^{+}$ & 976 & 983 \\
\hline $\mathrm{Na}^{+}$ & 975 & 984 \\
\hline $\mathrm{K}^{+}$ & 975 & 983 \\
\hline $\mathrm{Rb}^{+}$ & 972 & 983 \\
\hline $\mathrm{Cs}^{+}$ & 972 & 982 \\
\hline
\end{tabular}

Para explicar esta diferença de comportamento no deslocamento das bandas, em função do cátion substituinte, é preciso considerar a proximidade de cada um dos grupos éter com os agregados iônicos, nos quais os cátions estão inseridos.

A explicação proposta neste trabalho baseia-se no modelo de Yeager e Steck [25] (figura 1.3), o qual descreve a existência de 3 micro-ambientes no Nafion: (A) a cadeia fluorocarbônica, (B) uma região interfacial e (C) os agregados iônicos.

Neste modelo ocorrem intrusões da cadeia lateral nos agregados iônicos e conseqüentemente os grupos éter que ficam mais próximos da extremidade da cadeia lateral estão mais sujeitos à ação dos diferentes cátions.

Assim, a banda I, que é mais influenciada pela substituição dos cátions, é atribuída ao grupo éter que se encontra mais próximo da extremidade da cadeia lateral, enquanto que a banda II é atribuida ao grupo éter que se encontra mais próximo da matriz polimérica. 


\subsection{A água e o grupo sulfonato}

A condutividade iônica das membranas Nafion é fortemente dependente do conteúdo de água nas mesmas. Estudos utilizando microscopia de força atômica $^{[20]}$ indicam que a alteração do conteúdo de água, em ionômeros, induz uma reorganização das cadeias poliméricas. Assim, elucidar o mecanismo de interação da água com os agregados iônicos é fundamental para uma melhor compreensão das propriedades de transporte na membrana.

De acordo com os modelos propostos para o Nafion ${ }^{[17,19,37]}$, a água, neste ionômero, deveria estar exposta a três ambientes, os quais deveriam ser constituídos por moléculas de água que participam da solvatação das espécies carregadas, moléculas de água que se comportam como se estivessem em solução e moléculas de água que estariam expostas ao ambiente fluorocarbônico.

Falk ${ }^{[29]}$ já havia estudado o espectro infravermelho das espécies $\mathrm{H}_{2} \mathrm{O}, \mathrm{HDO}$ e $\mathrm{D}_{2} \mathrm{O}$, nas membranas Nafion e concluído que nestas membranas a água está exposta a dois ambientes distintos. No primeiro deles as moléculas de água participam de ligações de hidrogênio, seja com outras moléculas de água, seja com os oxigênios do grupo sulfonato e no segundo ambiente as moléculas de água não participam de ligações de hidrogênio e por isso devem estar expostas a um ambiente fluorocarbônico.

Para se entender a interação da água no interior dos agregados, foi monitorado o deslocamento de banda do grupo sulfonato nos espectros Raman e infravermelho.

O grupo $\left(-\mathrm{SO}_{3}{ }^{-}\right)$ligado à extremidade da cadeia lateral apresenta simetria local pertencente ao grupo de ponto $C_{3 v}$. A tabela de caracteres do grupo $C_{3 v}$ é mostrada na tabela 5.2: 
Tabela 5.2. Tabela de caracteres do grupo $\mathrm{C}_{3 \mathrm{v}}$

\begin{tabular}{c|cccc}
\hline $\mathbf{C}_{3 v}$ & $\mathbf{E}$ & $\mathbf{2} \mathbf{C}_{3}$ & $\mathbf{3 \sigma}$ & \\
\hline $\mathrm{A}_{1}$ & 1 & 1 & 1 & $\mathrm{~T}_{\mathrm{z}, \alpha_{\mathrm{zz}}}$ \\
$\mathrm{A}_{2}$ & 1 & 1 & -1 & $\mathrm{R}_{\mathrm{z}}$ \\
$\mathrm{E}$ & 2 & -1 & 0 & $\left(T_{\mathrm{x}}, T_{\mathrm{y}}\right)$ \\
& & & & $\left(\mathrm{R}_{\mathrm{x}}, \mathrm{R}_{\mathrm{y}}\right)$
\end{tabular}

Da aplicação das regras de seleção para a atividade nos espectros Raman e infravermelho, pode-se concluir que o grupo sulfonato apresenta em seus espectros Raman e infravermelho, modos de estiramento simétrico (espécie $A_{1}$ ) e de estiramento degenerado (espécie E), entretanto, a banda do modo de estiramento degenerado é superposta no espectro fotoacústico da membrana e portanto, usou-se a banda de estiramento simétrico (na região de $1060 \mathrm{~cm}^{-1}$ ) para caracterizar mudanças no ambiente químico no interior dos agregados.

Pode-se observar nos espectros que existe um deslocamento na banda de estiramento simétrico do grupo sulfonato para números de onda menores à medida que o raio do cátion substituinte aumenta. Essa correlação pode ser visualizada na tabela 5.3:

Tabela 5.3. Estiramento simétrico do grupo $\mathrm{SO}_{3}{ }^{-}$nos espectros fotoacústicos

\begin{tabular}{|c|c|c|}
\hline Forma da membrana & Raio lónico/(nm) & Freqüência/(cm $\left.{ }^{-1}\right)$ \\
\hline Original $\left(\mathrm{H}^{+}\right)$ & - & 1062 \\
\hline $\mathrm{Li}^{+}$ & 0,06 & 1072 \\
\hline $\mathrm{Na}^{+}$ & 0,095 & 1066 \\
\hline $\mathrm{K}^{+}$ & 0,133 & 1060 \\
\hline $\mathrm{Rb}^{+}$ & 0,148 & 1059 \\
\hline $\mathrm{Cs}^{+}$ & 0,169 & 1056 \\
\hline
\end{tabular}


A troca dos íns também produz modificações espectrais nas regiōes onde são observadas as bandas da água. Observa-se que, com o aumento do raio iônico do cátion, diminuem as intensidades das bandas de estiramento e deformação angular da água, indicando que o teor de água é modificado pela inserção de cátions mais volumosos e que, portanto, os cátions competem com a água na ocupação da membrana.

Mais do que uma diminuição do conteúdo total, parece que existe uma seletividade nas moléculas de água que são expulsas da membrana. Ostrowska e Narebska ${ }^{[38]}$ efetuaram o ajuste de curva das bandas da água no Nafion e atribuiram as bandas na região de 3000 a $3380 \mathrm{~cm}^{-1}$ aos estiramentos $\mathrm{O} H$ da água, expostos direta ou indiretamente aos grupos sulfonatos, e as bandas acima desta região foram atribuídas às moléculas de água que interagem com outras moléculas de água, ou que interagem com a matriz fluorocarbônica.

Nos espectros fotoacústicos do Nafion, a inserção de cátions de metais alcalinos acarreta uma forte diminuição das bandas na região de 3000 a $3400 \mathrm{~cm}^{-}$ ${ }^{1}$, indicando que os cátions substituintes expulsaram seletivamente as moléculas de água que se encontravam nas proximidades dos grupos sulfonato.

Mas, mesmo entre os cátions, existe uma modificação do conteúdo de água exposta ao ambiente fluorocarbônico e aos agregados. Esta diferença pode ser obtida através da análise do deslocamento das bandas da água, pois as posições das bandas de estiramento e deformação angular da água são influenciadas pelas ligaçōes de hidrogênio.

Conforme apontado por Falk ${ }^{[29]}$, a banda de estiramento O-H é deslocada para números de onda menores com o aumento das interaçōes de hidrogênio e um efeito contrário ocorre com a banda de deformação angular que é deslocada para números de onda maiores com o aumento das interações de hidrogênio.

A tabela 5.4 apresenta as posições de máxima intensidade para as bandas de estiramento simétrico e deformação angular da água em função do cátion substituinte: 
Tabela 5.4. Influência do cátion nas bandas de estiramento e deformação angular da água.

\begin{tabular}{|c|c|c|}
\hline Forma da membrana & $\begin{array}{c}\text { Estiramento simétrico/ } \\
\left(\mathbf{c m}^{-1}\right)\end{array}$ & $\begin{array}{c}\text { Deformação angularl } \\
(\mathbf{c m})\end{array}$ \\
\hline ácida, original & - & 1706 \\
\hline $\mathrm{Li}^{+}$ & 3511 & 1632 \\
\hline $\mathrm{Na}^{+}$ & 3512 & 1625 \\
\hline $\mathrm{K}^{+}$ & 3520 & 1624 \\
\hline $\mathrm{Rb}^{+}$ & 3524 & 1626 \\
\hline $\mathrm{Cs}^{+}$ & 3504 & 1635 \\
\hline
\end{tabular}

$\mathrm{Na}$ tabela 5.4, pode-se observar que na seqüenncia $\mathrm{Li}^{+} \rightarrow \mathrm{Rb}^{+}$as bandas de estiramento simétrico são deslocadas para números de onda maiores e as bandas de deformação angular são deslocadas para números de onda menores, o que nos permite inferir que nesta seqüência a substituição dos cátions acarreta um aumento da proporção de moléculas de água expostas ao ambiente fluorocarbônico. No caso do $\mathrm{Cs}^{+}$ocorre o contránio, e espera-se que, comparativamente aos demais cátions, haja uma menor proporção de moléculas de água exposta ao ambiente fluorocarbônico.

Nos espectros Raman também se pode observar uma influência do raio iônico do cátion na freqüência de estiramento simétrico do grupo $\mathrm{SO}_{3}{ }^{-}$, entretanto, as bandas do grupo sulfonato apresentam deslocamentos distintos quando são comparados os espectros Raman e infravermelho, a tabela 5.5 ilustra esta diferença: 
Tabela 5.5 Comparação do estiramento simétrico do grupo $\mathrm{SO}_{3}{ }^{-n}$ nos espectros Raman e fotoacústicos.

\begin{tabular}{|c|c|c|}
\hline $\begin{array}{c}\text { Forma da } \\
\text { membrana }\end{array}$ & Raman/ $\left(\mathrm{cm}^{-1}\right)$ & Infravermelho/(cm $\left.{ }^{-1}\right)$ \\
\hline Original, $\mathrm{H}^{+}$ & 1057 & 1062 \\
\hline $\mathrm{Li}^{+}$ & 1064 & 1072 \\
\hline $\mathrm{Na}^{+}$ & 1064 & 1066 \\
\hline $\mathrm{K}^{+}$ & 1062 & 1060 \\
\hline $\mathrm{Rb}^{+}$ & 1059 & 1059 \\
\hline $\mathrm{Cs}^{+}$ & 1055 & 1056 \\
\hline
\end{tabular}

Pode-se notar na tabela 5.5 que as diferenças entre os espectros Raman e infravermelho são mais acentuadas para os cátions que apresentam menor raio iônico.

A interpretação apresentada neste trabalho é que na aquisição do espectro Raman, utilizando microscopia Raman, a temperatura, no ponto de incidência do laser, aumenta, o que ocasiona a evaporaçăo de água e com a diminuição do conteúdo de água, a interação do cátion com o grupo sulfonato é modificada, deslocando a banda de estiramento do grupo sulfonato para números de onda menores, quando este é comparado com o infravermelho.

Resultados similares foram apresentados por Lowry e Mauritz ${ }^{[39]}$, que obtiveram espectros infravermelhos para as membranas substituidas por metais alcalinos e as submeteram a desidratação, relatando que na membrana desidratada, a banda de estiramento simétrico do grupo sulfonato apresentava valores menores para os números de onda, quando comparada com a membrana hidratada.

Outro fator que corrobora com esta interpretação é o fato de o deslocamento observado entre os espectros infravermelho e Raman é mais intenso para as membranas que possuem maior conteúdo de água (caso do $\mathrm{Li}^{+}$) e, portanto, serem mais suscetiveis a modificações da quantidade de água que as que possuem menor conteúdo de água (caso do $\mathrm{Cs}^{+}$). 


\subsection{A Matriz Fluorocarbônica}

\subsubsection{Modos vibracionais de espécie $A_{1}$}

No espectro Raman as bandas mais fortes da cadeia fluorocarbônica são aquelas que correspondem aos modos vibracionais de espécie $A_{1}$. Estas bandas apresentam-se em 1374,729, 385 e $293 \mathrm{~cm}^{-1}$ e atribuição delas pode ser encontrada na literatura ${ }^{[36,40,41]}$.

No espectro infravermelho os modos vibracionais que correspondem a estas bandas não são ativos, conforme foi exposto na seção 5.3 .

\subsubsection{Modos vibracionais de espécie $A_{2}$}

Os modos vibracionais de simetria $A_{2}$ devem apresentar atividade apenas no espectro infravermelho do ionômero.

Kobayashi: ${ }^{[41]}$ efetuou estudos no infravermelho sobre a polarização das bandas do PTFE e de moléculas homólogas $\left(\mathrm{C}_{20} \mathrm{~F}_{42}\right)$ e $\left(\mathrm{C}_{24} \mathrm{~F}_{50}\right)$ e concluiu que os modos vibracionais de simetria $A_{2}$ correspondem às seguintes bandas: $524,630 \mathrm{e}$ $642 \mathrm{~cm}^{-1}$.

Nos espectros infravermelhos apresentados neste trabalho podem ser observadas bandas bastante fortes em 527 e $639 \mathrm{~cm}^{-1}$, que devem corresponder aos modos vibracionais de simetria $A_{2}$; entretanto nos espectros obtidos não há resolução suficiente para que se possa verificar a existência de outra banda (em $630 \mathrm{~cm}^{-1}$ ) adjacente à banda em $639 \mathrm{~cm}^{-1}$.

\subsubsection{Modos vibracionais de espécie $E_{1}$}

Os modos vibracionais de espécie $E_{1}$ devem apresentar atividade tanto no espectro Raman quanto no espectro infravermelho. Entretanto, nos espectros fotoacústicos obtidos, na região do infravermelho, algumas das bandas que 
correspondem aos modos vibracionais de espécie $E_{1}$ estão saturadas e superpostas e sua visualização é prejudicada, além disso, por razões de ordem experimental, o intervalo de aquisição dos espectros Raman e infravermelho não foi o mesmo.

Desta maneira, nem todas as bandas que correspondem aos modos vibracionais de simetria $E_{1}$ podem ser observadas igualmente nos espectros Raman e infravermelho.

A região de $1200 \mathrm{~cm}^{-1}$ apresenta bandas que estão saturadas e superpostas, não sendo possível efetuar a atribuição destas bandas com os espectros disponíveis, entretanto é possível obter a resolução destas bandas se for utilizada uma membrana de menor espessura.

Xue et al. ${ }^{[42]}$ registraram o espectro infravermelho do Nafion usando filmes finos obtidos através da evaporaçāo do solvente de uma solução alcoólica do ionômero e resolveram as bandas na região de $1200 \mathrm{~cm}^{-1}$, encontrando nesta região duas bandas: uma em $1212 \mathrm{~cm}^{-1}$ à qual os autores atribuiram ao estiramento anti-simétrico do grupo $\left(-\mathrm{CF}_{2^{-}}\right)$e outra banda em $1156 \mathrm{~cm}^{-1}$ a qual foi atribuída ao estiramento simétrico do grupo $\left(-\mathrm{CF}_{2^{-}}\right)$.

Entretanto, Kobayashi et al. ${ }^{[1]}$ trabalhando com filmes finos do PTFE, adquiriram o espectro infravermelho desses filmes, resolvendo as bandas na região de $1200 \mathrm{~cm}^{-1}$. Esta resolução mostrou a existência de 3 bandas: 1252 , 1206 e $1151 \mathrm{~cm}^{-1}$, às quais, através de medidas de polarização, os autores atribuíram a modos vibracionais degenerados de simetria $E_{1}$.

A atribuição de Kobayashi sobre a simetria dos modos vibracionais das bandas nesta região, parece-nos mais razoável, pois a nossa atribuição da banda em $2360 \mathrm{~cm}^{-1}$ é a de um modo vibracional que é o resultado de uma combinação dos modos vibracionais das bandas em 1156 e $1212 \mathrm{~cm}^{-1}$, o que implica necessariamente que os modos vibracionais destas bandas devem apresentar a mesma simetria.

Esta observação de que a banda em $2360 \mathrm{~cm}^{-1}$ deveria ser uma banda de combinação do (-CF $\left.2^{-}\right)$, já havia sido feita por Quezado e Falk ${ }^{[43]}$, entretanto, como eles não possuíam a resolução das bandas na região de $1200 \mathrm{~cm}^{-1}$, não puderam fazer sua atribuição. 


\subsubsection{Modos vibracionais de espécie $E_{2}$}

Os modos vibracionais de simetria $E_{2}$ da cadeia fluorocarbônica, assim como os modos vibracionais de simetria $A_{1}$ só devem estar presentes no espectro Raman do ionômero.

Estudos anteriores sobre a análise vibracional do PTFE ${ }^{[36,41]}$ indicaram que as bandas em $308,389,676,741$ e $1295 \mathrm{~cm}^{-1}$ pertencem a modos vibracionais degenerados de simetria $E_{2}$.

Nos espectros obtidos estas bandas devem corresponder às bandas em: 309,666 e $1294 \mathrm{~cm}^{-1}$.

Não foi possível observar no espectro Raman as bandas presentes em 389 e $741 \mathrm{~cm}^{-1}$, pois estas bandas estão superpostas a outras bandas no espectro.

\subsubsection{Comparação Experimental X Teórica}

Admitindo parâmetros semi-empínicos Koenig e Boerio ${ }^{[36]}$ calcularam os valores esperados para as freqüências das bandas do PTFE para a conformação (157) e em seguida obtiveram os espectros Raman do PTFE.

Efetuando medidas de polarização das bandas do PTFE e empregando filmes finos do polímero, Kobayashi et al. ${ }^{[41]}$ fizeram a atribuição das bandas.

A comparação dos nossos resultados com os valores calculados e obtidos experimentalmente pelos autores acima, encontra-se na tabela 5.6: 
Tabela 5.6: Comparação dos valores de freqüência obtidos experimentalmente com os valores obtidos por cálculos semi-empíricos

\begin{tabular}{|c|c|c|c|c|c|}
\hline Espécie & $\begin{array}{c}\text { Calculado } \\
\text { hélice } \\
\left(15_{7}\right)^{[36]} /\left(\mathrm{cm}^{-}\right.\end{array}$ & $\begin{array}{l}\text { Experimental } \\
\text { Koenig }{ }^{[36]} / \\
\left(\mathrm{cm}^{-1}\right)\end{array}$ & $\begin{array}{c}\text { Experimental } \\
\text { Kobayashi } \\
{[41] /\left(\mathrm{cm}^{-1}\right)}\end{array}$ & $\begin{array}{c}\text { Este } \\
\text { trabalho/ } \\
\left(\mathrm{cm}^{-1}\right)\end{array}$ & $\begin{array}{c}\text { Tentativa } \\
\text { de } \\
\text { atribuição }\end{array}$ \\
\hline \multirow[t]{4}{*}{$A_{1}$} & 304 & 291 & - & 293 & $\gamma_{t}\left(\mathrm{CF}_{2}\right)$ \\
\hline & 383 & 383 & - & 385 & $\delta\left(\mathrm{CF}_{2}\right)$ \\
\hline & 725 & 729 & $738^{a}$ & 729 & $v_{s}\left(C F_{2}\right)$ \\
\hline & 1379 & 1379 & $1379^{\mathrm{a}}$ & 1374 & $v_{s}(C C)$ \\
\hline \multirow[t]{3}{*}{$A_{2}$} & 527 & 516 & 531 & 527 & $\gamma_{r}\left(C_{2}\right)$ \\
\hline & 636 & 638 & 632 & 639 & $\gamma_{w}\left(C F_{2}\right)$ \\
\hline & 1444 & 1450 & - & - & $v_{a}\left(C F_{2}\right)$ \\
\hline \multirow[t]{8}{*}{$\mathrm{E}_{1}$} & 1141 & 1150 & 1155 & - & $v\left(\mathrm{CF}_{2}\right)$ \\
\hline & 1226 & 1210 & 1219 & - & $v\left(\mathrm{CF}_{2}\right)$ \\
\hline & 1251 & 1242 & $1230^{a}$ & - & $v\left(\mathrm{CF}_{2}\right)$ \\
\hline & 192 & 203 & - & - & $\gamma_{r}\left(\mathrm{CF}_{2}\right)$ \\
\hline & 281 & 277 & - & - & - \\
\hline & 13 & - & - & - & - \\
\hline & 578 & 553 & 555 & - & - \\
\hline & 313 & 321 & - & - & - \\
\hline \multirow[t]{9}{*}{$E_{2}$} & 1345 & 1295 & $1300^{a}$ & 1294 & $v(\mathrm{CC})$ \\
\hline & 1442 & - & - & - & $v_{a}\left(C_{2}\right)$ \\
\hline & 660 & 676 & - & 666 & $\gamma_{w}\left(C_{2}\right)$ \\
\hline & 380 & 389 & - & - & $\delta\left(\mathrm{CF}_{2}\right)$ \\
\hline & 20 & - & - & - & - \\
\hline & 300 & 308 & $313^{a}$ & 309 & $\gamma_{t}\left(C F_{2}\right)$ \\
\hline & 527 & - & - & - & - \\
\hline & 734 & 741 & $752^{\mathrm{a}}$ & - & $\nu_{s}\left(C F_{2}\right)$ \\
\hline & 118 & - & - & - & - \\
\hline
\end{tabular}

a valores obtidos utilizando-se o polímero em pó. 


\subsection{O Estudo Térmico}

Foram realizados estudos sobre o comportamento térmico das membranas Nafion nas formas ácida e substituída pelos diferentes cátions dos metais alcalinos. Para a substituição dos cátions, as membranas permaneceram imersas em soluções de concentração $1 \mathrm{~mol} / \mathrm{L}$ por um periodo de 24 horas.

Neste estudo térmico foram empregadas duas técnicas: a calorimetria exploratória diferencial (DSC) e a termogravimetria (TG); sendo que uma descrição mais pormenorizada de cada uma dessas técnicas já foi apresentada no capítulo 3.

\subsubsection{Termogravimetria das membranas}

Foram obtidas as curvas TG das membranas Nafion nas formas ácida e nas formas salinas, em atmosfera inerte de $N_{2}$, utilizando-se o equipamento da TA Instruments, modelo Hi-Res TGA 2950, num intervalo de temperatura de 25 a $700^{\circ} \mathrm{C}$.

As curvas obtidas são apresentadas a seguir.

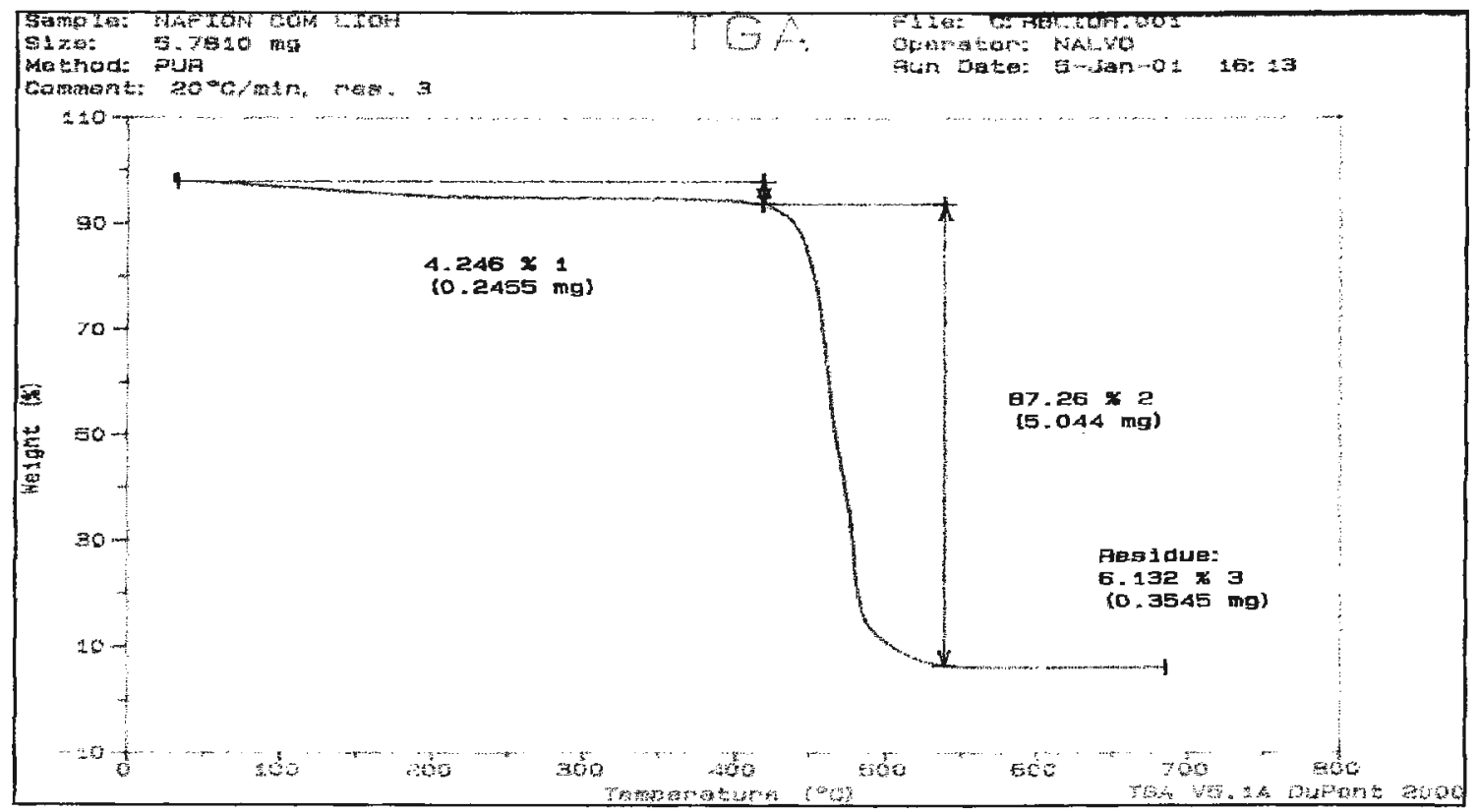

Figura 5.13: Curva TG da membrana substituída por $\mathrm{Li}^{+}$. 


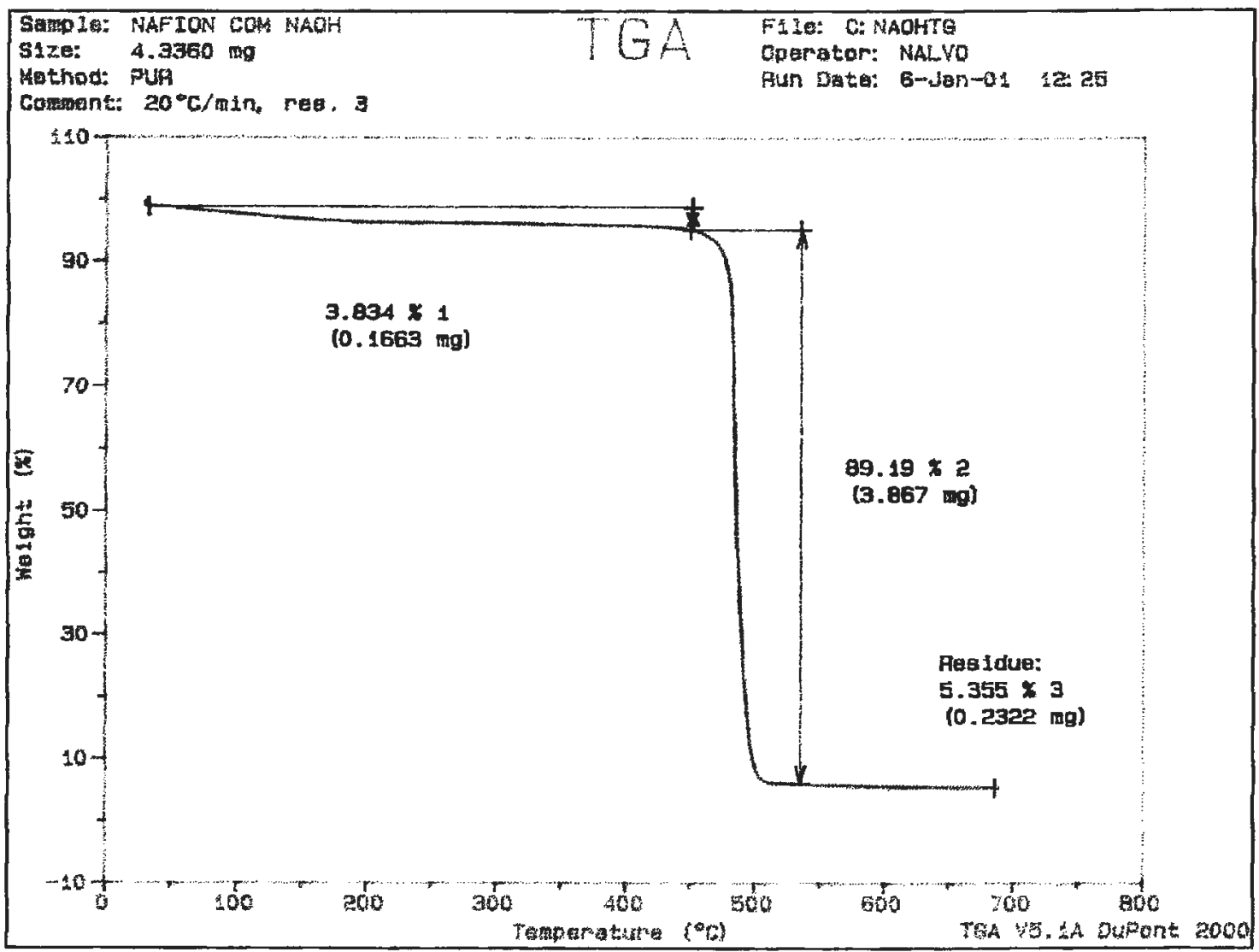

Figura 5.14: Curva $\mathrm{Tg}$ da membrana substituída por $\mathrm{Na}^{+}$. 


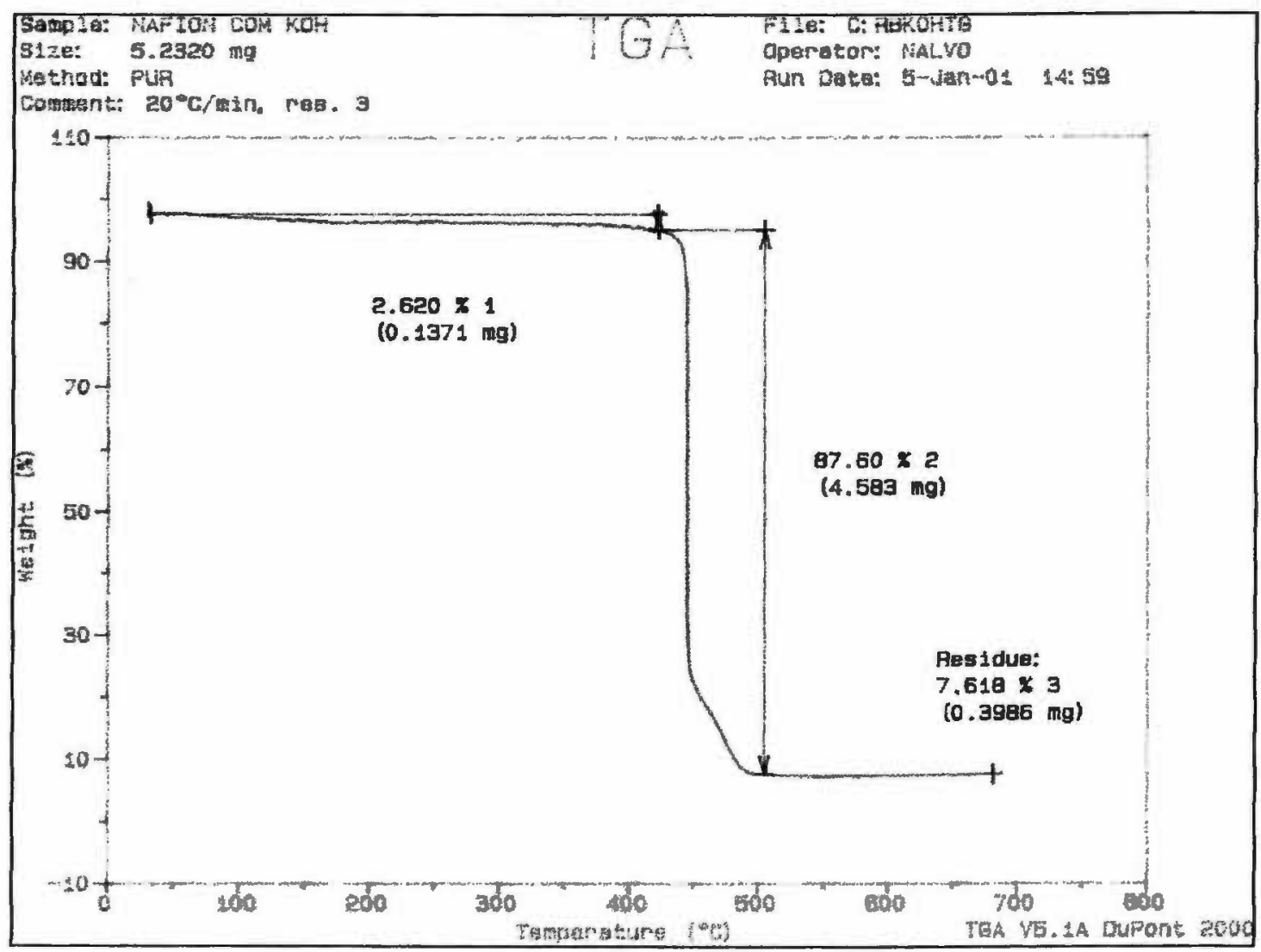

Figura 5.15: Curva TG da membrana substituída por $\mathrm{K}^{+}$. 


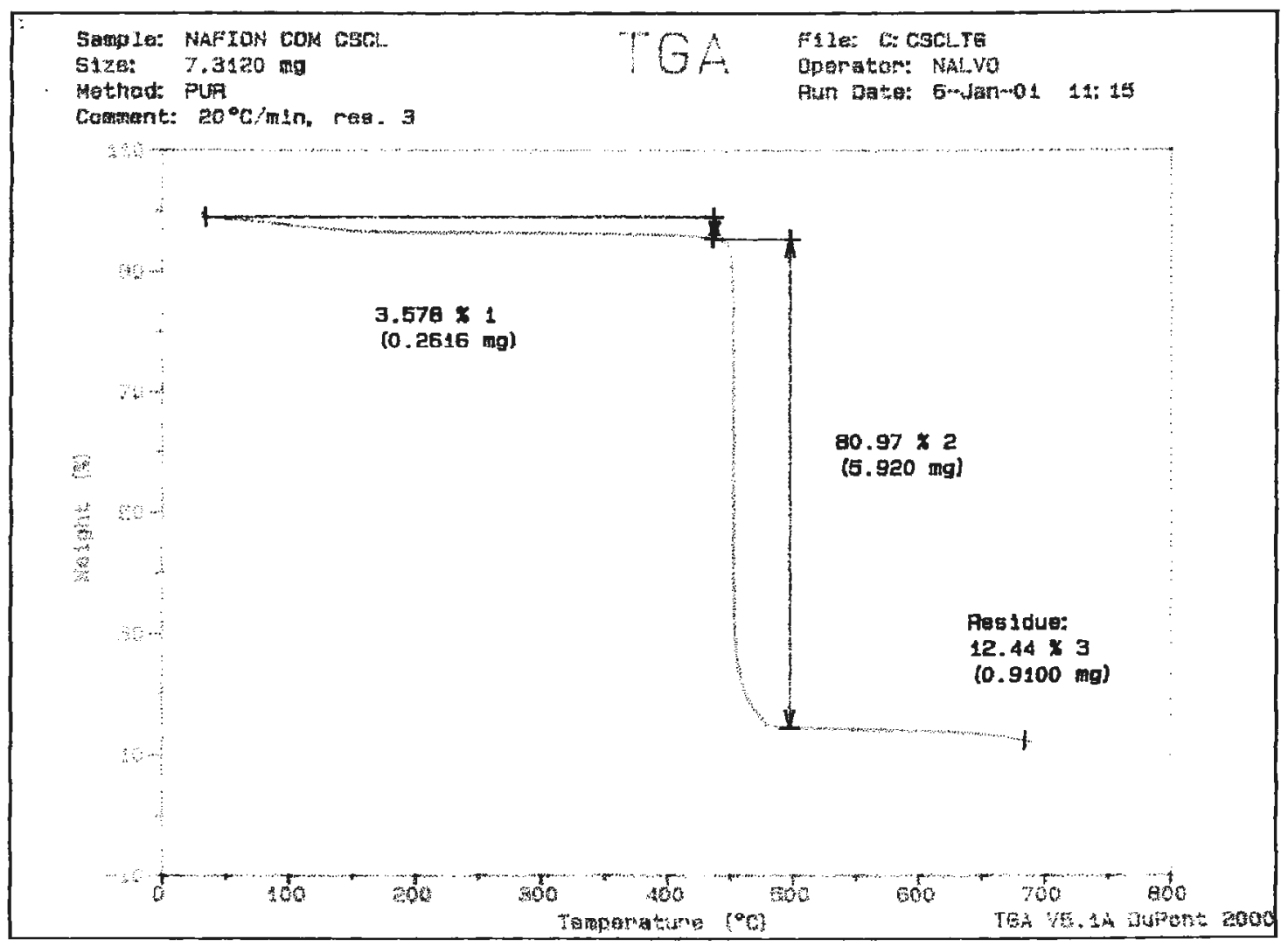

Figura 5.16: Curva TG da membrana substituída por $\mathrm{Cs}^{+}$.

\subsubsection{Avaliação do conteúdo de água por TG}

Para verificar eventuais modificações do conteúdo de água no interior das membranas com a variação dos íons, foram registradas as variações das massas das membranas, considerando a variação de massa das amostras no intervalo de temperatura de 25 a $400^{\circ} \mathrm{C}$. 
das membranas, considerando a variação de massa das amostras no intervalo de temperatura de 25 a $400^{\circ} \mathrm{C}$.

A tabela 5.7 apresenta estes resultados:

Tabela 5.7 Perda de massa de água em função do cátion substituinte.

\begin{tabular}{|c|c|c|}
\hline Forma da membrana & Rajo iónico $/(\mathrm{A})$ & $\begin{array}{c}\text { Porcentagem de massa } \\
\text { perdida }\end{array}$ \\
\hline $\mathrm{Li}^{+}$ & 0,6 & $4.2 \%$ \\
\hline $\mathrm{Na}^{+}$ & 0,95 & $3,8 \%$ \\
\hline $\mathrm{K}^{+}$ & 1,33 & $2,6 \%$ \\
\hline $\mathrm{Rb}^{+}$ & 1,48 & $1,9 \%$ \\
\hline $\mathrm{Cs}^{+}$ & 1,69 & $3,6 \%$ \\
\hline
\end{tabular}

Os dados mostram que, em geral, um aumento no raio iônico do cátion substituinte acarreta uma diminuição do conteúdo de água presente na membrana. Este resultado é coerente com os espectros fotoacústicos das membranas, nos quais existe uma diminuiçāo das intensidades das bandas de estiramento e deformação angular da água com o aumento do raio iônico do cátion substituinte.

Entretanto, os valores obtidos para o conteúdo de água na membrana não apresentam uma variação monotônica do raio iônico do cátion com o conteúdo de água, logo existem pelo menos três possibilidades:

1) a distribuição dos cátions no interior da membrana é dependente do raio iônico dos mesmos e isso afeta de maneira não-linear o conteúdo de água nas membranas;

2) como a substituição dos cátions na membrana foi feita a partir de sais com diferentes ânions, a variação dos ânions pode acarretar uma modificação no conteúdo de água;

3) Ambos os efeitos podem estar influenciando o conteúdo de água na membrana. 
a variação dos cátions modifica a proporção de moléculas de água expostas ao meio fluorocarbônico.

Pôde-se observar também uma dependência no deslocamento das bandas dos grupos éter em função dos cátions, portanto, é razoável supor que a distribuição dos cátions na membrana varie com os diferentes cátions, dando suporte à primeira hipótese levantada.

Para investigar a influência do ânion no conteúdo de água da membrana, obteve-se as curvas TG da membrana substituida por diferentes sais de rubídio. As curvas de termogravimetria obtidas são apresentadas a seguir:

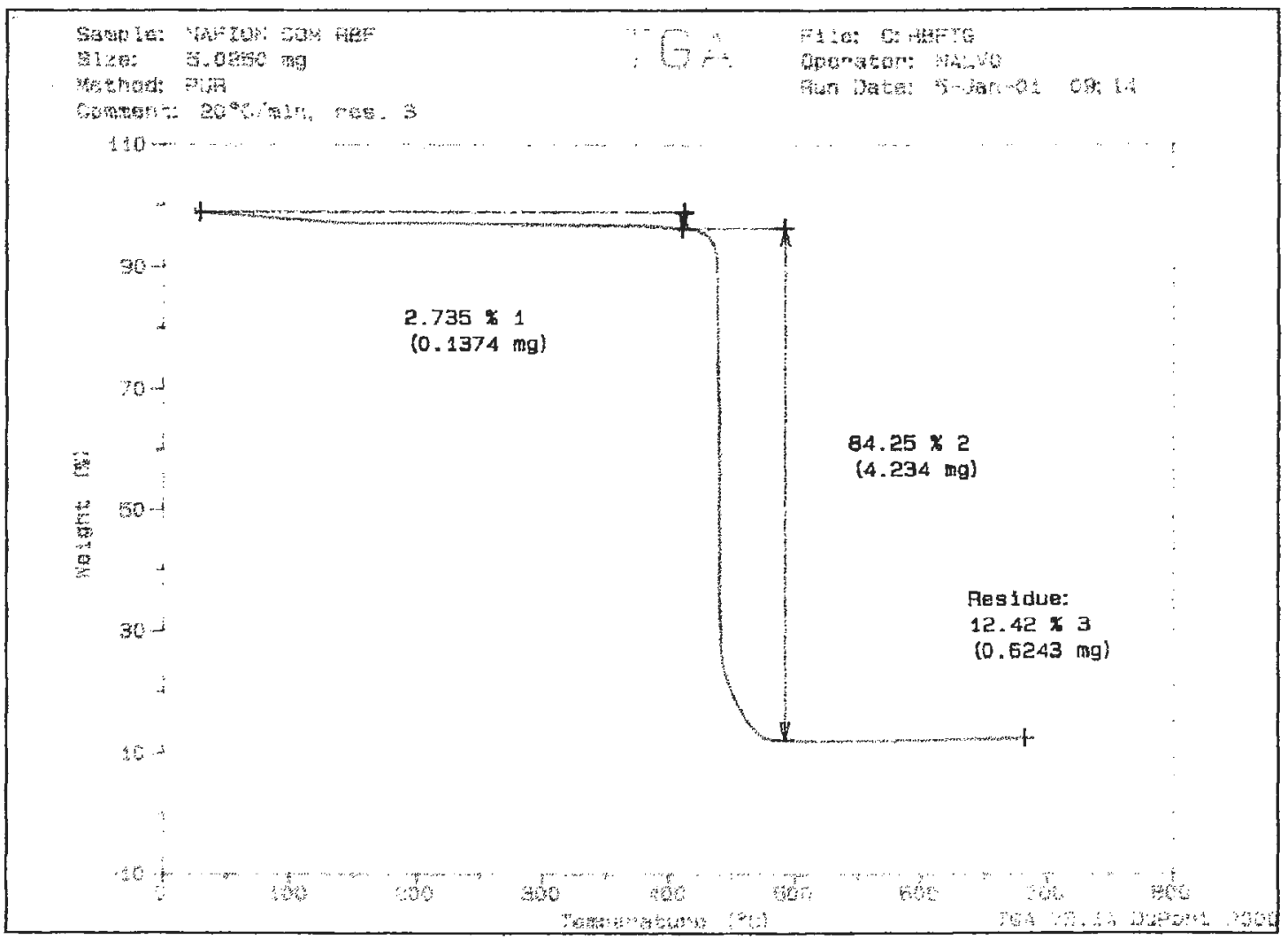

Figura 5.17: Curva TG da membrana substituída usando-se RbF. 


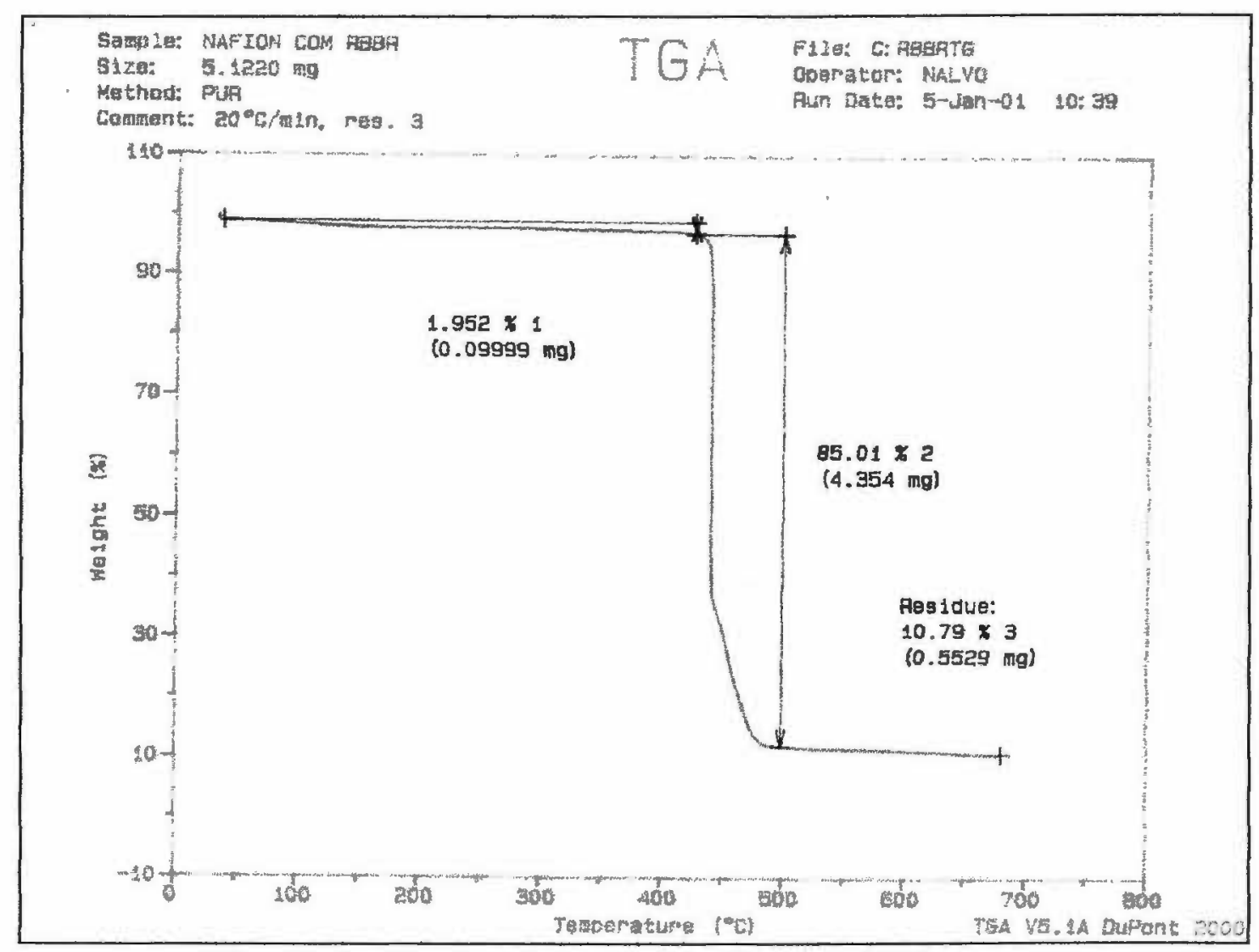

Figura 5.18: Curva $T G$ da membrana substituida, usando-se $\mathrm{RbBr}$. 


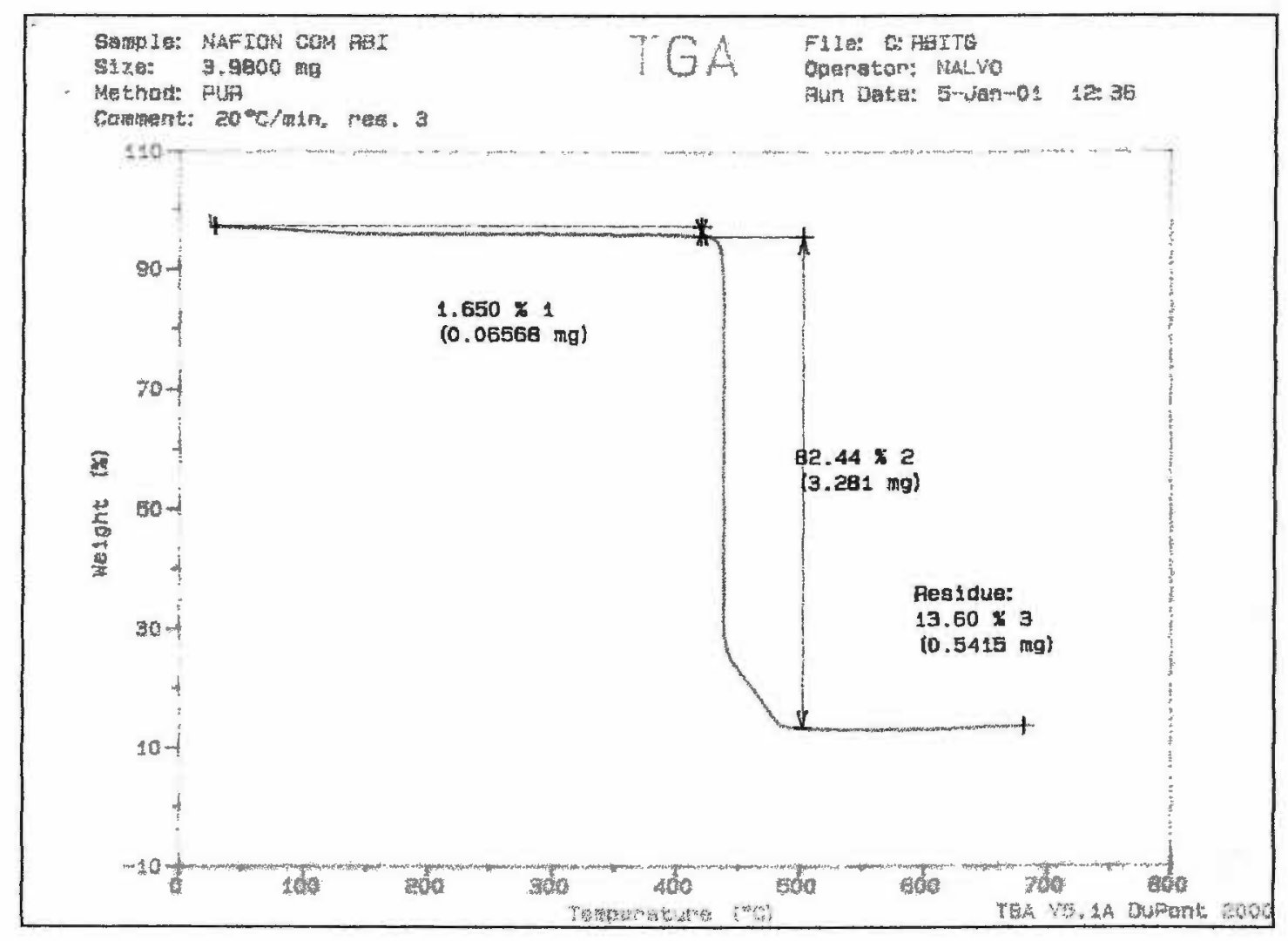

Figura 5.19: Curva TG da membrana substituída usando-se Rbl. 


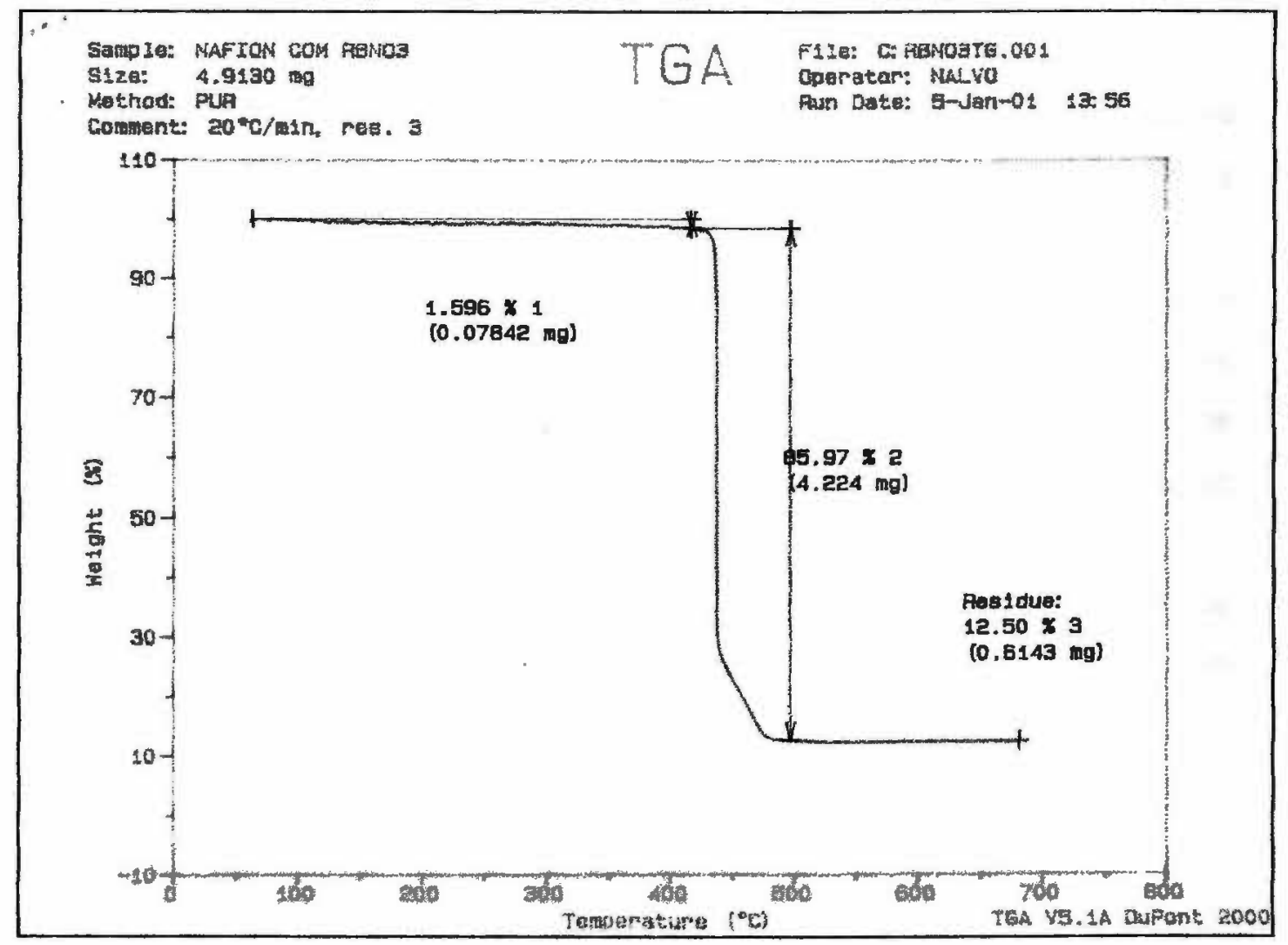

Figura 5.20: Curva TG da membrana substituída usando-se $\mathrm{RbNO}_{3}$.

Os valores obtidos para a variação da massa de água nas membranas em função dos ânions estão apresentados na tabela 5.8: 
Tabela 5.8 Perda de massa de água para diferentes sais de rubídio.

\begin{tabular}{|c|c|}
\hline Ánion associado & Porcentagem de massa perdida \\
\hline $\mathrm{F}^{-}$ & $2,74 \%$ \\
\hline $\mathrm{Br}$ & $1,95 \%$ \\
\hline$\Gamma^{-}$ & $1,65 \%$ \\
\hline $\mathrm{NO}_{3}^{-}$ & $1,6 \%$ \\
\hline
\end{tabular}

Estes resultados indicam que também o ânion deve ocupar um espaço no interior da membrana, modificando o conteúdo de água; o que é forte evidência para a hipótese 2 e conseqüentemente para a hipótese 3.

Embora os resultados da termogravimetria apontem de maneira bastante clara a ocupação dos ânions na membrana, ainda não dispomos de uma interpretação para a localização dos mesmos, pois não foi observado nos espectros Raman e infravermelho o deslocamento de nenhuma banda em função da troca do ânion.

Este resultado sobre a ocupação dos ânions no agregado e a dependência do conteúdo de água na membrana em função do ânion, ainda não foram descritos na literatura.

\subsubsection{A degradação térmica da membrana}

A degradação térmica da membrana Nafion na forma ácida foi descrita na literatura ${ }^{[44]}$, e segundo os autores ela deve ocorrer em 3 etapas, as quais correspondem aos seguintes eventos térmicos:

1) 400 a $440^{\circ} \mathrm{C}$ processo de dessulfonação

2) 440 a $470^{\circ} \mathrm{C}$ decomposição da cadeia lateral

3) 470 a $520^{\circ} \mathrm{C}$ decomposição da matriz polimérica. 


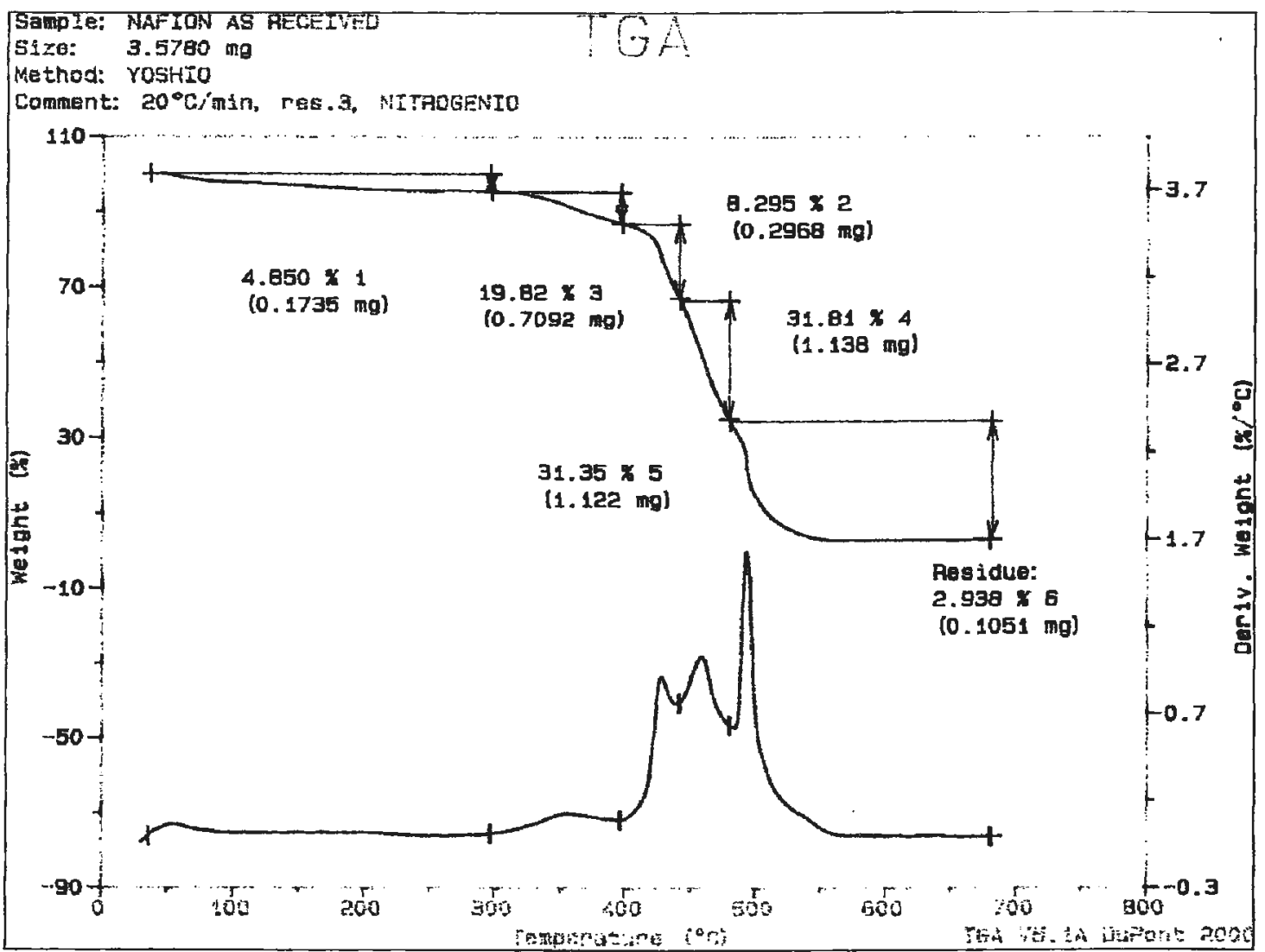

Figura 5.21: Curvas TG e DTG para a membrana em sua forma original (ácida).

Diferente do que ocorre na forma ácida, a degradação térmica das membranas substituidas pelos diferentes cátions parece ocorrer em uma única etapa, conforme pode ser observado a partir das derivadas primeiras das curvas TG, para as membranas substituídas. A seguir são apresentadas as derivadas primeiras das curvas TG das membranas substituídas pelos cátions rubidio e césio: 


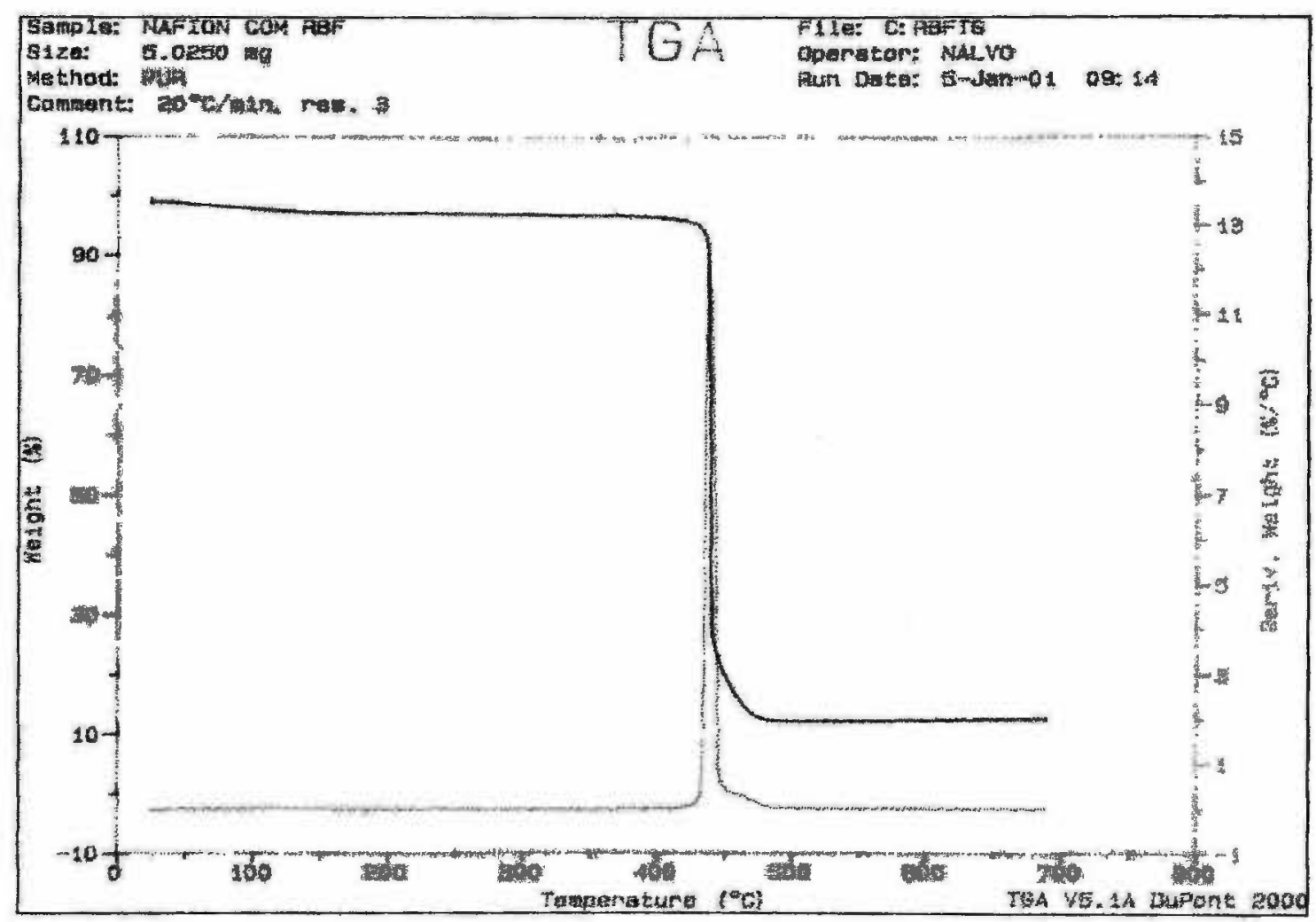

Figura 5.22: Curvas TG e dTG para a membrana substituída por Rb". 


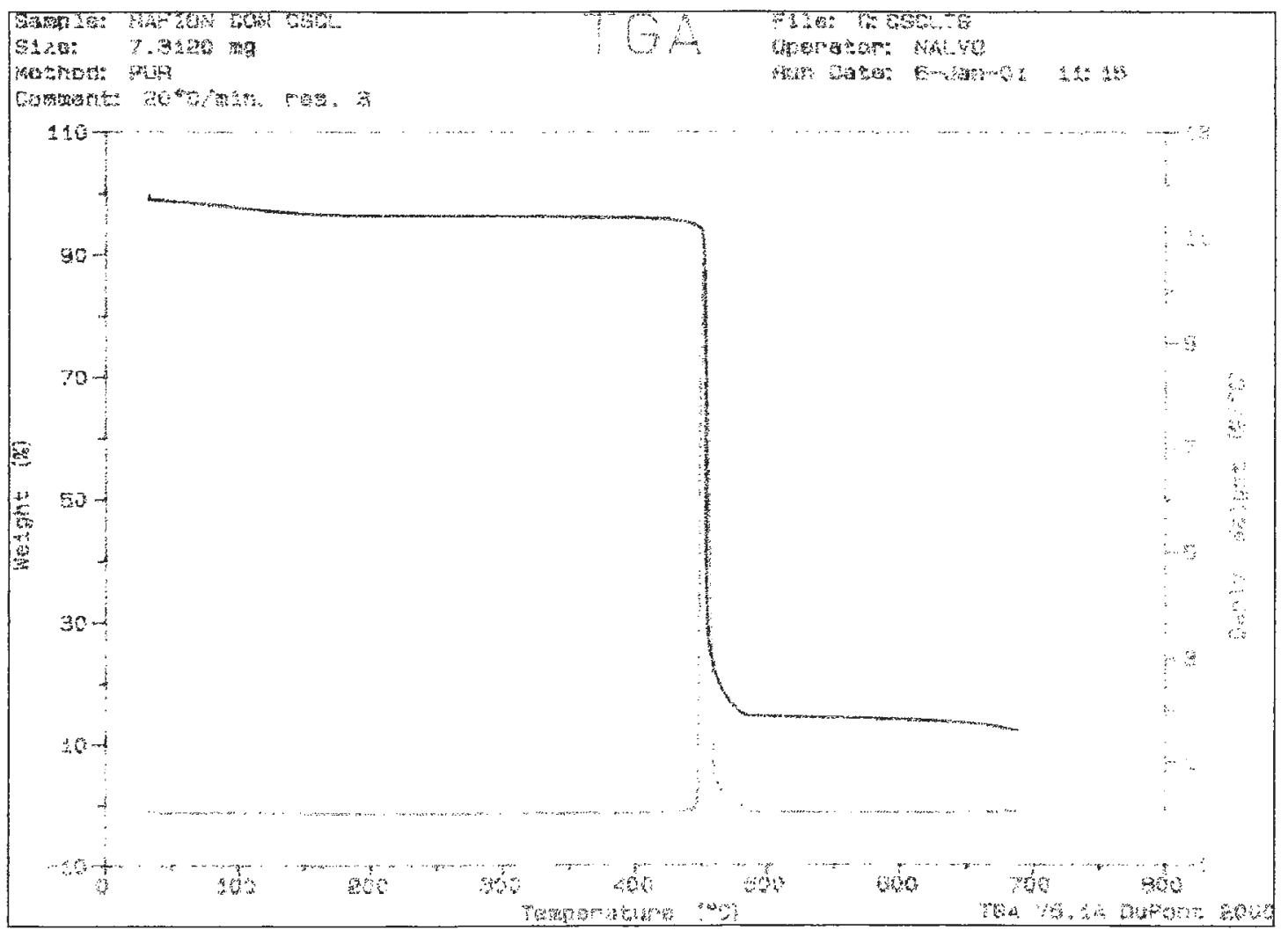

Figura 5.23: Curvas TG e dTG para as membranas substituídas por $\mathrm{Cs}^{+}$.

Estudando a degradação térmica do Nafion- $\mathrm{Na}^{+}$, Almeida e Kawano ${ }^{[44]}$ levantaram a hipótese de que a maior estabilidade térmica da membrana substituída, quando comparada com a membrana na forma ácida, era devida à formação do par-iônico $\left(-\mathrm{SO}_{3}{ }^{-} \mathrm{Na}^{+}\right)$o que deveria aumentar a estabilidade da ligação (C-S) e inibir a primeira etapa de decomposição da membrana (dessulfonação da membrana).

Esta hipótese de inibição da etapa (1) parece razoável, pois trabalhando com membranas Nafion- $\mathrm{K}^{+}$, Wilkie ${ }^{[45]}$ analisou os produtos de degradação térmica, no modo isotérmico (ao redor de $400^{\circ} \mathrm{C}, 2 \mathrm{~h}$ ), e a análise dos produtos revelou apenas $\mathrm{CO}_{2}$ e $\mathrm{SiF}_{4}$, não sendo detectado $\mathrm{SO}_{2}$ ou $\mathrm{SO}_{3}$ entre os produtos, e indicando, portanto, que até a temperatura considerada, não há ruptura da ligação C-S. 


\subsection{DSC das membranas}

As curvas DSC das membranas Nafion foram obtidas usando-se equipamento de DSC-10 da TA Instruments. $O$ intervalo de aquisição das curvas foi de 25 a $350^{\circ} \mathrm{C}$ e a taxa de aquecimento foi de $10^{\circ} \mathrm{C} / \mathrm{min}$. Durante 0 aquecimento, a amostra e a referência foram submetidas a uma atmosfera de nitrogênio e o fluxo do gás foi de $40 \mathrm{ml} / \mathrm{min}$. As curvas obtidas são apresentadas a seguir:

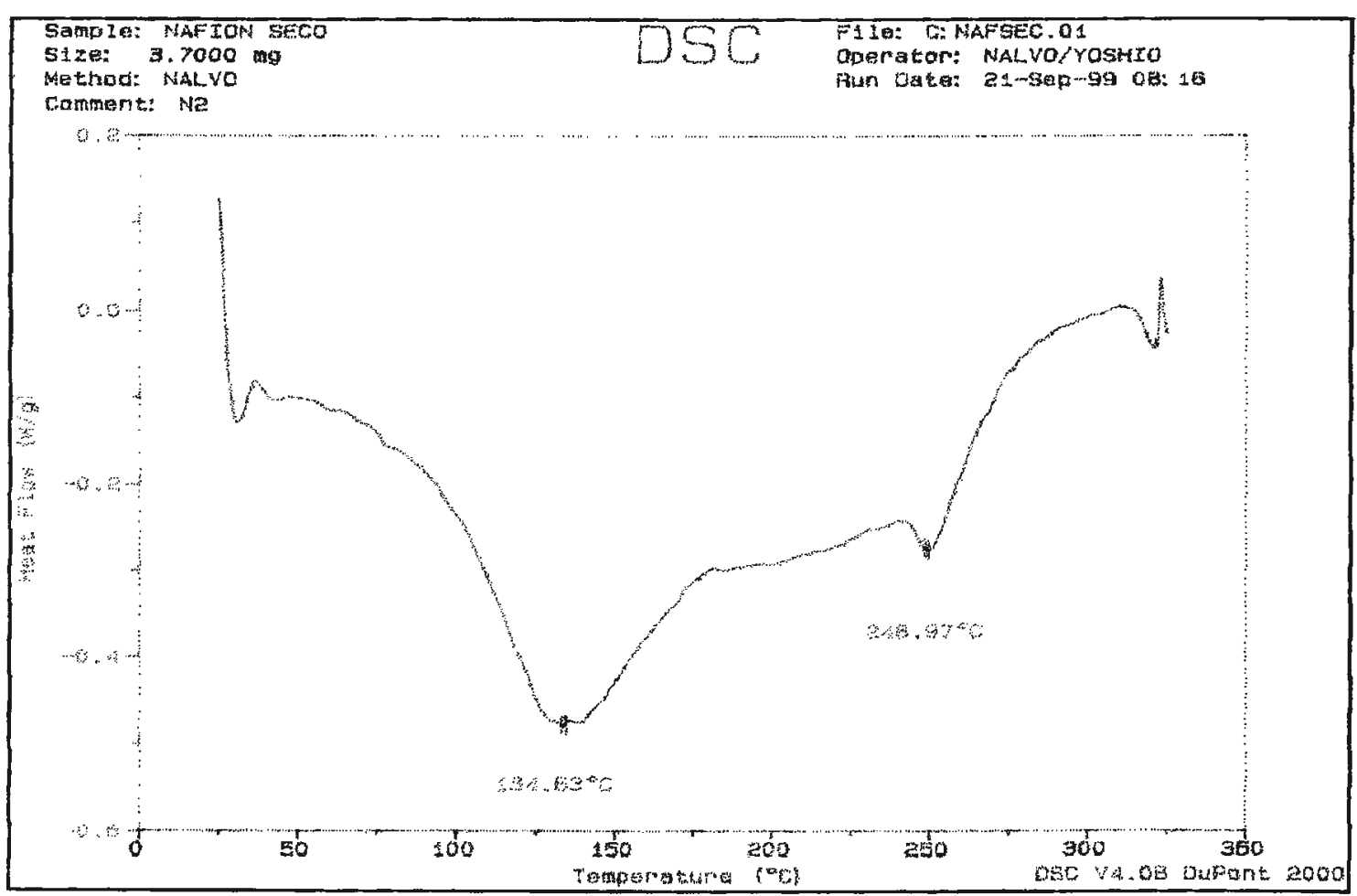

Figura 5.24: Curva DSC da membrana Nafion submetida a processo de desidrataçăo (primeira corrida). 


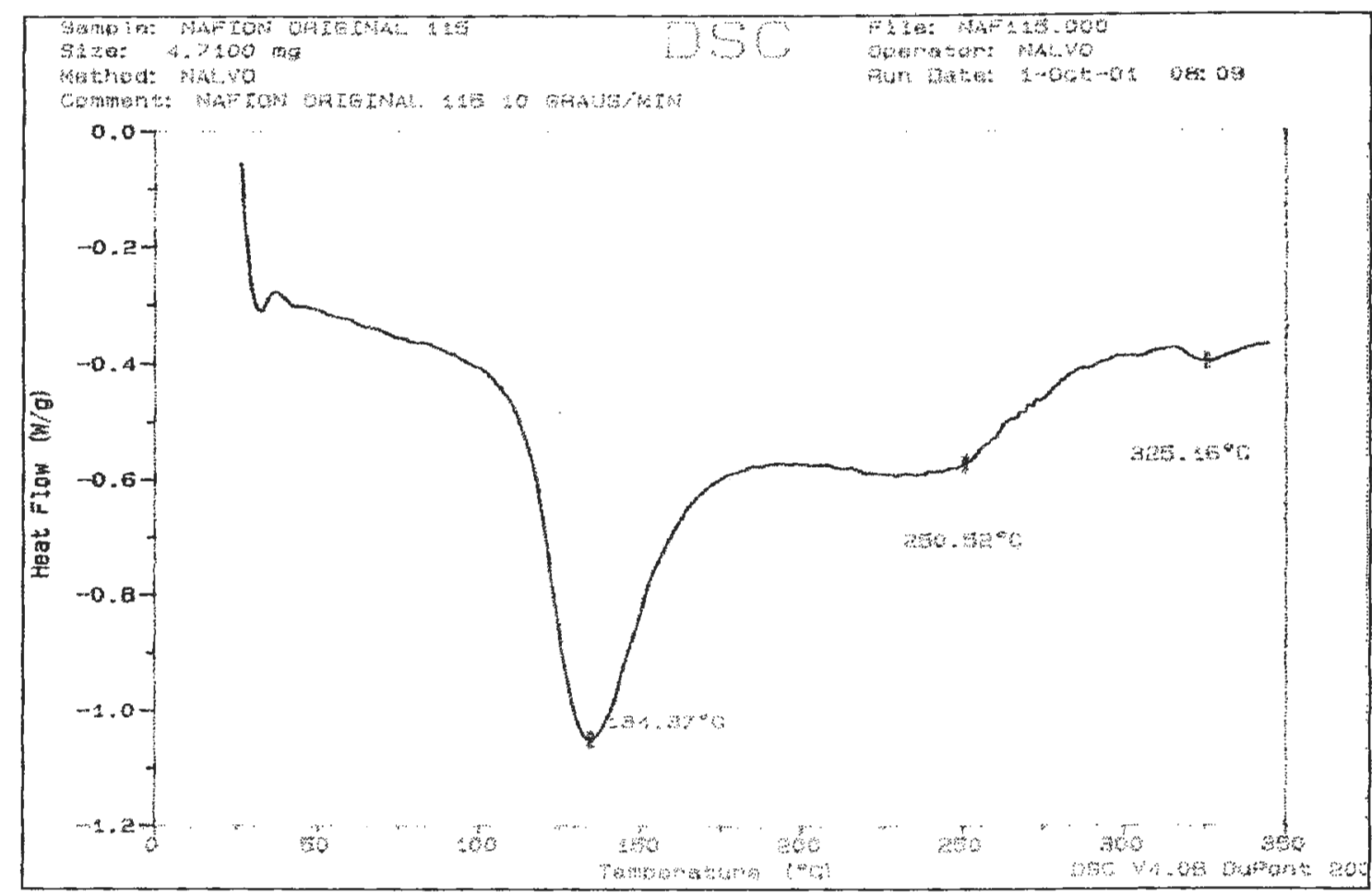

Figura 5.25: Curva DSC da membrana na forma ácida. 


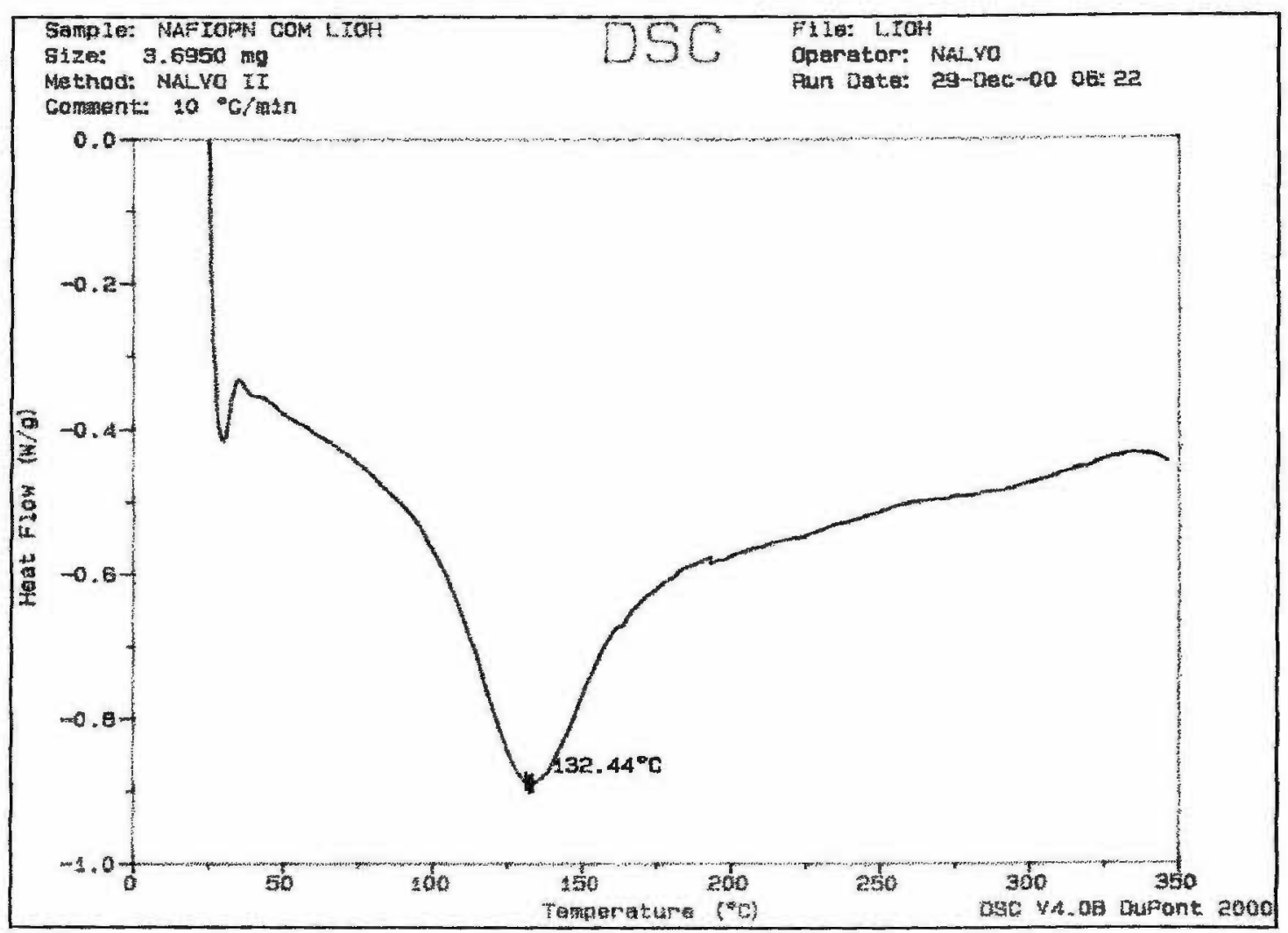

Figura 5.26: Curva DSC da membrana substituída por Li. 


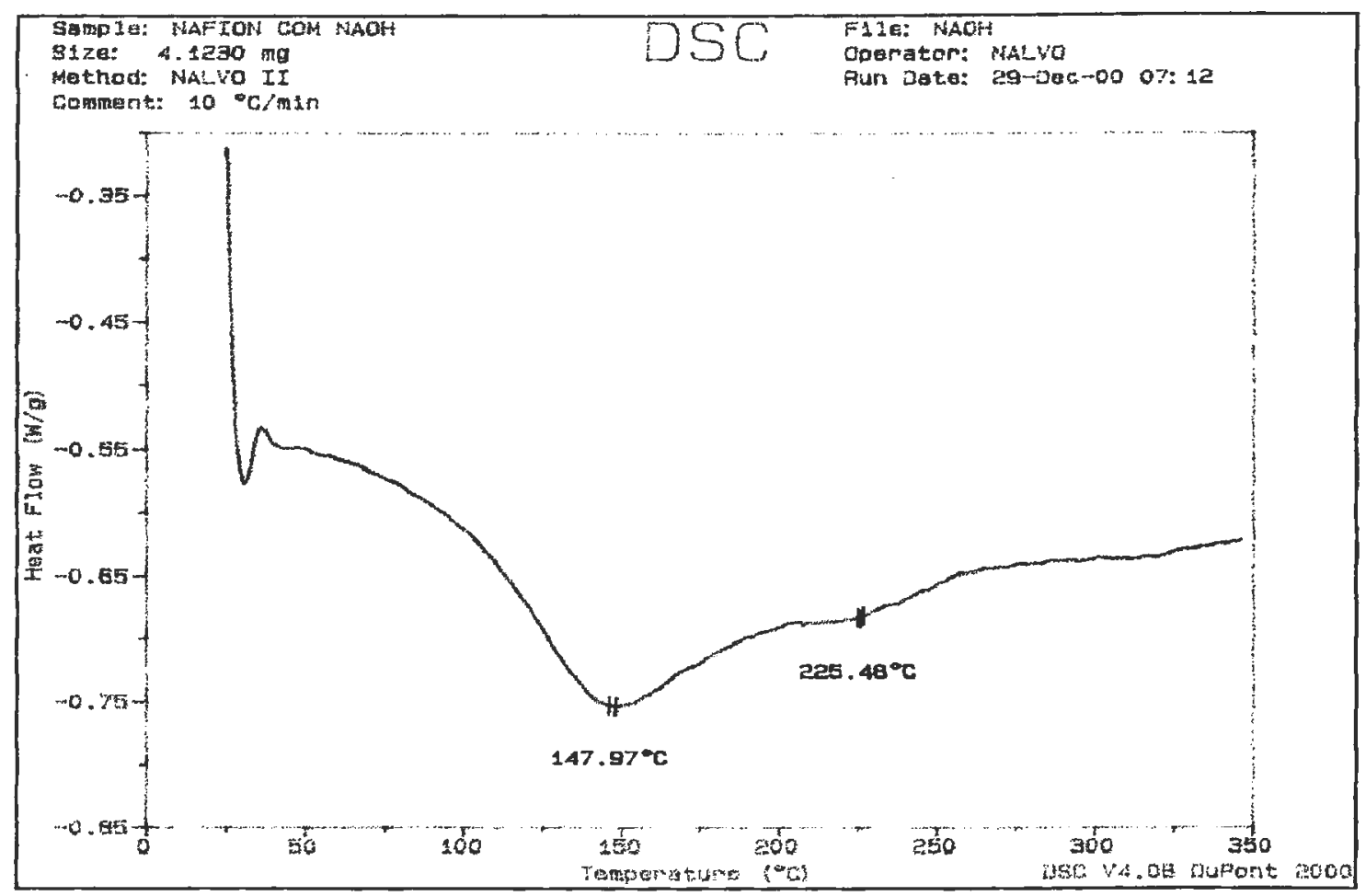

Figura 5.27: Curva DSC da membrana substituída por $\mathrm{Na}^{+}$. 


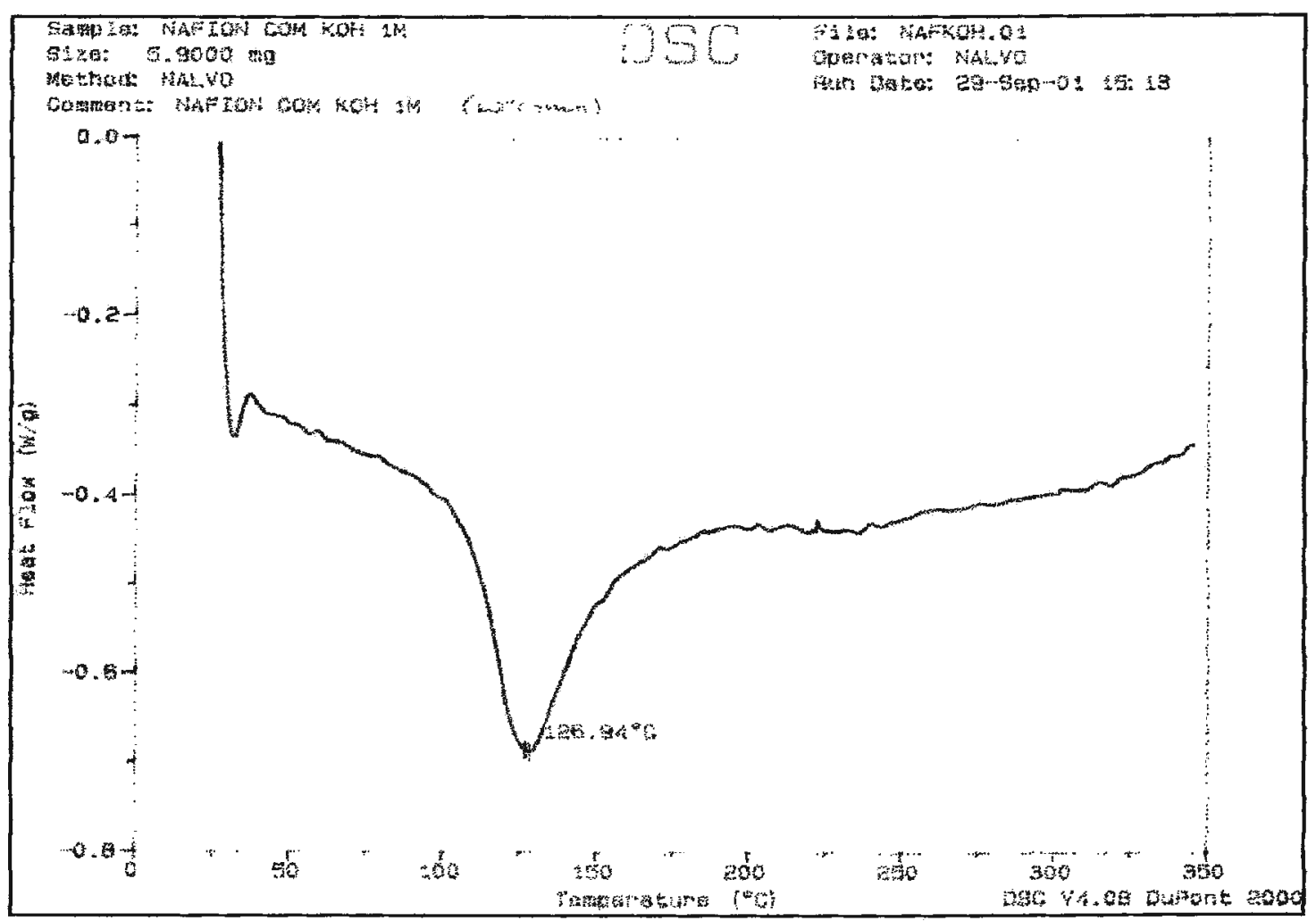

Figura 5.28: Curva DSC da membrana substituída por $\mathrm{K}^{+}$. 


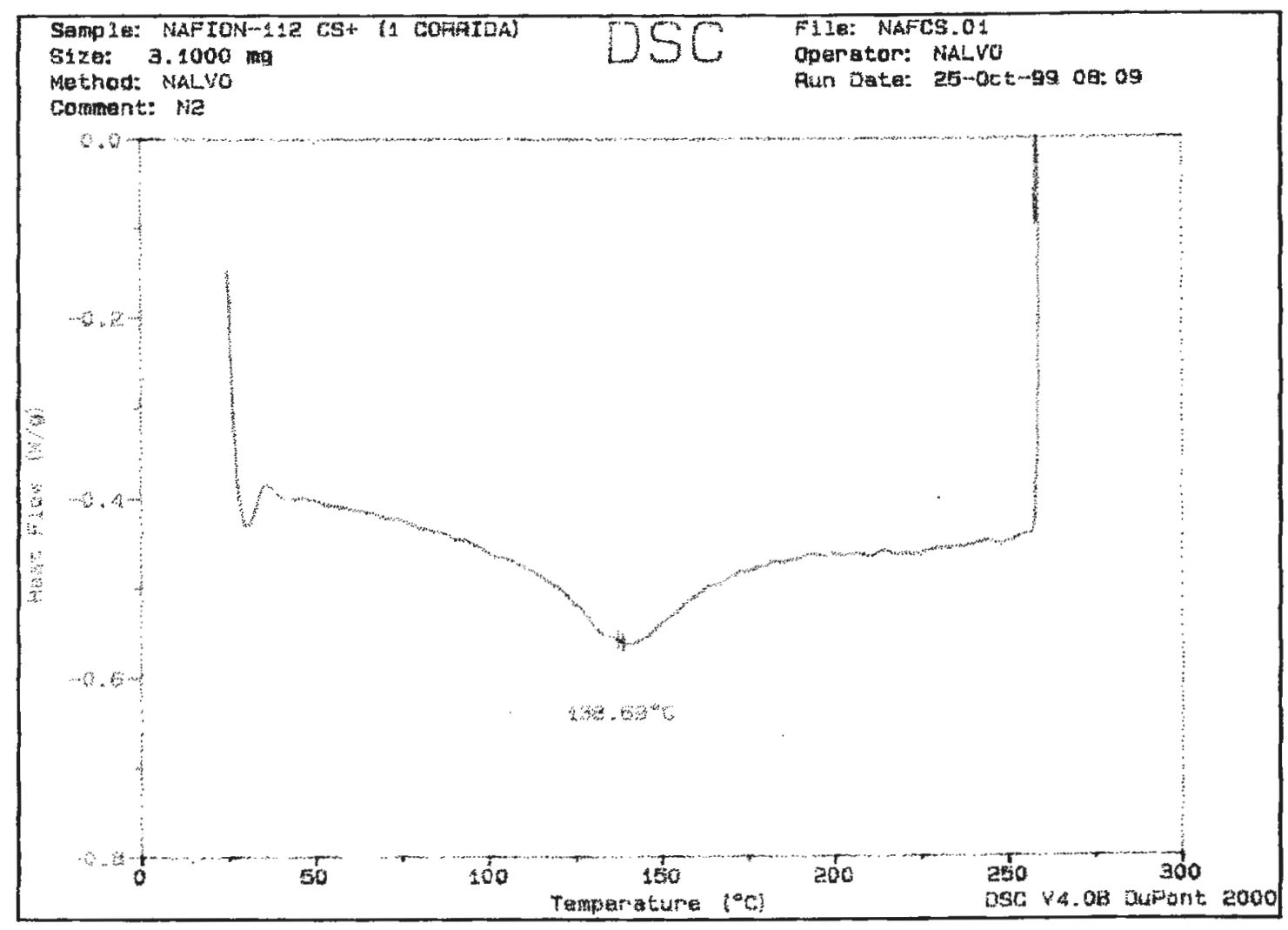

Figura 5.29: Curva DSC da membrana substituída por $\mathrm{Cs}^{+}$.

O DSC da membrana Nafion em sua forma (original) ácida apresenta três eventos endotérmicos no intervalo de temperatura de 25 a $350^{\circ} \mathrm{C}$. O primeiro evento ao redor de $135^{\circ} \mathrm{C}$, o segundo em $250^{\circ} \mathrm{C}$ e o terceiro em $325^{\circ} \mathrm{C}$. Nas membranas substituídas pelos cátions de metais alcalinos, o segundo evento endotérmico é pouco pronunciado e o terceiro evento endotérmico está completamente ausente. 
Tanto a largura, quanto a temperatura de ocorrência do primeiro evento endotérmico são influenciadas pela substituição iônica, conforme pode ser visualizado nas figuras acima. Dada que a substituição dos cátions ocorre no interior dos agregados, este evento endotérmico é atribuído à uma evento intraagregado. Almeida e Kawano[46] trabalhando com análise térmica, e Kyu et al. ${ }^{[47]} \mathrm{e}$ Mauritz et al..$^{[4]}$ trabalhando com relaxação mecânica, atribuíram este evento à uma transição ordem-desordem das cargas no interior do agregado.

Conforme pode ser observado nas curvas de DSC, a temperatura do primeiro pico endotérmico não varia monotonicamente com o raio iônico dos cátions. Almeida e Kawano também registraram o fato. Entretanto, ainda não foi encontrada uma explicação para esta variação não monotônica da temperatura de $\mathrm{T}_{1}$ (ao redor de $130^{\circ} \mathrm{C}$ ).

Entretanto, esta desorganização das cargas não significa a destruição dos agregados, pois Gierke ${ }^{[5]}$ estudando o SAXS das membranas Nafion- $-\mathrm{Na}^{+}$ aquecidas a aproximadamente $350^{\circ} \mathrm{C}$ concluiu que mesmo nesta temperatura $\circ$ agregado iônico ainda estava presente na membrana.

Pode-se observar um aumento da largura do primeiro evento endotérmico à medida que o raio iônico do cátion aumenta, e admitindo a interpretação de Almeida e Kawano para este evento endotérmico, pode-se concluir que a distribuição dos cátions é menos homogênea para os cátions de maior raio iônico.

Estudos da membrana Nafion usando raios- $X^{[5,21]}$ relataram que existe uma diminuição da cristalinidade do polímero quando este é submetido a hidratação. Esse fato em conjunto com a informação de que a temperatura de fusão do PTFE ocorre em $325^{\circ} \mathrm{C}$, permite-nos concluir que o terceiro evento endotérmico no Nafion corresponde à fusão das regiōes cristalinas na membrana.

Foi efetuado um breve estudo sobre o efeito da mudança da polaridade do solvente sobre o DSC das membranas. As curvas obtidas a partir destes experimentos são apresentadas a seguir: 


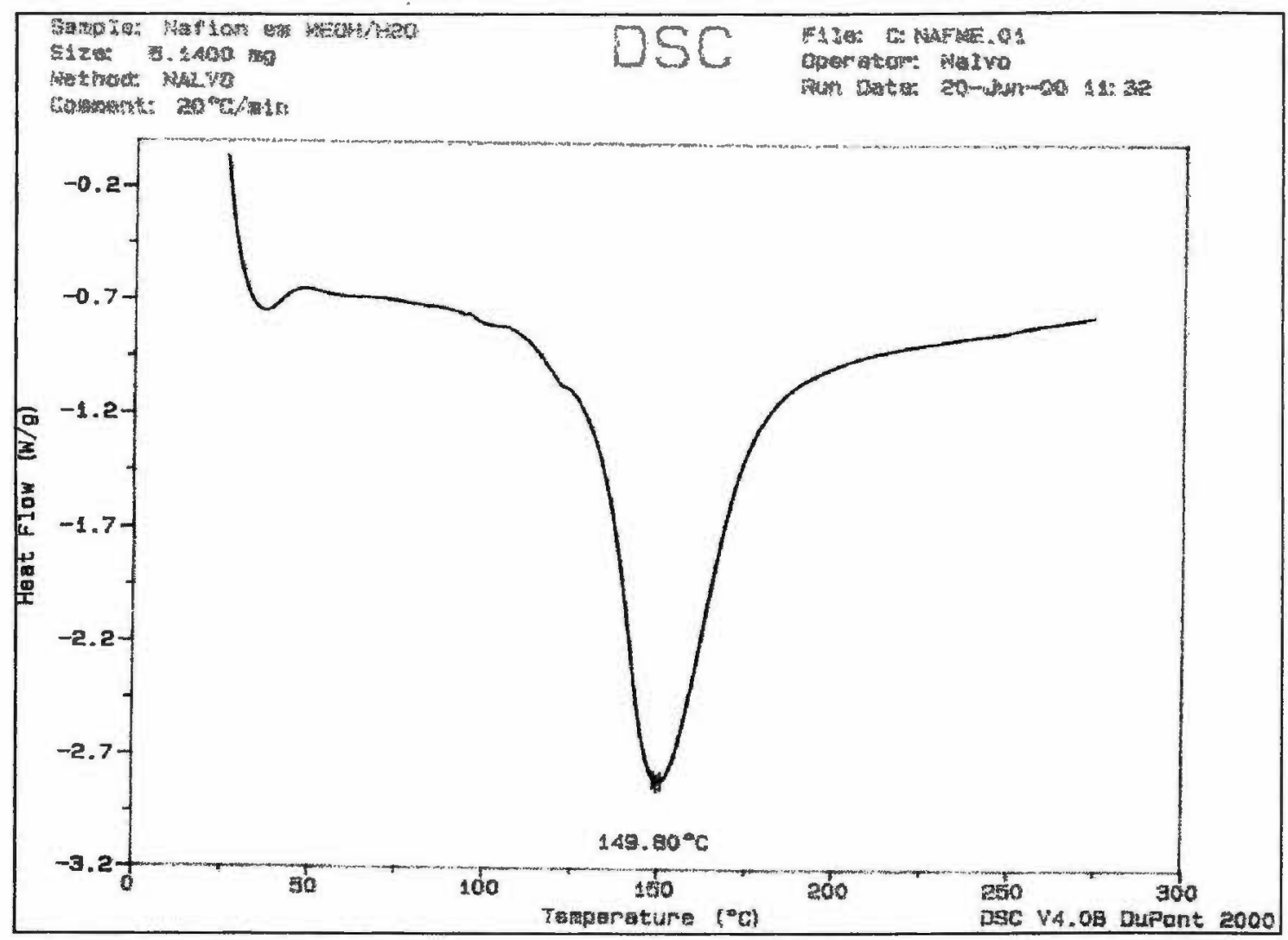

Figura 5.30: Curva DSC da membrana após imersão em solução metanolágua (1:1 relação em volume). 


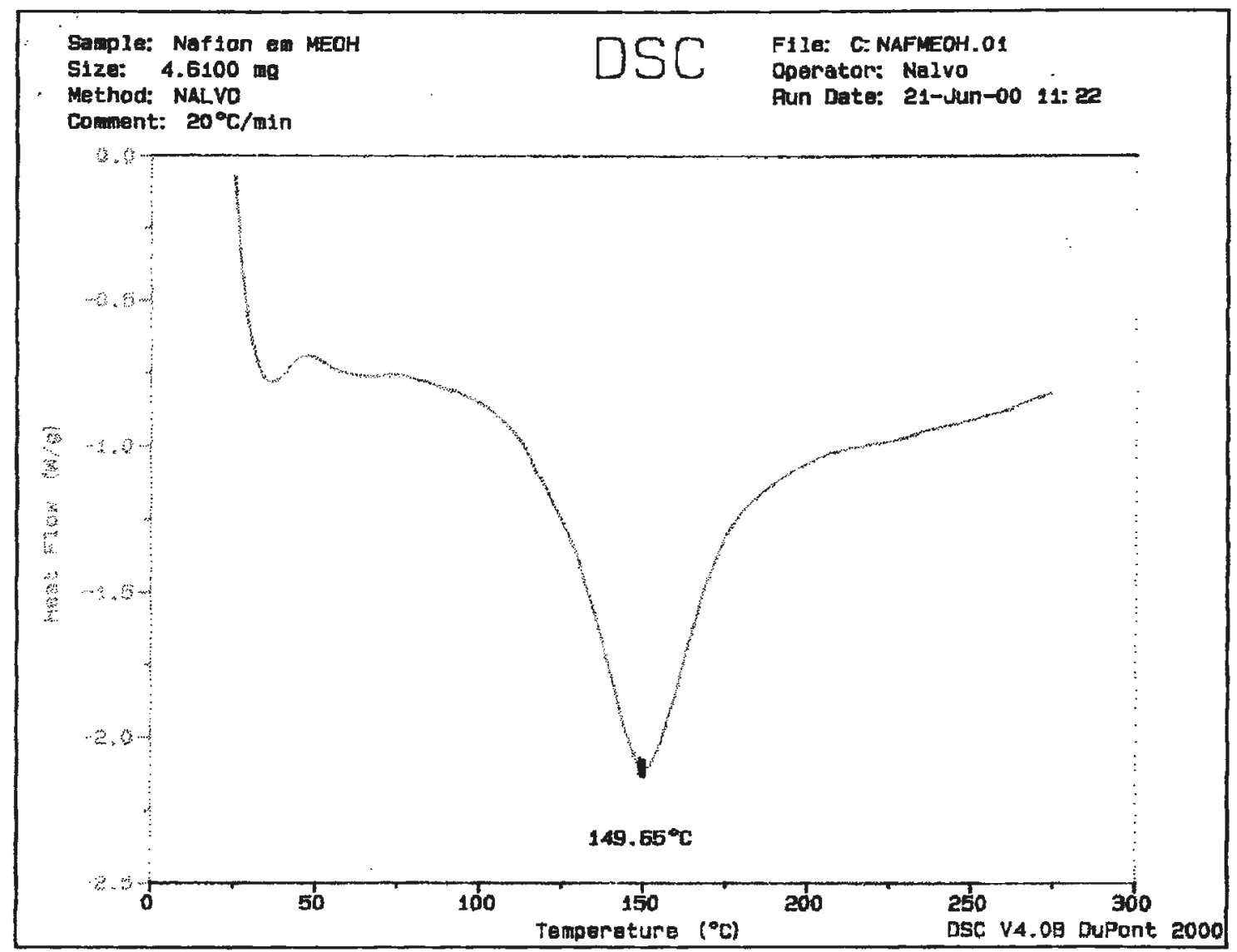

Figura 5.31: Curva DSC da membrana após imersão em metanol puro. 


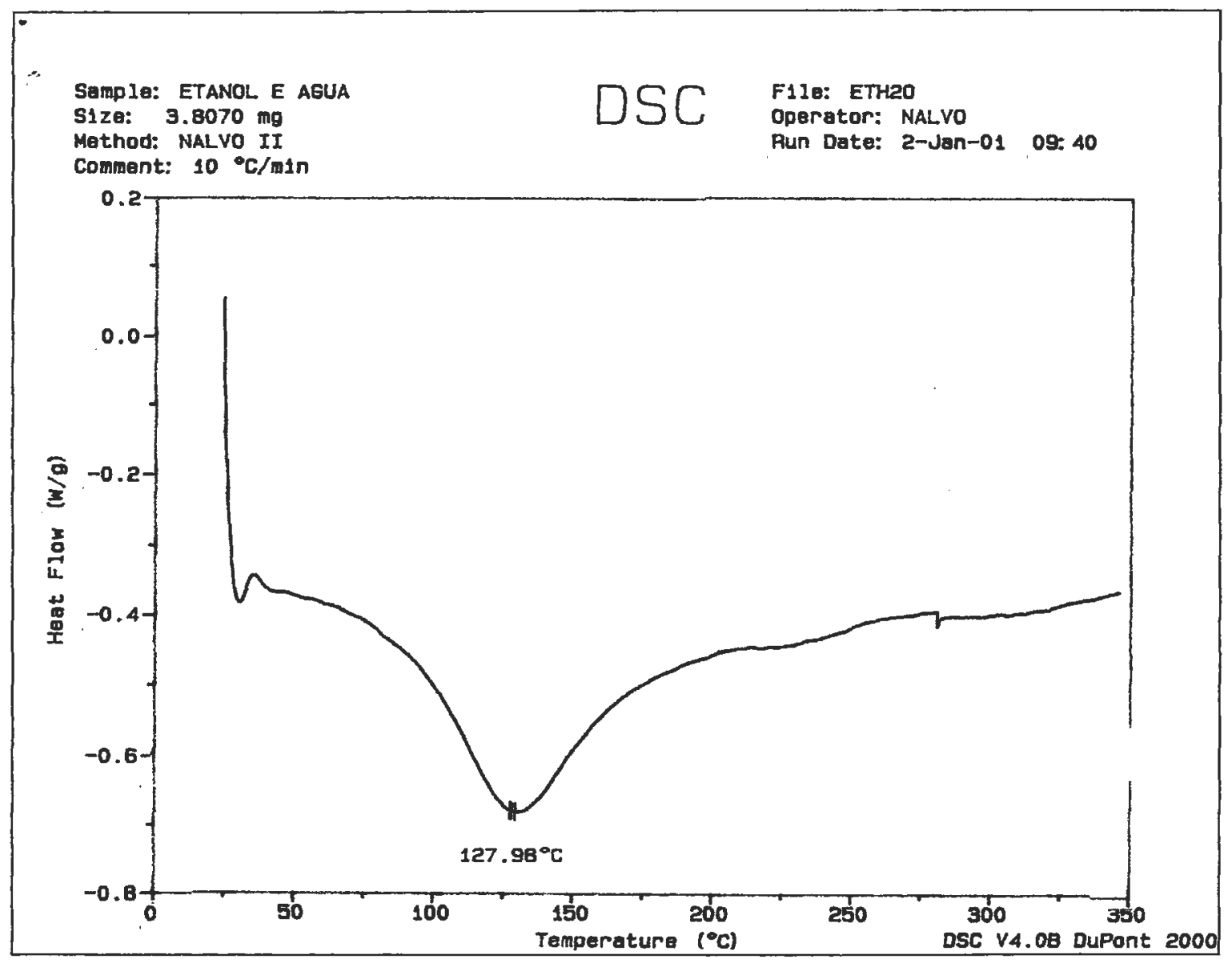

Figura 5.32: Curva DSC após imersão em solução água/etanol (1:1) 


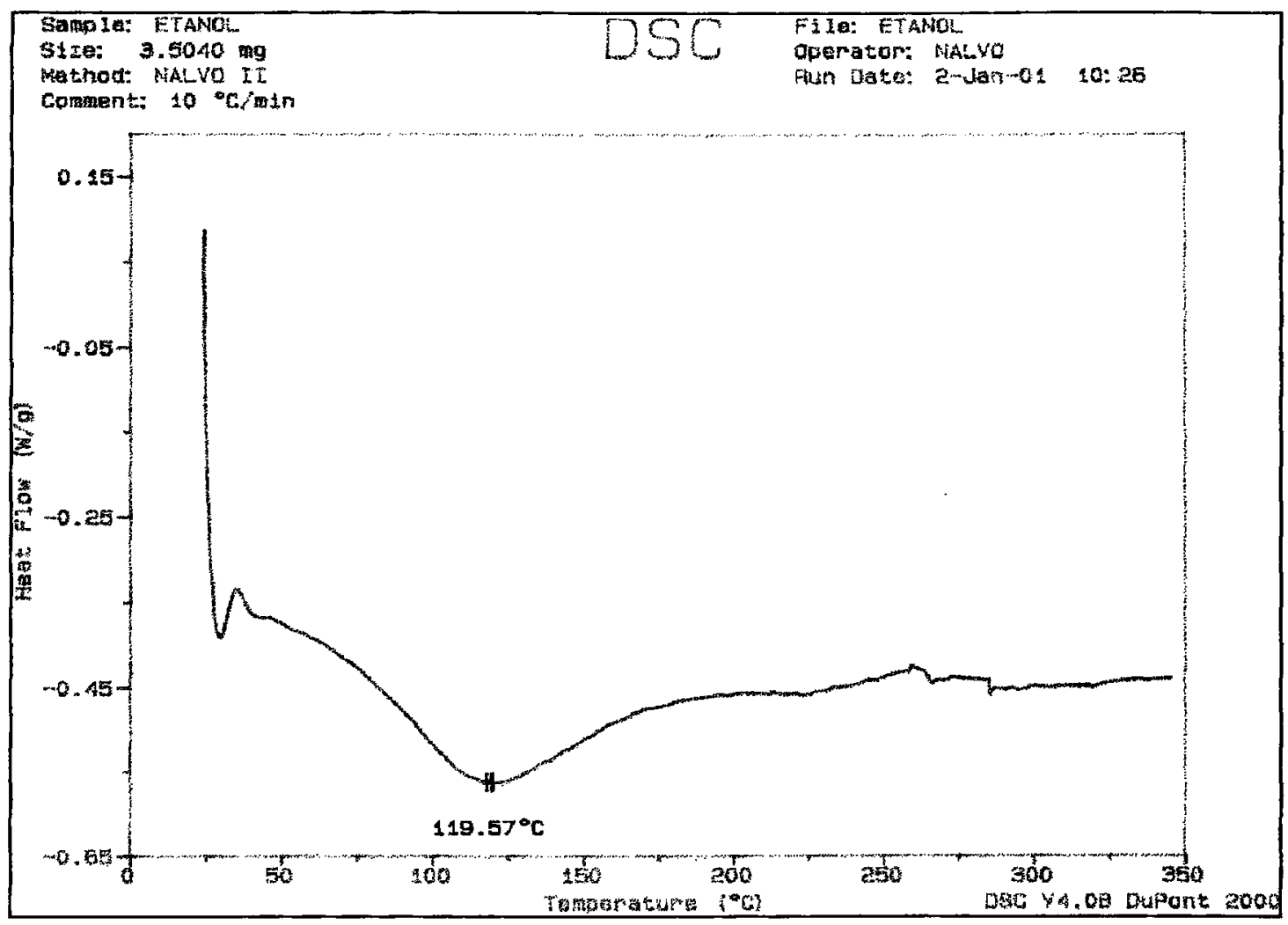

Figura 5.33: DSC da membrana após imersão em etanol puro.

Desta segunda série de experimentos podem ser extraídas algumas conclusões acerca do primeiro pico $T_{1}$. Laporta et al. ${ }^{[48]}$ argumentaram que o primeiro evento endotérmico era devido unicamente à evaporação do solvente contido no interior da membrana. Entretanto, se $\mathrm{T}_{1}$ dependesse exclusivamente da evaporação do solvente, este evento endotémico deveria ocorrer numa temperatura mais elevada para a membrana imersa em etanol puro, quando comparado com a membrana imersa em metanol puro.

Na seqüência das curvas apresentadas acima, à medida que a constante dielétrica do meio no qual as membranas são imersas diminui, aumenta a largura do evento endotérmico, indicando a mudança de polaridade altera a interação entre as cargas no interior dos agregados iônicos. 


\section{Conclusões}

O Nafion é um ionômero constituído por uma matriz de politetrafluoroetileno (PTFE) contendo ramificações laterais terminadas em grupos sulfônicos. A presença destas cadeias laterais modifica as propriedades físicas do ionômero, quando este é comparado com seu polímero precursor.

Neste trabalho foram desenvolvidos estudos vibracionais e térmicos deste ionômero. Para proceder à análise vibracional, dividiu-se o ionômero em 3 regiões: o grupo sulfônico; o grupo éter e a matriz fluorocarbônica. $O$ grupo sulfônico apresenta modos vibracionais de estiramento simétrico $\left(1060 \mathrm{~cm}^{-1}\right)$ e de estiramento degenerado (na região de $1300 \mathrm{~cm}^{-1}$ ). Entretanto, a banda do modo de estiramento degenerado encontra-se superposta a outras bandas no espectro $e$ sua visualização é prejudicada. Assim, foi utilizada a banda do modo de estiramento simétrico para caracterizar modificações no ambiente químico dos agregados.

Essa banda (em $1060 \mathrm{~cm}^{-1}$ ) sofreu influência da substituição dos cátions no interior dos agregados. Ela é deslocada para números de onda maiores na medida em que a densidade de carga do cátion aumenta.

A substituição dos cátions também alterou o conteúdo de água na membrana, conforme foi observado pela diminuição de intensidade das bandas de estiramento e de deformação angular da água.

O Nafion apresenta dois grupos éter, os quais deram origem no espectro a duas bandas: uma em 984 e outra na região de $970 \mathrm{~cm}^{-1}$. A substituição de cátions metálicos alterou apenas a posição da banda em $970 \mathrm{~cm}^{-1}$, indicando que esta banda deve pertencer ao grupamento éter que se encontra localizado mais próximo da terminação da cadeia lateral, a qual sofre influência do ambiente iônico.

A atribuição das bandas da matriz polimérica foi feita considerando-se que a cadeia de PTFE apresenta estrutura helicoidal $\left(15_{7}\right)$. Nesta estrutura é prevista 
a existência de 4 espécies de simetria que apresentam atividade nos espectros Raman e infravermelho. Os modos de espécie $A_{1}$ e $E_{2}$ são ativos apenas no Raman, os modos de espécie $A_{2}$ são ativos apenas no infravermelho e os modos vibracionais de espécie $E_{1}$ apresentam atividade tanto no Raman quanto no infravermelho. Nenhuma das bandas da matriz polimérica foi alterada de maneira detectável, com a substituição dos cátions.

A atribuição das bandas da matriz polimérica ficou da seguinte maneira:

- Bandas de espécie $A_{1}: 293,385,729$ e $1374 \mathrm{~cm}^{-1}$;

- Bandas de espécie $A_{2}: 527$ e $639 \mathrm{~cm}^{-1}$;

- Bandas de espécie $E_{1}$ : pacote de bandas não resolvido, na região de $1200 \mathrm{~cm}^{-1}$. A atribuição encontrada na literatura para o PTFE resolve o espectro em três bandas: 1151,1206 e $1252 \mathrm{~cm}^{-1}$;

- Bandas de espécie $E_{2}: 309,666$ e $1294 \mathrm{~cm}^{-1}$.

A análise térmica dividiu-se em: termogravimetria e calorimetria exploratória diferencial. A termogravimetria indicou que a troca dos cátions altera o conteúdo de água no interior da membrana, com cátions mais volumosos apresentando menor conteúdo de água.. A substituição de ânions, mantendo-se fixo o cátion, também produz alteração do conteúdo de água.

Através da análise termogravimétrica pôde-se concluir que a membrana substituida é termicamente mais estável e apresenta padrão de decomposição térmica distinto, se comparada com a membrana na forma ácida. A decomposição da membrana na forma ácida ocorre em três etapas, sendo a primeira delas a quebra da ligação C-S, já as membranas substituídas decompõem-se em apenas uma etapa. O diferente mecanismo de degradação sugere que a inserção de cátions aumenta a estabilidade da ligação C-S, inibindo este primeiro passo na degradação das membranas.

A calorimetria exploratória diferencial mostrou que a membrana na forma ácida apresenta três eventos endotérmicos: em $134^{\circ} \mathrm{C}$; em $250^{\circ} \mathrm{C}$ e o último em $325^{\circ} \mathrm{C}$. O primeiro evento endotérmico também está presente nas membranas nas formas salinas, porém este pico é fortemente influenciado pela troca dos íons e 
pelo grau de hidratação da membrana. O segundo evento em $250^{\circ} \mathrm{C}$ é muito pouco pronunciado nas membranas substituídas e o terceiro pico endotérmico, em $325^{\circ} \mathrm{C}$, está completamente ausente nas membranas nas formas salinas.

De acordo com trabalhos anteriores ${ }^{[46]}$ o primeiro evento endotérmico (ao redor de $130^{\circ} \mathrm{C}$ ) é devido a uma transição de ordem-desordem das cargas no interior dos agregados. O terceiro evento endotérmico em $325^{\circ} \mathrm{C}$ é devido à fusão da matriz fluorocarbônica. 


\section{Referências Bibliográficas}

1. Bazuin, C.G. e Eisenberg, A., Ind.Eng.Chem.Prod.Res.Dev., 20, 271 (1981).

2. Bazuin C.G. e Eisenberg A., J.Chem.Edu., 58, 938 (1981)

3. Lundberg, R.D., Encyclopedia of Polymer Science and Engineering, v.8, 394 (1987).

4. Yeo, S.C.e Eisenberg, A., J. Appl. Polym. Sci., 21, 875 (1971).

5. Gierke, T.D.; Munn, E. e Wilson, F.C., J. Polym. Sci., Polym. Phys. Ed., 19, 1687 (1981).

6. Marx, C.L.; Caufield, D.F. e Cooper, S.L., Macromolecules, 6, 344 (1973).

7. Roche, E.J.; Stein, R.S.; Russel, T.P. e Macknight, W.J., J. Polym. Sci., Polym. Phys. Ed., 18, 1497 (1980).

8. Yarusso, D.J. e Cooper, S.L., Macromolecules, 16, 1871 (1983).

9. Fujimura, M.; Hashimoto, T. e Kawai, H., Macromolecules, 14, 1309 (1981).

10. Eisenberg, A., Macromolecules, 3, 147,1970.

11. Forsman, W.C. Macromolecules, 15, 1032-1040, (1982).

12. Dreyfus, B. Macromolecules, 18, 284-292, (1985).

13. Datye, V.K.; Taylor P.L. Macromolecules, 18, 1479, (1985) .

14. Marx, C.L.; Caufield, D.F. e Cooper, S.L., Macromolecules, 6, 344, (1973).

15. Macknight, W.J.; Taggart, W.P. e Stein, R.S. J.Polym.Sci., 18, 1497, (1980)

16. Yarusso, D.J. e Cooper, S.L., Macromolecules, 16, 1871, (1983)

17. Eisenberg, A.; Hird, B. e Moore, R.B. Macromolecules, 23, 4098, (1990).

18. McLean R.S., Doyle M., Sauer B., Macromolecules, 33, 6541, (2000)

19. Gebel G., Polymer, 41, 5829 (2000).

20. James P.J.; McMaster T.J.; Newton J.M. e Miles M.J., Polymer, 41, 4223 (2000)

21. Halim J., Büchi F.N., Haas O.; Stamm M. e Scherer G.G., Electrochem.Acta, 39, 1303 (1994)

22. Blanchard R.M. e Nuzzo R.G., J.Polym.Sci., Polym.Phys., 38, 1512 (2000)

23. Cable K.M.; Mauritz K.A. e Moore R., J.Polym.Sci., Polym.Phys., 33, 1065 (1995) 
24. Boyle N.G.; McBrierty e Douglass D.C., Macromolecules, 16, 75 (1983)

25. Yeager H.L. e Steck A., J.Electrochem.Soc., 128, 1880 (1981)

26. Xie G. e Okada T., Electrochem.Acta, 41, 1569 (1996)

27. Zawodzinski T.A.; Derovin C.; Radzinski S.; Sherman R.J.; Smith V.T.; Springer

T.E. e Gottesfeld S., J.Electrochem.Soc., 140, 1041 (1993)

28. Gierke T.D., J.Electrochem. Soc., 124, C319 (1977)

29. Falk M., Can.J.Chem., 58, 1495 (1980)

30. James P.J.; McMaster T.J.; Newton J.M. e Miles M.J., Polymer, 41, 4223, (2000)

31. Goldstein H., Classical Mechanics, Addison-Wesley, Reading, (1980).

32. Sala O., Fundamentos da espectroscopia Raman e no infravermelho, 1995.

33. Perkins W., J.Chem.Edu., 63, A5 (1986)

34. Hatakeyama T. e Quinn F.X., Thermal Analysis, Fundamentals and Application to Polymer Science, Sec.Ed., John Wiley \& Son, NY, (1999).

35. Mathot V.B.F., Calorimetry and Thermal Analysis of Polymers, Hanser, Munich, (1994).

36. Koenig J.L., Boerio F.J. e Hannon M.J., J.Chem.Phys., 50, 2829, (1969).

37. Futerko P. e Hsing I.M., Electrochem.Acta, 45, 1741 (2000)

38. Ostrowska J. e Narebska A., Colloid. \& Polym. Sci., 262, 305, (1984).

39. Lowry S.R. e Mauritz K.A., J.Am.Chem.Soc., 102, 4665, (1980).

40. Bribes J.L.; Boukari M.E. e Maillols J., J.Raman Spectr., 22, 275 (1991)

41. Kobayashi M., Sakashita M. e Adachi T., Macromolecules, 28, 316, (1995).

42. Xue T., Trent J.S. e Osseoasare K., J.Membrane Sci., 45, 261, (1989).

43. Quezado S.; Kwak J.C.T. e Falk M., Can.J.Chem., 62, 958 (1984).

44. Almeida S.H. e Kawano Y., Polym. Deg. Stab. 1 (1998).

45. Wilkie C.A., Thomsen J.R. e Mittleman M.L., J.Appl.Polym.Sci., 42, 901, (1991).

46. Almeida S.H. e Kawano Y., J.Therm.Anal.Cal., 58, 569 (1999).

47.Su S. e Mauritz K.A., Macromolecules, 27, 2079 (1994)

48. Laporta M., Pegoraro M. e Zanderighi L., Phys. Chem.chem.Phys., 1, 4619 (1999). 